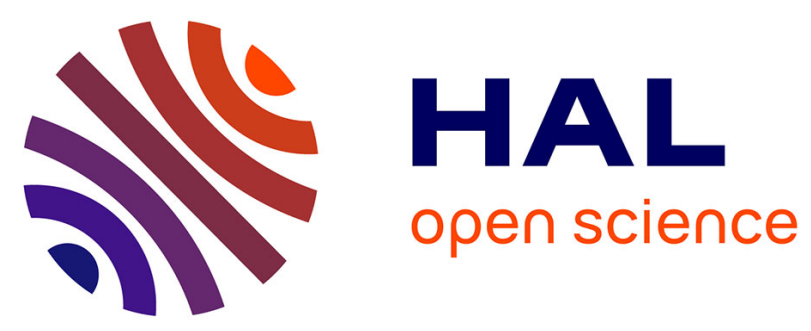

\title{
Persistent gas emission originating from a deep basaltic magma reservoir of an active volcano: the case of Aso volcano, Japan
}

\author{
Masataka Kawaguchi, Toshiaki Hasenaka, Kenneth T. Koga, Estelle F. \\ Rose-Koga, Atsushi Yasuda, Natsumi Hokanishi, Yasushi Mori, Kenji \\ Shimizu, Takayuki Ushikubo
}

\section{To cite this version:}

Masataka Kawaguchi, Toshiaki Hasenaka, Kenneth T. Koga, Estelle F. Rose-Koga, Atsushi Yasuda, et al.. Persistent gas emission originating from a deep basaltic magma reservoir of an active volcano: the case of Aso volcano, Japan. Contributions to Mineralogy and Petrology, In press. hal-03029942v1

\section{HAL Id: hal-03029942 \\ https://hal.science/hal-03029942v1}

Submitted on 29 Nov 2020 (v1), last revised 8 Oct 2021 (v2)

HAL is a multi-disciplinary open access archive for the deposit and dissemination of scientific research documents, whether they are published or not. The documents may come from teaching and research institutions in France or abroad, or from public or private research centers.
L'archive ouverte pluridisciplinaire HAL, est destinée au dépôt et à la diffusion de documents scientifiques de niveau recherche, publiés ou non, émanant des établissements d'enseignement et de recherche français ou étrangers, des laboratoires publics ou privés. 


\section{Contributions to Mineralogy and Petrology}

\section{Persistent gas emission originating from a deep basaltic magma reservoir of an active volcano: the case of Aso volcano, Japan \\ --Manuscript Draft--}

Manuscript Number:

Full Title:

Article Type:

Keywords:

Corresponding Author:
CTMP-D-20-00146R1

Persistent gas emission originating from a deep basaltic magma reservoir of an active volcano: the case of Aso volcano, Japan

\section{Original Paper}

Melt inclusion; Volatile element; Magma mixing; Primitive magma; Storage depth; Excess degassing

Masataka Kawaguchi

Kumamoto University

Kumamoto, JAPAN

\section{Corresponding Author Secondary}

Information:

Corresponding Author's Institution:

Kumamoto University

\section{Corresponding Author's Secondary} Institution:

First Author:

Masataka Kawaguchi

First Author Secondary Information:

Order of Authors:

Masataka Kawaguchi

Toshiaki Hasenaka

Kenneth T. Koga

Estelle F. Rose-Koga

Atsushi Yasuda

Natsumi Hokanishi

Yasushi Mori

Kenji Shimizu

Takayuki Ushikubo

Order of Authors Secondary Information:

Funding Information:

\begin{tabular}{l|l|}
\hline $\begin{array}{l}\text { Japan Society for the Promotion of } \\
\text { Science } \\
\text { (17K05682) }\end{array}$ & Prof. Toshiaki Hasenaka \\
\hline $\begin{array}{l}\text { Ministry of Education, Culture, Sports, } \\
\text { Science and Technology }\end{array}$ & Prof. Toshiaki Hasenaka \\
$\begin{array}{l}\text { Campus France } \\
\text { (JP19-00641) }\end{array}$ & Mr. Masataka Kawaguchi \\
\hline $\begin{array}{l}\text { Région Auvergne-Rhône-Alpes } \\
\text { (SCUSI) }\end{array}$ & Dr. Estelle F. Rose-Koga \\
\hline
\end{tabular}

Abstract:

Volcanic gas emission is considered to reflect the degassing of magma beneath volcanoes. The combined observations of gas measurement and petrological study are expected to constrain the volatile concentrations and storage depths of the preeruptive and primitive magma. Aso volcano (Japan) is a constantly-monitored, persistently-degassing volcano, and an ideal site to acquire gas and petrologic data. We analyzed the melt inclusions and phenocryst minerals of Holocene basaltic eruption products, and reported their major and volatile element concentrations. The samples showed abundant evidence of magma mixing, such as reverse mineral zoning, and highly variable mineral and glass compositions. $\mathrm{SiO} 2$ measured in melt inclusions varied from 46.0 to $65.8 \mathrm{wt}$. \%. High-volatile concentration, S up to 3750 


\section{Response to Reviewers:}

ppm, were only found in mafic melt inclusions hosted by high-Fo olivine phenocrysts ( Fo82). The pre-eruptive storage depths were determined from volatile concentrations: $2 \mathrm{~km}$ and $4 \mathrm{~km}$ depth for Strombolian eruption and sub-Plinian eruption, respectively. The volatile-rich primitive magma, one endmember of the mixedmagma, originated from a deeper level $(>10 \mathrm{~km})$ than these magma reservoirs. Initial volatile concentrations of the primitive magma were determined using multiple constraints: $>4.68$ wt. \% H2O, 400 - 750 ppm CO2, 3750 ppm S, 716 ppm Cl, and 324 ppm F. The observed variation of volcanic gas composition was best explained by the mixing of the gas segregated from at least a depth of $10 \mathrm{~km}$, with that from the shallow reservoirs. This study illustrated the method to identify the primitive mafic magma responsible for deep volatile flux in a mature volcano with complex magmatic processes.

\section{Dear Prof. Grove and reviewers:}

Thank you for your thoughtful and constructive feedback regarding our manuscript titled "Persistent gas emission originating from a deep basaltic magma reservoir of an active volcano: the case of Aso volcano, Japan". Please find attached our revised manuscript and responses to the reviewer's comments. We have carefully read all comments and revised the manuscript accordingly.

In this revision, we rearranged the discussion order and added sentences to make it clearer. As suggested by the reviewers, we have also examined another degassing model and compared with our melt inclusion data, which is now enclosed into supplementary material. In addition, following the reviewer's suggestion, we have added a new summary figure for conclusion. Our manuscript has been greatly improved in other respects as well by the reviewers contributions.

Lastly, thank you again for giving us the opportunity to strengthen our manuscript with your valuable comments and queries. We have worked hard to incorporate your feedback and hope that the revised version is now suitable for publication.

Sincerely

Masataka Kawaguchi 


\title{
Persistent gas emission originating from a deep basaltic magma reservoir of an active volcano: the case of Aso volcano, Japan
}

3

4

\begin{abstract}
Masataka Kawaguchi**,
1. Graduate School of Science and Technology, Kumamoto University, 2-39-

1 Kurokami, Chuo-ku, Kumamoto-shi, Kumamoto 860-8555, Japan, 181d9061@st.kumamoto-u.ac.jp

2. Université Clermont Auvergne, CNRS, IRD, OPGC, Laboratoire Magmas et Volcans, F-63000 Clermont-Ferrand, France,
\end{abstract} masataka.kawaguchi@etu.uca.fr

Toshiaki Hasenaka, Center for Water Cycle, Marine Environment and Disaster management, Kumamoto University, 2-39-1 Kurokami, Chuo-ku, Kumamotoshi, Kumamoto 860-8555, Japan, hasenaka@ kumamoto-u.ac.jp

Kenneth T. Koga, Université Clermont Auvergne, CNRS, IRD, OPGC, Laboratoire Magmas et Volcans, F-63000 Clermont-Ferrand, France, ken.koga@uca.fr

Estelle F. Rose-Koga, Université Clermont Auvergne, CNRS, IRD, OPGC, Laboratoire Magmas et Volcans, F-63000 Clermont-Ferrand, France, estelle.koga@uca.fr

Atsushi Yasuda, Earthquake Research Institute, The University of Tokyo, 1-1-1 Yayoi, Bunkyo-ku, Tokyo 113-0032, Japan, yasuda@eri.u-tokyo.ac.jp

Natsumi Hokanishi, Earthquake Research Institute, The University of Tokyo, 11-1 Yayoi, Bunkyo-ku, Tokyo 113-0032, Japan, hokanishi@eri.u-tokyo.ac.jp Yasushi Mori, Kitakyushu Museum of Natural History and Human History, 2-41, Higashida, Yahatahigashi-ku, Kitakyushu 805-0071, Japan, mori@ kmnh.jp Kenji Shimizu, Kochi Institute for Core Sample Research, Japan Agency for Marine-Earth Science and Technology (JAMSTEC), 200 Monobe-otsu Nankoku, Kochi 783-8502, Japan, shimmy@jamstec.go.jp

Takayuki Ushikubo, Kochi Institute for Core Sample Research, Japan Agency for Marine-Earth Science and Technology (JAMSTEC), 200 Monobe-otsu Nankoku, Kochi 783-8502, Japan, ushikubot@jamstec.go.jp

** Indicate the corresponding author 


\section{Abstract}

Volcanic gas emission is considered to reflect the degassing of magma beneath volcanoes. The combined observations of gas measurement and petrological study are expected to constrain the volatile concentrations and storage depths of the pre-eruptive and primitive magma. Aso volcano (Japan) is a constantly-monitored, persistentlydegassing volcano, and an ideal site to acquire gas and petrologic data. We analyzed the melt inclusions and phenocryst minerals of Holocene basaltic eruption products, and reported their major and volatile element concentrations. The samples showed abundant evidence of magma mixing, such as reverse mineral zoning, and highly variable mineral and glass compositions. $\mathrm{SiO}_{2}$ measured in melt inclusions varied from 46.0 to $65.8 \mathrm{wt}$. \%. High-volatile concentration, $S$ up to $3750 \mathrm{ppm}$, were only found in mafic melt inclusions hosted by high-Fo olivine phenocrysts ( $\sim$ Fo82). The pre-eruptive storage depths were determined from volatile concentrations: $2 \mathrm{~km}$ and $4 \mathrm{~km}$ depth for Strombolian eruption and sub-Plinian eruption, respectively. The volatile-rich primitive magma, one endmember of the mixed-magma, originated from a deeper level $(>10 \mathrm{~km})$ than these magma reservoirs. Initial volatile concentrations of the primitive magma were determined using multiple constraints: $>4.68$ wt. $\% \mathrm{H}_{2} \mathrm{O}, 400-750$ ppm CO 2,3750 ppm S, 716 ppm $\mathrm{Cl}$, and $324 \mathrm{ppm} \mathrm{F}$. The observed variation of volcanic gas composition was best explained by the mixing of the gas segregated from at least a depth of $10 \mathrm{~km}$, with that from the shallow reservoirs. This study illustrated the method to identify the primitive mafic magma responsible for deep volatile flux in a mature volcano with complex magmatic processes.

\section{Keywords}

Melt inclusion, Volatile element, Magma mixing, Primitive magma, Storage depth, Excess degassing.

\section{Introduction}

Arc volcanoes are known for their explosive eruptions driven by abundant dissolved volatile elements in their magma. It has been recognized that gas exsolution is the key player triggering rapid magma ascent and eruption (Roggensack et al. 1997; Pioli et al. 2009; Edmonds and Wallace 2017). Therefore, volcanic gas emission is considered to reflect the degassing of magma beneath volcanoes, and is one of the commonly observed and monitored activities, even in the quiescent period. Such persistent degassing of active volcanoes has been seen in arc volcanoes of the world (e.g. Miyakejima, Shinohara et al. 2003; Stromboli, Burton et al. 2007). Typically, volatile element behavior in magmas is governed by their solubility, and the amounts of volatile elements issued from magma are closely related to their pre-eruptive abundance. Thus, it is critical to determine the depths at which magmas were present, and their initial compositions through the studies of volcanic products. To investigate pre-eruptive volatile concentration and possibly primitive concentration, the study of melt inclusions is a 
powerful tool since the melt is trapped in a host crystal at depth, and isolated from interaction with surrounding magma (e.g. Anderson 1973; Sisson and Layne 1993; Wallace 2005). In fact, melt inclusions are not perfectly isolated from surrounding magmas since $\mathrm{H}^{+}$can diffuse through the host olivine (e.g. Gaetani et al. 2012) and $\mathrm{CO}_{2}$ can be redistributed in shrinkage bubbles (e.g. Tucker et al. 2019). Therefore, $\mathrm{H}_{2} \mathrm{O}$ and $\mathrm{CO}_{2}$ measurements in melt inclusions are regarded as minimum values indicating the condition of last equilibration. However, several studies have pointed out discrepancies between total masses of emitted gas measurements and melt inclusion-estimation of dissolved gas in glasses (e.g. Wallace 2005; Shinohara 2008). This is commonly referred to as "excess degassing", and is observed in subduction zone volcanism (e.g. Métrich and Wallace 2008; Roberge et al. 2009; Wallace and Edmonds 2011; de Moor et al. 2017). It appears necessary to reconcile the melt inclusion-based volatile budget with the surface observation and this is the task we want to tackle in this study.

Aso volcano (Japan) is the ideal study site to compare gas emissions and petrological samples, including melt inclusions. It is a constantly monitored persistent degassing volcano since the 1970s, emitting more than 100 - 200 tons of $\mathrm{SO}_{2}$ a day, even during the quiescent period (e.g. Mori et al. 2013; Shinohara et al. 2018; Japan Meteorological Agency (JMA) 2020). In addition, Holocene eruptions from Aso produced olivine-bearing tephra samples, ideal for finding quenched melt inclusions. For example, a recent melt inclusion study of historical Aso eruption products reported a shallow storage depth of erupted magma and a large excess of $\mathrm{SO}_{2}$ degassing from Aso volcano (Saito et al. 2018). However, this previous study did not report volatile element concentrations of a primitive magma. Moreover, geophysical studies revealed multiple magma reservoirs with depths down to $24 \mathrm{~km}$ (below sea level: bsl) (Sudo and Kong 2001; Sudo et al. 2006; Abe et al. 2010; Hata et al. 2016).

In this study, we analyzed the bulk tephra of less evolved erupted products, matrix glasses, melt inclusions (glass and host minerals) to obtain information on the preeruptive magma process, storage depth and characteristics of primitive magma of Aso volcano. This paper reports the first petrological description of the deep magma reservoirs of Aso volcano using melt inclusion data and corroborating gas composition model. Our petrological constraints on a magma plumbing system give us the primitive $\mathrm{H}_{2} \mathrm{O}, \mathrm{CO}_{2}, \mathrm{~F}$, $\mathrm{Cl}$, and $\mathrm{S}$ concentrations of Aso, a persistently-degassing active volcano.

\section{Samples and methods}

\section{Geological setting of Aso volcano and its cones}

Aso volcano, located in central Kyushu Island of the Southwest Japan Arc, is one of the most active volcanoes of the volcanic front related to the Philippine sea plate subduction (Nakada and Kamata 1991; Kamata 1998; Miyoshi et al. 2008a, b). It has been active for at least 0.8 million years (e.g. Watanabe et al. 1989). Its activity is characterized by two different types of volcanisms: caldera-forming gigantic pyroclasticflow eruptions (from $270 \mathrm{ka}$ to $89 \mathrm{ka}$ ), and post-caldera extrusive activities (<89 ka) (Ono 
and Watanabe 1985). In the post-caldera stage, various types of magma (basalt to rhyolite) were erupted from, at least, 17 observable vents in the caldera (Watanabe 2001; Miyoshi et al. 2005).

Holocene activities are well described in tephrostratigraphic studies (Miyabuchi and Watanabe 1997; Miyabuchi 2009, 2010, 2017). The tephra is mostly basaltic and limited to the ejections from central cones. The last silicic eruption deposited Aso central cone pumice 1 (ACP1; Takada 1989) at $4.0 \mathrm{ka}$ (Miyabuchi and Watanabe 1997; Hirata et al. 2020). ACP1 is the only silicic product in Holocene, which is dacitic banded pumice related to the effusion of Akamizu andesite lava flow (Miyabuchi 2017). Subsequently, volcanic activity of Kishimadake (3.7 ka), Ojodake (3.5 ka), Komezuka and Kamikomezuka cones (3.0 ka) was derived from basaltic to basaltic andesite magmas (Fig. 1; Miyabuchi and Watanabe 1997; Miyabuchi 2010; Hirata et al. 2020). Nakadake cone is formed in three stages: old volcanic $(22-7.3 \mathrm{ka})$, young volcanic $(7.3-3.7 \mathrm{ka})$ and youngest pyroclastic stages (<3.7 ka; Ono and Watanabe 1985; Miyabuchi 2009). Today, Nakadake is the only active central cone since the last eruption of Kamikomezuka (ca. $3.0 \mathrm{ka}$ ). All basaltic rocks in the post-caldera stage of Aso volcano evolved to lowMg high-alumina basalt (MgO < 6.1 wt.\%; Kuno 1960; Sisson and Grove 1993).

The magma chambers beneath Aso caldera have been described by geophysical surveys. Abe et al. (2010) reported a large low-velocity layer (LVL) from a depth of 11 to $25 \mathrm{~km}$ (for consistency hereafter, all the depths in the paper are referred as depths from the vent of the edifice, adding $1 \mathrm{~km}$ to the depth below sea level), by receiver function tomography. Hata et al. (2016) identified the magma pathway from $21 \mathrm{~km}$ deep beneath the caldera by electromagnetic survey, and reported two anomaly centers ( $\mathrm{C} 1$ and $\mathrm{C} 2$ ) separated by $3 \mathrm{~km}$ in horizontal distance. $\mathrm{C} 1$ is located $5 \mathrm{~km}$ beneath Kishimadake cone, which corresponds to the main magma chamber feeding present-day Nakadake eruptions. This is in good agreement with earlier studies that reported the $\mathrm{C} 1$ chamber between 4 and $10 \mathrm{~km}$ depth, by deformation analysis of the volcano (Sudo et al. 2006) and seismic low-velocity anomaly (Sudo and Kong 2001). C2 is located $3 \mathrm{~km}$ beneath Nakadake cone. However, this C2 anomaly is geographically offsetted from the crater of Nakadake, and instead, a crack-like conduit extending from 0.3 to $2.8 \mathrm{~km}$. A continuing passage was identified beneath this cracked-conduit, based on a region of lack of seismic reflectors at a depth from 2.5 to $4.5 \mathrm{~km}$ beneath the crater based on a 3-D seismic reflection analysis (Tsutsui and Sudo 2004). In this paper, we call this shallow magma passage as C2.

\section{Tephra and scoria descriptions}

We collected tephra deposits of eruptions from Kishimadake ( $c a .3 .7 \mathrm{ka}$ ), Ojodake (ca. $3.5 \mathrm{ka}$ ), Kamikomezuka ( $c a .3 .0 \mathrm{ka}$ ) and Nakadake (the youngest pyroclastic cone; $<3.7 \mathrm{ka}$ ). Tephra samples were specifically collected to avoid the diffusive volatileloss and daughter mineral crystallization within melt inclusions (Danyushevsky et al. 2002; Lloyd et al. 2013). Furthermore, we focused on recent (3.7 ka to present) eruption 
activities of basalt to basaltic andesite composition involving olivine phenocrysts. The sample set was therefore used to obtain information about crustal magma evolution and the volatile characteristics of magmas. All tephra samples contain phenocrysts of plagioclase, olivine, clinopyroxene, orthopyroxene, and opaque minerals. Detailed descriptions of these tephras are found in Miyabuchi $(2009,2010)$.

Five tephra samples used in this study correspond to the eruptions of four cones: Kishimadake scoria (KSS), Ojodake scoria (OJSU and OJSL), Kamikomezuka scoria (KKO), and Nakadake scoria (NKD14). Specifically, KSS, OJSU, and OJSL were collected from a tephra deposit site (A9418 section reported by Watanabe 1991; Miyabuchi and Watanabe 1997; Fig. 1). KSS was collected from the lowest unit of subPlinian scoria-fall deposits in the N6 stage. It is a vesicular basaltic black scoria with a maximum size of $4.8 \mathrm{~cm}$ (Miyabuchi and Watanabe 1997). OJSU and OJSL were collected from the uppermost and lowest unit of sub-Plinian scoria-fall deposits in the N4 stage, respectively. OJSU and OJSL are reddish-brown, weakly altered basaltic scoria, with a maximum size of $4.6 \mathrm{~cm}$ (Miyabuchi and Watanabe 1997). These deposits represent sub-Plinian eruption events, which are the biggest eruption events in Holocene (each with approximately $0.06 \mathrm{~km}^{3}$, VEI 3, Miyabuchi 2009). KKO was collected from Kamikomezuka cone, because the tephra deposit away from the edifice has not been identified presently. We sampled the black scoria from the outer part of the edifice from a road-cut outcrop, avoiding oxidized reddish scoria. KKO is poorly sorted, non-welded, vesicular scoria, ranging from $\mathrm{cm}$-size to cow-dung bomb (tens of $\mathrm{cm}$ ). NKD14 was collected from the crater rim of Nakadake cone's first crater, immediately after the eruption of Nov. 27, 2014. The samples were cm-size, well-vesiculated, black scoria. The eruption of Nakadake cone in the period 2014 - 2015 is the first magmatic eruption in 24 years (Ikebe et al. 2008; JMA 2016). In the most violent phase, Strombolian eruptions occurred with ejections of scoria lapilli and bombs at Nakadake cone's first crater (Yokoo and Miyabuchi 2015).

\section{Melt inclusion preparation}

These 5 tephra samples were used for petrological observation and chemical analysis (i.e. bulk rock, phenocrysts and melt inclusions). Samples were washed in an ultrasonic bath, and only lapilli-size scoria (up to $6 \mathrm{~cm}$ ) were chosen. Five grams of each sample were powdered using a ball milling machine with an alumina cup and a ball, for bulk rock X-ray fluorescence analysis (XRF). Olivine, pyroxene, and plagioclase crystals were handpicked under an optical microscope from scoria crushed by hand and sieved (from 0.25 to $1 \mathrm{~mm}$ ). The picked crystals were mounted in resin and polished until the melt inclusion was exposed. They were then measured using an electron probe microanalyzer (EPMA) and a reflectance Fourier transform infrared spectroscope (FTIR). Selected olivine crystals hosting melt inclusions of KSS and NKD14 were removed from the resin after EPMA and FTIR analyses, then mounted together in indium for secondary ion mass spectrometry (SIMS). 
196

\section{Analytical methods}

\section{$\underline{\text { Bulk rock major and trace elements }}$}

Bulk rock major and trace elements were determined by XRF on flux-fused disks using a Philips PANalytical MagiX PRO spectrometer at the Kitakyushu Museum of Natural History and Human History. The detailed analytical procedures are described by Mori and Mashima (Mori and Mashima 2005). Accuracy was reported as $\pm 0.1 \%$ relative for $\mathrm{SiO}_{2}$ and for trace elements, and varied from 5 to 25 ppm (Table 1).

\section{$\underline{\text { Major and volatile elements in melt inclusion, mineral and glass }}$}

Major elements, $\mathrm{S}$, and $\mathrm{Cl}$ concentrations were determined in melt inclusions, host minerals and groundmass glasses using a JXA8800R electron probe microanalyzer at the Earthquake Research Institute (ERI), University of Tokyo. The analytical settings were $15 \mathrm{kV}$ acceleration voltage, $12 \mathrm{nA}$ beam current, with counting times for $\mathrm{Na}, \mathrm{Al}, \mathrm{K}$, $\mathrm{Fe}, \mathrm{Mg}, \mathrm{Si}, \mathrm{Ti}, \mathrm{V}, \mathrm{Mn}$, and $\mathrm{Ca}$ at $20 \mathrm{~s}$, and $30 \mathrm{~s}$ for $\mathrm{Ni}, \mathrm{Cr}$ in mafic minerals and for $\mathrm{S}$ and $\mathrm{Cl}$ in hydrous melt. Beam diameter was set at $10 \mu \mathrm{m}$ for glass and plagioclase, and focused $(1 \mu \mathrm{m})$ for other minerals. During melt inclusion and groundmass glass analysis, $\mathrm{Na}$ and $\mathrm{K}$ were always measured in the first analytical cycle to minimize alkali loss (Devine et al. 1995). All analyses applied oxide ZAF correction. Analytical uncertainties are $<0.7 \%$ relative for $\mathrm{Si},<1 \%$ relative for $\mathrm{Al}, \mathrm{Fe}, \mathrm{Mg}$, and $\mathrm{Ca},<5 \%$ relative for $\mathrm{Ti}$ and $\mathrm{Na},<10 \%$ relative for $\mathrm{K}$, and $<20 \%$ relative for $\mathrm{Mn}, \mathrm{V}, \mathrm{Ni}, \mathrm{Cr}, \mathrm{S}$, and $\mathrm{Cl}$.

In addition to the EPMA analysis, the core and rim compositions of phenocrysts were analyzed by energy-dispersive X-ray spectroscopy (EDS, AZtec system; Oxford Instruments) connected to a JEOL JSM-7001F field-emission electron microscope (FESEM) at Kumamoto University, using $15 \mathrm{kV}$ acceleration voltage and $1 \mathrm{nA}$ beam current. The beam diameter settings were the same as the EPMA setting at the University of Tokyo for all the host minerals. Analytical uncertainties are typically $0.5 \%$ relative for $\mathrm{SiO}_{2}, 1 \%$ relative for $\mathrm{Al}_{2} \mathrm{O}_{3}, 1.5 \%$ relative for $\mathrm{FeO}, 0.5 \%$ relative for $\mathrm{MgO}, 2 \%$ relative for $\mathrm{TiO}_{2}$ and $\mathrm{Na}_{2} \mathrm{O}, 1.5 \%$ relative for $\mathrm{K}_{2} \mathrm{O}, 1 \%$ relative for $\mathrm{CaO}$. Other minor elements such as $\mathrm{MnO}$ and $\mathrm{P}_{2} \mathrm{O}_{5}$ can be as high as $20 \%$ relative.

Water concentrations in melt inclusions were determined by FTIR microreflectance spectroscopy using a JASCO FT-IR-660 plus, equipped with an IRT-30VC analytical microscope at the ERI, following the procedures described by Yasuda (2014). The IR spectra were obtained using $15 \times 15$ to $60 \times 60 \mu \mathrm{m}^{2}$ rectangular apertures, and by accumulating 220 to 1500 scans, over a range of 400 to $7800 \mathrm{~cm}^{-1}$. A gold mirror was used as a reflectance reference. Water concentrations were quantified using an empirical linear relationship for basalt to rhyolite compositions for total $\mathrm{H}_{2} \mathrm{O}$ concentrations, measured in the $3650 \mathrm{~cm}^{-1}$ wavelength region. The analytical uncertainty $(2 \sigma)$ of the FTIR reflectance spectroscopy was $<0.3 \mathrm{wt}$. \% . While the detection limit of the method 
strongly depended on the sample, we estimated the detection limits as $0.14 \mathrm{wt}$. \% (Yasuda 2014).

$\mathrm{H}_{2} \mathrm{O}, \mathrm{CO}_{2}, \mathrm{~F}, \mathrm{~S}$, and $\mathrm{Cl}$ concentrations in selected melt inclusions were determined by a SIMS (Cameca IMS-1280HR of Kochi Institute, JAMSTEC, Japan) following the procedure described by Shimizu et al. (2017). This analytical method favors a weaker primary current (up to $0.5 \mathrm{nA}$ ) than in previous studies (1-1.5 nA primary current; Le Voyer et al. 2010; Helo et al. 2011; Rose-Koga et al. 2012, 2014; 20 nA primary current in Hauri et al. 2002) and uses in-house standards covering the concentration range found in the natural samples in this study. In short, a $20 \mathrm{keV}(10 \mathrm{keV}$ at the ion source and $10 \mathrm{keV}$ at the sample surface) $\mathrm{Cs}^{+}$ion beam of 300-500 pA was defocused to be 10-15 $\mu \mathrm{m}$ in diameter. Secondary ions were accelerated at $10 \mathrm{kV}$. A -10 $\mathrm{keV}$ electron beam with a diameter of $\sim 100 \mu \mathrm{m}$ was applied for electrostatic charge compensation of the analysis area. The field aperture was set at the size corresponding to $5 \times 5 \mu \mathrm{m}$ on the sample surface. Mass resolving power was set at $\sim 6000$ to separate mass interferences (for example, to separate ${ }^{34} \mathrm{~S}{ }^{1} \mathrm{H}$ interference on ${ }^{35} \mathrm{Cl}$ requires $5120 \mathrm{MRP}$; Burdo and Morrison 1971). Negative secondary ions of ${ }^{12} \mathrm{C},{ }^{16} \mathrm{OH},{ }^{19} \mathrm{~F},{ }^{30} \mathrm{Si},{ }^{31} \mathrm{P},{ }^{32} \mathrm{~S}$, and ${ }^{35} \mathrm{Cl}$ and the mass position of 11.9 amu were measured by an axial electron multiplier using the peak switching method. An analysis consisted of 10 cycles, and the total measurement time for each analysis was $\sim 6 \mathrm{~min}$. Repeated analysis of a secondary basaltic glass standard from East Pacific Rise, EPR-G3 (Shimizu et al. 2017), yielded a relative standard deviation $(1 \sigma)$ for $\mathrm{H}_{2} \mathrm{O}, \mathrm{CO}_{2}, \mathrm{~F}, \mathrm{Cl}$, and $\mathrm{S}$ of $1.4,3.2,1.5,2.5$, and $0.9 \%$, respectively. This SIMS analysis was conducted after EPMA analysis. Therefore, although we were careful to polish the sample with alumina powder again before SIMS analysis, measured $\mathrm{CO}_{2}$ concentrations were reported in the supplementary material but not used due to possible carbon contamination. The measured values for $\mathrm{S}$ and $\mathrm{Cl}$ agreed within $25 \%$ between EPMA and SIMS analysis. So when volatile elements were measured by two methods, we adopted SIMS values rather than EPMA because analytical uncertainty of these elements by SIMS are generally lower (e.g. Rose-Koga et al. 2020). In this study, we did not find satisfactory agreement between $\mathrm{H}_{2} \mathrm{O}$ determined by FTIR and by SIMS (uncertainty of FTIR measurements is close to $40 \%$ ) so in the following, we only consider $\mathrm{H}_{2} \mathrm{O}$ concentrations measured by SIMS, based on the better detection limit and precision of the method.

\section{$\underline{\text { Sulfur speciation analysis }}$}

Selected inclusions were analyzed for $\mathrm{S} K \alpha$ peak positions to constrain the $\mathrm{fO}_{2}$ conditions of the glasses. The wavelength of $\mathrm{S} K \alpha$ radiation $[\lambda(\mathrm{S} K \alpha)]$ for melt inclusions was measured using the EPMA following the procedures described by Yasuda et al. (2001), based on the method of Wallace and Carmichael (1994) and Carroll and Rutherford (1988). Sulfur speciation as the proportion of $S^{6+}$ over a total $S$ content was determined by measuring a relative shift from the peak position of an anhydrite mineral 
273 (Carroll and Rutherford 1988), with an assumption that $\mathrm{S}^{2-}$ and $\mathrm{S}^{6+}$ are the only two

274 relevant species in silicate melt (Jugo et al. 2010). To avoid sulfur oxidation due to 275 prolonged beam exposure (i.e. Rowe et al. 2007), we conducted a measurement with 276 multiple spots for each melt inclusion. Therefore, we added up the wavelength scan data 277 of individual spots to determine the precise peak position. A Gaussian curve fitting was 278 used for sulfur peak deconvolution. Analytical uncertainty ranges from 5 to $10 \%$ relative 279 (Table S1).

\section{Data processing: Post-entrapment crystallization correction}

Major and volatile element data for all melt inclusions hosted in olivine were corrected for the effects of post-entrapment crystallization (PEC; e.g. Danyushevsky et al. 2000) by incremental calculation of equilibrium olivine ( $0.1 \mathrm{wt}$. \% step) adding into the residual melt, until the melt reaching equilibrium with host olivine (Toplis 2005), following the procedures described in Danyushevsky et al. (2000). The melt $\mathrm{Fe}^{2+} / \mathrm{Fe}^{\text {Total }}$ ratios were calculated from the empirical equation of Kilinc et al. (1983), assuming a constant $\mathrm{fO}_{2}(\triangle \mathrm{FMQ}+1.0)$ based on measured $\mathrm{S} K \alpha$ peak shifts of all eruptions (Jugo et al. 2010). Temperatures of olivine-melt equilibrium were calculated using the olivinesaturated melt thermometer of Sugawara (2000), corrected for the effect of water on olivine liquidus temperature according to Médard and Grove (2008). We assumed an average $\mathrm{H}_{2} \mathrm{O}$ concentration of NKD14 and KSS analyzed by SIMS for melt inclusions that were not analyzed individually for $\mathrm{H}_{2} \mathrm{O}$. Note, $\mathrm{K}_{\mathrm{D}}$ and temperature were recalculated at each increment of olivine addition. The melt inclusions were not corrected for postentrapment diffusive Fe-loss (Danyushevsky et al. 2000), as total $\mathrm{FeO}$ concentrations in melt inclusions are either the same or higher than those in bulk rocks. Corrected volatile concentrations were adjusted assuming volatiles are perfectly incompatible to host minerals and corrected values are used in the figures and reported in Table 2 (raw uncorrected data in supplementary material S1).

Plagioclase-, clinopyroxene-, and orthopyroxene-hosted melt inclusions were not corrected for PEC because there is no universally accepted procedure, although some attempts have been reported (Yasuda et al. 2001; Neave et al. 2017; Hartley et al. 2018). Among these samples, only the melt inclusions in equilibrium with host minerals were used for the magmatic temperature calculation, in which the exchange coefficients were within expected range of basaltic composition: $\left(\mathrm{K}_{\mathrm{D}}(\mathrm{Fe}-\mathrm{Mg})_{\mathrm{cpx}-\mathrm{liq}}=0.28 \pm 0.08, \mathrm{~K}_{\mathrm{D}}(\mathrm{Fe}-\right.$ $\mathrm{Mg})_{\text {opx-liq }}=0.29 \pm 0.06$, and $\mathrm{K}_{\mathrm{D}}(\mathrm{An}-\mathrm{Ab})_{\text {pl-liq }}=0.27 \pm 0.01$ or $0.1 \pm 0.05$ (depending on the calculated temperature; Putirka 2008).

\section{Results}

The analysis of five scoria from Aso edifices produced data of major elements for bulk rocks along with 204 melt inclusion data (major and volatile element concentrations) and host mineral compositions. More than 890 point-analyses were made to determine major element compositions of groundmass glasses and phenocrysts (core 
and rim; Tables $1-3$ and $\mathrm{S} 1-\mathrm{S} 3)$.

\section{Petrography}

All samples were porphyritic with approximately 40 vol.\% crystals. Plagioclase, clinopyroxene, olivine plus minor orthopyroxene, and opaque minerals were present. In all samples, plagioclase phenocrysts commonly showed dusty zone and honeycomb texture (Fig. 2a), and all orthopyroxene phenocrysts had reaction rims of olivine and clinopyroxene (Fig. 2b). Aggregates of phenocrysts (i.e. plagioclase, clinopyroxene, olivine, and opaque minerals) were frequently found in all samples (Fig. 2c). The groundmass consisted of microlites of plagioclase, clinopyroxene, olivine, and magnetite. The groundmass of KSS occasionally showed the heterogeneous mingling texture where crystals are relatively abundant (Fig. 2d).

\section{Host mineral compositions}

The olivine phenocrysts were grouped into two types based on the core Fo contents $[\mathrm{Mg} /(\mathrm{Fe}+\mathrm{Mg}) \times 100$ in mole], as low-Fo (62 to 72) and high-Fo (72 to 82) (Fig. 3a). High-Fo olivine was observed only in KKO, OJSU, OJSL, and KSS. Low-Fo olivine was found in all samples. As Fo content of the phenocryst rims ranged from 68 to 78 in KKO, OJSU, OJSL, and KSS, and from 64 to 67 in NKD14 (Table S3), generally low-Fo olivine phenocrysts were reversely zoned, whereas olivine phenocrysts in NKD14 were homogeneous. All high-Fo olivine phenocrysts were normally zoned. Clinopyroxene and orthopyroxene phenocryst cores in all samples were in the range of 65-76 and 61-71, respectively $(\mathrm{Mg} \#=[\mathrm{Mg} /(\mathrm{Fe}+\mathrm{Mg}) \times 100$ in mole $])$. The majority of clinopyroxene phenocrysts in KKO, OJSU, OJSL, and KSS were reversely zoned. Mg\# of NKD14 varied little, at $\sim 70$. The compositions in the rims of olivine and clinopyroxene phenocrysts were the same as the minerals found in reaction rims of orthopyroxene phenocrysts. The plagioclase phenocrysts were also divided into two types based on the normal and reverse zoning patterns. The An content $[\mathrm{Ca} /(\mathrm{Ca}+\mathrm{Na}) \times 100$ in mole] of the plagioclase phenocryst cores was within the 55-93 range.

\section{Major and volatile elements in melt inclusions}

The tephra samples of this study were basaltic to basaltic andesite with $\mathrm{SiO}_{2}$ ranging from 51.5 to 54.3 wt. \% (large circles in Fig. 3c). Melt composition in inclusions varied significantly more than that of the bulk tephra composition: $\mathrm{SiO}_{2}$ ranging from 46.0 to 65.8 wt. \%. This range mostly overlapped with the compositional variation of post-caldera volcanic products (grey circles in Fig. 3c). The melt inclusion compositions of NKD14 were generally similar to evolved matrix glass and varied little, and were distinguished from the melt inclusions of KKO, OJSU, OJSL, and KSS.

In our sample set, the core composition of host olivines were clearly divided into two groups with Fo72 representing the divide (Fig. 3a). We interpreted that olivines have grown from two distinctively different lavas, which we called mafic and felsic. 
Based on the anti-correlation of $\mathrm{SiO}_{2}$ concentration in olivine-hosted melt inclusions with host Fo content, we concluded that magma composition can be divided into two groups above and below $55 \mathrm{wt}$.\% $\mathrm{SiO}_{2}$. The high $\mathrm{SiO}_{2}$ corresponded to low-Fo olivine and low $\mathrm{SiO}_{2}$ corresponded to high-Fo olivine. Thus, in the following we grouped all the melt inclusions lower than $55 \mathrm{wt} . \% \mathrm{SiO}_{2}$ in a mafic group, and others in a felsic group. $\mathrm{S}$ concentration in melt inclusions correlates well with host Fo content and is anti-correlated with $\mathrm{SiO}_{2}$ (Fig. 3a) and $\mathrm{K}_{2} \mathrm{O}$, indicating a mafic volatile-rich (with $\mathrm{S}$ up to $3750 \mathrm{ppm}$ and $\mathrm{Cl}$ up to $1311 \mathrm{ppm}$ ) magma, and a felsic volatile-poor magma (Fig. 3b). NKD14 inclusions were notably different, with less than $434 \mathrm{ppm} \mathrm{S}$, indicating extensive degassing. Melt inclusion $\mathrm{Cl}$ concentrations varied from $530 \mathrm{ppm}$ to $1311 \mathrm{ppm}$ (Table 2 and Table S1; SIMS value is preferred to EMP value when both are reported). F concentrations were determined only on a subset of olivine-hosted melt inclusions and therefore there are fewer data. F concentrations varied between 258 and $853 \mathrm{ppm}$ (Table 2 and Table S1). $\mathrm{F}$ and $\mathrm{Cl}$ correlates with $\mathrm{SiO}_{2}$ and $\mathrm{K}_{2} \mathrm{O}$ and anti-correlate with host Fo content. $\mathrm{H}_{2} \mathrm{O}$ concentrations measured in melt inclusions vary between 0.47 to $2.89 \mathrm{wt} . \%$ (NKD14-Olivine-4-m4 and KSS-Olivine-4-m11, respectively; Table 2 and Table S1).

\section{Discussion}

\section{Evidence for magma mixing}

Zoning in magmatic minerals characterizes their crystallization in a magma chamber and can trace the history of magma cooling (e.g. Costa et al. 2008), and magma mixing (e.g. Sakuyama 1979). Among the tephra samples in this study, phenocrysts in every sample indicate textural evidence of magma mixing that could have been produced by the introduction of hotter magma: for example, the reverse zoning and disequilibrium texture, such as the honey-comb texture of plagioclase and reaction rim of orthopyroxene (Fig. 2a and 2b; Tsuchiyama 1985). The coexistence of normally zoned plagioclase and olivine phenocrysts with these disequilibrium phenocrysts suggests that magma mixing of at least two distinct components has occurred (e.g. Sakuyama 1979). This interpretation is supported by the compositional variation of the melt inclusions; felsic melt inclusions are hosted in reversely zoned phenocrysts such as plagioclase, clinopyroxene, orthopyroxene, and low-Fo olivine. Mafic melt inclusions are hosted in high-Fo olivine and some of plagioclase (Fig. 3).

The presence of orthopyroxenes surrounded by reaction rims and An-rich zones in the middle part of plagioclases in NKD14 (Fig. 2f) indicates that the 2014 magma is also the result of mixing. Such petrological features are found in magmatic products of every Nakadake eruption (Miyoshi et al. 2005). Thus, we consider that all the Nakadake eruption products are the result of magma mixing, rather than the derivatives from a single parental magma. In addition, Miyoshi et al. (2005) also show that the compositional variation in the trace elements in the post-caldera basaltic rocks of Aso volcano is consistent with a magma mixing model and not with a fractional crystallization process. Therefore, at least two types of magmas are present beneath the Nakadake cone, and feed 
394

395

396

397

398

399

400

401

402

403

404

405

406

407

408

409

410

411

412

413

414

415

416

417

418

419

420

421

422

423

424

425

426

427

428

429

430

431

432

433

434

its eruption.

\section{Characterization of mixing endmembers}

We conducted a two-component mixing model calculation of two distinct magmas, one silicic endmember and one mafic endmember, based on the major element variation of melt inclusions (see Supplementary document S4). The model used the most primitive basaltic melt (Melt ID: 2-m1 hosted in an olivine) and the most $\mathrm{SiO}_{2}$-rich dacitic melt (Melt ID: d2-m1 hosted in a plagioclase) of KSS as the mafic and silicic endmember, respectively. The major element variation was well reproduced with the mixing model for melt inclusions of all host minerals (Fig. S4-5). While the major variance of concentration variations was explained by a simple mixing process, in close inspection of trends, it is likely that crystal fractionation contributed to the dispersion from the mixing model. It should also be noted that the mixing model required the presence of independent mixing endmembers, it does not constrain their origin.

It is important to note that there is a surface expression of this silicic endmember in the Aso eruption products, while the mixing endmember is set by a melt inclusion. Major element compositions of ACP1 dacitic pumice (Takada 1989), the only Holocene felsic product erupted three hundred years before that of KSS, are similar to the endmember, and this indicates the presence of the silicic magma. Furthermore, the presence of a banded pumice was reported in ACP1 prior to KSS (Miyabuchi 2017). This banded texture is evidence of magma mingling and therefore the mixing trend is unlikely a result of assimilation and crystal fractionation of single parental magma. The cores of reversely zoned phenocrysts of KSS scoria samples were formed at equilibrium conditions with the silicic endmember. Therefore, the temperature of silicic endmember magma was determined with a two-pyroxene thermometer by pairing core compositions (Putirka 2008). The estimated temperatures of the silicic endmember are $1010-1025^{\circ} \mathrm{C}$ for KKO, OJSU, OJSL, and $\mathrm{KSS}\left( \pm 13^{\circ} \mathrm{C}, 1 \sigma\right.$ for samples, while standard error of the thermometer is $\pm 38^{\circ} \mathrm{C}$ ). We adopted this estimated range as the temperature of the silicic endmember magma. These estimated temperatures are higher than those of typical dacitic magma with 4 - 5 wt. $\% \mathrm{H}_{2} \mathrm{O}$ (e.g. $770-915{ }^{\circ} \mathrm{C}$ for Mount St. Helens, Gardner et al. 1995) and lower than that estimated for a completely anhydrous dacitic magmas, for example Puna Geothermal Venture Wellfield, Hawaii have the highest temperature estimates $1050^{\circ} \mathrm{C}$ (Teplow et al. 2009). This silicic endmember magma (T between 1010$1025^{\circ} \mathrm{C}$ ) will mix with the mafic endmember (most likely hotter) magma at temperature presumably higher than $1010-1025^{\circ} \mathrm{C}$.

Basaltic lava corresponding to the pure mafic endmember is absent among the eruption products of the entire post caldera stage (Miyoshi et al. 2005), while it is found in olivine-hosted melt inclusion. Many tephras of this study also contain normally zoned phenocrysts with high-Fo and high-An cores. As for the case of the silicic endmember, it is possible to assume the equilibrium of these cores with the mafic endmember melt. We therefore calculated the magmatic temperature of the pure mafic endmember, using 
Sakuyama's method (Sakuyama et al. 2014), which involves the combined application of a plagioclase-melt hygrometer (Lange et al. 2009) and an olivine-saturated melt geothermometer (Sugawara 2000; Médard and Grove 2008). This method accounts for the $\mathrm{H}_{2} \mathrm{O}$-dependency of the olivine thermometer by simultaneously solving for $\mathrm{H}_{2} \mathrm{O}$ and temperature using an additional constraint from the plagioclase hygrometer. The resulting temperature of mafic endmember magma varies between $1051-1063{ }^{\circ} \mathrm{C}$, depending on the assumed pressure condition of the magma chamber ( $0.1-0.5 \mathrm{GPa}$, respectively). In addition, the entrapment temperature of the endmember inclusion (KSS-2-m1) is 1092 ${ }^{\circ} \mathrm{C}$ based on the olivine-liquidus thermometer (Table S1, Sugawara 2000; Médard and Grove 2008). Considering the uncertainties of the thermometry methods, these temperature estimates are likely representing the range for the mafic magma. By taking the high temperature result $\left(\sim 1090{ }^{\circ} \mathrm{C}\right)$, the temperature difference between mafic and felsic $\left(1010-1025^{\circ} \mathrm{C}\right)$ endmembers is at least $65^{\circ} \mathrm{C}$.

The mixing trend among volatile elements is present and generally consistent with the trend of major elements. However, in detail, there are systematic disparities from the mixing curve (Supplementary document $\mathrm{S} 4$ ). Notably, abundances of $\mathrm{H}_{2} \mathrm{O}, \mathrm{S}$, and $\mathrm{Cl}$ for NKD14 sample, are depleted compared to the mixing trend traced by KSS melt inclusions (Fig. S4-4). This is best explained by significant degassing occurring during/after magma mixing. Furthermore, there is no single melt inclusion uniquely representing suitable mafic endmember volatile concentrations. The sample KSS-2-m1 is selected as the major element endmember, but its $\mathrm{H}_{2} \mathrm{O}$ contents are not the highest values. From the inspection of the trend, we inferred that the mafic endmember must have higher volatile content thus most likely lost water after its entrapment. If melt inclusions formed at a deeper depth, and were stored in a shallower magma chamber, it is expected that $\mathrm{H}^{+}$ diffusion through the olivine would equilibrate the melt inclusion with the surrounding magma (Portnyagin et al. 2008; Chen et al. 2011; Gaetani et al. 2012; Bucholz et al. 2013; Ferriss et al. 2016). Complete re-equilibrated melt inclusion would have erased the mixing trend. It is not the case here, we have found suitable endmember volatile element concentrations that satisfy the general trend. Because the mafic endmember magma is expected to be volatile-rich, it's $\mathrm{H}_{2} \mathrm{O}$ concentration has to be higher than the $\mathrm{H}_{2} \mathrm{O}$ of the mixed-magma (e.g. that of the melt inclusions). The maximum estimated $\mathrm{H}_{2} \mathrm{O}$ concentration (4.68 wt. \%) based on the hygrometer discussed above is therefore taken as the concentration for the volatile-rich mafic endmember. This value of $4.68 \mathrm{wt} . \% \mathrm{H}_{2} \mathrm{O}$ is higher, by about 2 wt. $\%$, than the highest $\mathrm{H}_{2} \mathrm{O}$ concentration measured in the melt inclusion. Sakuyama's method implicitly ignores the $\mathrm{CO}_{2}$ activity in magma, and predicts lower $\mathrm{H}_{2} \mathrm{O}$ content when considering $\mathrm{CO}_{2}$-bearing system (by 0.9 wt. \% less $\mathrm{H}_{2} \mathrm{O}$, assessed from an experimental result of Melekhova et al. 2017). Furthermore, this volatile content is the value at the condition of olivine - plagioclase crystallization, most likely of the cooling magma in the crust. At this point, we have no other constraint on the $\mathrm{H}_{2} \mathrm{O}$ concentration of the mafic endmember and the primary magma could have an even higher $\mathrm{H}_{2} \mathrm{O}$ content. 


\section{Volatile concentrations of primitive basaltic melt}

478

479

480

481

482

483

484

485

486

487

488

489

490

491

492

493

494

495

496

497

498

499

500

501

502

503

504

505

506

507

508

509

510

511

512

513

514

515

516

The melt inclusions similar to the mafic endmember of the mixing model showed element concentrations with primitive character, such as low incompatible element concentrations (low $\mathrm{K}_{2} \mathrm{O}, \mathrm{Cl}$, and $\mathrm{F}$ ), and higher volatile element such as $\mathrm{S}$. However, $\mathrm{H}_{2} \mathrm{O}$ concentration is likely equilibrated to a lower pressure conditions, and $\mathrm{CO}_{2}$ concentration in melt inclusion appears to be low. While these melt inclusions are hosted in high Fo olivine, the $\mathrm{H}_{2} \mathrm{O}$ and $\mathrm{CO}_{2}$ abundances are not of primitive character. On the contrary, as $\mathrm{F}, \mathrm{S}$, and $\mathrm{Cl}$ are not expected to diffuse through the host olivine, and at the time of entrapment, they retain the value closest to the primitive magma. In an attempt to constrain the mafic endmember composition, compositional trends are examined with ratios of $\mathrm{S}, \mathrm{Cl}$, and $\mathrm{F}$ over $\mathrm{K}_{2} \mathrm{O}$. These ratios are less affected by crystallization within melt inclusions and before entrapment, assuming the strong incompatibility of $\mathrm{K}_{2} \mathrm{O}$ in magmatic minerals near basaltic liquidus (Fig. 4). Because the composition of the mafic endmember points towards that of the primitive magma, the maximum values are taken from Fig. $4 \mathrm{a}, \mathrm{b}$, and $\mathrm{c}$, as the primitive volatile ratios: $\mathrm{S} / \mathrm{K}_{2} \mathrm{O}$ $=0.711, \mathrm{Cl} / \mathrm{K}_{2} \mathrm{O}=0.170$, and $\mathrm{F} / \mathrm{K}_{2} \mathrm{O}=0.047$.

Dissolved $S$ concentrations, up to $3750 \mathrm{ppm}$ in the mafic group melt inclusions, are higher than many melt inclusions from subduction-like hydrous basalt (Fig. 5a; $\mathrm{S}$ mostly between 900 and 2500 ppm; e.g. Wallace 2005), while high S content appears to occur in oxidized magmas (Roggensack 2001; Webster et al. 2010). Our primitive magma S estimate is therefore $3750 \mathrm{ppm}$, the highest measured concentration in a melt inclusion of the mafic group. We also noted that $\mathrm{S}$ concentration of half of the melt inclusions are supersaturated in sulfide, plotting above the sulfur concentration at sulfide saturation (SCSS, Fig. 5b), while no sulfide is found in the melt inclusions or in the groundmass. These sulfide supersaturated melt inclusions must be at high $\mathrm{fO}_{2}$ condition, so that the concentration of sulfide-precipitating $\mathrm{S}^{2-}$ in magma is lower than SCSS. In fact, it has been shown that arc basalt magmas have higher oxygen fugacities than MORB magmas (e.g. Wallace 2005; Kelley and Cottrell 2009). In addition to this, the redox state of the melt inclusions was determined and ranges from FMQ + 0.68 to FMQ + 1.41 (Average = $1.05,1 \sigma=0.17$, corresponding to $\mathrm{S}^{6+} / \mathrm{S}_{\text {total }}=0.14-0.85$, Table $\left.\mathrm{S} 1\right)$. Such oxidizing conditions allow for (i) higher S solubility in the mafic magma (Carroll and Rutherford 1985; Jugo et al. 2010) and (ii) the presence of both $S^{2-}$ and $S^{6+}$ in the melt. Fig. 5 b also shows a dashed line expected for the SCSS corrected for abundance of $\mathrm{S}^{2-}$ species $\left(S^{6+} / S_{\text {total }}=0.85\right)$. Such first order correction puts all of our melt inclusion to be below sulfur saturation, consistent with our observation. Also, S concentrations of all the melt inclusions are under-saturated with respect to anhydrite saturation (SCAS was from 5300 to 6000 ppm, Li and Ripley 2009; Baker and Moretti 2011). The elevated S concentrations in the undersaturated oxidized melt are therefore considered to represent, less-degassed, non-sulfide-fractionated, S concentrations, at least at the condition of the shallow storage depth. 
Similarly, we also consider that the mafic endmember $\mathrm{Cl}$ and $\mathrm{F}$ concentrations are representative of primary concentrations, as the exsolution pressure of $\mathrm{Cl}$ and $\mathrm{F}$ is at shallower depths ( 100 MPa for $\mathrm{Cl}$ and $\sim 10 \mathrm{MPa}$ for F; Spilliaert et al. 2006) than for other volatile species. $\mathrm{Cl}$ concentration in the Aso primitive magma was $716 \mathrm{ppm}$ (took the value of the mafic end member melt inclusion: KSS-2-m1) which is higher than that of MORB (Fig. 6; max $500 \mathrm{ppm} \mathrm{Cl,} \mathrm{Le} \mathrm{Voyer} \mathrm{et} \mathrm{al.} \mathrm{2015),} \mathrm{as} \mathrm{it} \mathrm{is} \mathrm{interpreted} \mathrm{as} \mathrm{the}$ addition of $\mathrm{Cl}$ to the subarc mantle from the subducting slab (e.g. Straub and Layne 2003). On the contrary, F concentration in the primitive magma was $324 \mathrm{ppm}$, which is the same order of magnitude as that of MORB (max $500 \mathrm{ppm}$, Le Voyer et al. 2015). This suggests that $\mathrm{F}$ addition to the subarc mantle was insignificant.

The $\mathrm{Cl} / \mathrm{F}$ ratios of melt inclusions globally reflect the composition of the slabagent added to the mantle source as $\mathrm{F}$ fractionate from $\mathrm{Cl}$ depending on the physical character of the flux leaving the slab (Le Voyer et al. 2010; Van den Bleeken and Koga 2015; Narvaez et al. 2018). Observed Cl/F ratio of melt inclusions from Aso volcano are relatively high (from 1 to 2.5, Fig. 6) compared with that of MORB (Saal et al. 2002; Wanless and Shaw 2012; Wanless et al. 2014, 2015; Le Voyer et al. 2017; Shimizu et al. 2019). Because $\mathrm{Cl} / \mathrm{F}$ values in arc magma are characterized by several parameters such as the composition of slab, nature of the fluid and fractionating minerals in residual slab, and the degree of melting of arc magma, the physical character of slab derived flux is determined with a set of assumptions. In any case, the primitive magmas with MORBlike $\mathrm{F}$ concentration and a high $\mathrm{Cl} / \mathrm{F}$ value (2.2) are found among the melt inclusions of calc-alkaline arc magmas in a typically "cold" subduction setting (Straub and Layne 2003; Rose-Koga et al. 2014). The halogen characteristics of our Aso melt inclusions were in the range of typical arc magma, and the value of the primitive magma was close to the melt inclusions of Iwate volcano, a prototypical example of the arc magma derived from aqueous fluid driven from a cold oceanic crust (Rose-Koga et al. 2014). This indication is consistent with studies based on high bulk $\mathrm{B} / \mathrm{Nb}$ ratios indicating aqueous fluid additions from the subducting Philippine sea plate in the source of the Aso basaltbasaltic andesite rocks (Miyoshi et al. 2008a, b). Other studies based on $\mathrm{Sr}, \mathrm{Nd}$, and $\mathrm{Pb}$ isotope variations of Quaternary lavas in the northern Kyushu area also support the model of slab-derived aqueous fluid addition from the subducted Philippine sea plate beneath Aso volcano (Shibata et al. 2014).

\section{Storage depth of the magma mixture}

Solubility of volatiles in magma strongly depends on pressure and temperature conditions, and the chemical composition of the magma (e.g. Dixon et al. 1995). In this section, we discuss the storage depth of the mixed-magma based on $\mathrm{H}_{2} \mathrm{O}$ concentration. For example, measured volatile concentrations of melt inclusions are considered to be reequilibrated to a condition of a magma storage. Alternatively, it is also possible to 
determine $\mathrm{H}_{2} \mathrm{O}$ concentrations estimated from plagioclase rim and groundmass glass pairs (geo-hygrometer, Lange et al. 2009), likely corresponding to the value of the mixed magma during the plagioclase rim growth. The $\mathrm{H}_{2} \mathrm{O}$ concentrations of such mixed magmas are, 2 wt.\% for NKD14 and KKO, and $\sim 3$ wt.\% for OJSU, OJSL and KSS (Table 4). Here, the hygrometer calibrated for the total fluid pressure is equal to $P\left(\mathrm{H}_{2} \mathrm{O}\right)$, neglecting the role of $\mathrm{CO}_{2}$. Yet, these values are comparable to those measured in the melt inclusions, and indicate a magma chamber pressures of $0.5 \mathrm{kbar}$ for NKD14 and $\mathrm{KKO}$, and $1.0 \mathrm{kbar}$ for OJSU, OJSL, and KSS (i.e. 2.1 and $4 \mathrm{~km}$ deep, respectively, Fig. 7 , note the depth is calculated using a density of $2200 \mathrm{~kg} / \mathrm{m}^{3}$ for the first $1 \mathrm{~km}$ and 2700 $\mathrm{kg} / \mathrm{m}^{3}$ for the crust at greater depths (Komazawa 1995), by solving for the depth, $\mathrm{h}[\mathrm{m}]$, $\mathrm{P}=\mathrm{g}\{2200(1000)+2700(\mathrm{~h}-1000)\})$. Because $\mathrm{CO}_{2}$ concentrations in the felsic group melt inclusions are notably low (0 - $77 \mathrm{ppm}$, Table S1), it makes negligible changes to the calculated equilibrium pressure ( $20 \mathrm{MPa}$, using RhyoliteMELTS/MagmaSat, Ghiorso and Gualda 2015). These pressures correspond to the depths of magma storage after mixing, since (1) the last growth rim of plagioclase must have occurred after mixing, as both normal and reverse zoning plagioclase have the same rim composition. (2) It is less likely that plagioclase rim significantly grew during sub-Plinian and Strombolian eruption. Melt inclusion $\mathrm{H}_{2} \mathrm{O}$ concentrations range from 0.47 to 2.89 wt. \%, indicating the minimum equilibrium pressure in agreement with the plagioclase-rim method. Two magma chambers, C2 and C1, detected by geophysical studies are also located at similar depths, 1 - 4 and 3 - 10 km, respectively (Tsutsui and Sudo 2004; Sudo et al. 2006; Hata et al. 2016; Fig. 7). At the depths, because the solubility of $\mathrm{CO}_{2}$ is so low, the conclusion presented here would remain the same even if the hygrometer calculation does not account for $\mathrm{CO}_{2}$.

The magma of the mafic endmember is expected to have more than $4.68 \mathrm{wt}$. \% $\mathrm{H}_{2} \mathrm{O}$, and it is therefore derived from a greater depth than these $\mathrm{C} 1$ and $\mathrm{C} 2$ storage depths. The corresponding equilibrium pressure is approximately $2.7 \mathrm{kbar}$ (SolEx, Witham et al. 2012; note MagmaSat give 2.3 kbar, Ghiorso and Gualda 2015; with $\mathrm{CO}_{2}$ of $340 \mathrm{ppm}$ reported in a melt inclusion from Nakadake by Saito et al. 2018) that is about $10 \mathrm{~km}$ deep below the edifice. As gas bubbles were seen in melt inclusions, large amounts of $\mathrm{CO}_{2}$ incorporated in such shrinkage bubbles significantly increases the entrapment pressure estimation (e.g. Moore et al. 2015). Therefore, our pressure estimations are minimum and true entrapment pressures of the basaltic magma certainly occurred at a depth greater than $10 \mathrm{~km}$. Recent melt inclusion studies reported more than $40-90 \%$ of the initial $\mathrm{CO}_{2}$ that was dissolved in the melt at the time of entrapment was lost to shrinkage bubbles, with an average loss of 75-80 \% (Hartley et al. 2014; Moore et al. 2015; Wallace et al. 2015). If $90 \%$ of initial $\mathrm{CO}_{2}$ is present in the shrinkage bubble and a maximum $\mathrm{CO}_{2}$ value of $340 \mathrm{ppm}$ is assumed in the melt (from Saito et al. 2018), then the expected initial value of the melt would reach $3400 \mathrm{ppm}$. This value is in the same order of magnitude as the initial $\mathrm{CO}_{2}$ concentration in a typical primary arc magma (Aster et al. 2016), and in this case the saturation pressure would exceed $5 \mathrm{kbar}(\sim 19 \mathrm{~km}$ depth equivalent). However, 
at the time of this study, bubble sizes were not documented with impossibility to go back to measuring them a posteriori since most are now polished away. In this case, we chose not to use the $\mathrm{CO}_{2}$ data of the melt inclusions. Hata et al. (2016) also reported a magma pathway from depths deeper than $11 \mathrm{~km}$, feeding the deeper $\mathrm{C} 1$ reservoir. Also, the presence of a seismic low-velocity layer at $11-25 \mathrm{~km}$ depth was reported and attributed to a magma ponding location beneath the Aso caldera (Abe et al. 2010). These observations are in good agreement with our petrological implication for the presence of volatile-rich basaltic magma beneath $\mathrm{C} 1$ magma reservoir at a depth greater than $10 \mathrm{~km}$.

\section{Persistent degassing from a deeper magma reservoir (>10km)}

\section{$\underline{\text { Excess degassing of } \mathrm{SO}_{2}} \underset{\text { and } \mathrm{CO}_{2}}{2 \text { from Nakadake } 2014 \text { eruption }}$}

Decomposition of magma mixing endmembers and the subsequent identification of the primitive magma composition provide critical information for investigating volcanic emission of gas and its mass balance. For the 2014 eruption of Aso volcano, the mass of erupted magma is insufficient to account for the mass of the observed $\mathrm{SO}_{2}$ gas emissions (Saito et al. 2018), which is commonly reported in many active volcanoes and is called "excess degassing". For Aso, approximately 90 - 140 times more magma than the erupted tephra mass is needed to account for the observed total $\mathrm{SO}_{2}$ emission of $1.4-2.2 \times 10^{5}$ tons for the period of 70 days from Nov. 2014 to Feb. 2015 (Table 5 and; also Saito et al. 2018). As demonstrated in the sections above, NKD magma is a mixed magma, so the gas phase must have come from the degassing of mafic and felsic endmember magmas. For this reason, we have used the highest volatile element concentrations determined for Nakadake samples (i.e. mixed magmas) for the sulfur budget calculation (Supplementary material S4). This calculation simply demonstrates that the mixed magmas are inadequate sources of the observed volcanic gas flux. The most commonly proposed explanation for this excess is the existence of a gas/fluid phase in the magma, possibly containing C-O-H-S and co-existing with the magma prior to the eruption (e.g. Anderson 1973; Wallace 2001; Scaillet and Pichavant 2003; Shinohara 2008). The magmatic volatile component must originate from the volatile-rich magma corresponding to the basaltic/mafic endmember. This magma must degas at a deeper depth than that indicated by the equilibrium solubility depth of NKD samples $(\sim 2 \mathrm{~km}$ at the depth of C2). Therefore, the degree of S excess should be re-assessed with a deeper, volatile-rich, basaltic magma. It should be noted that the observation of S-excess is common (e.g. Wallace and Edmonds 2011) and we simply point out here that the eruption of Nakadake edifice of Aso also shows such excess.

There are geophysical observations indicating that degassing is fed by volcanic activities corresponding to depths deeper than $\sim 2 \mathrm{~km}$. The $\mathrm{SO}_{2}$ gas emission of Aso volcano is continuously monitored during the eruptive and the quiescent periods. The 
amount of $\mathrm{SO}_{2}$ emission during the quiescent period (alternatively, "persistent degassing"; Shinohara 2008) is more than 100 - 200 tons/day from 1975 to 2006 (Mori et al. 2013). Ground deformation measurements since 1937 revealed deformation (deflation) of the deeper C1 magma reservoir synchronous to gas emission from Nakadake cone during the quiescent period (Sudo et al. 2006). This $\mathrm{C} 1$ deformation, located approximately $3 \mathrm{~km}$ West of Nakadake, causes no significant deformation on the surface around the crater. This degassing is therefore interpreted as open-system degassing of the $\mathrm{C} 1$ magma reservoir through stable conduit passages to Nakadake crater (Yamamoto et al. 1999; Sudo et al. 2006). Furthermore, deflation of the C1 reservoir was seen to slow down from 2008 to early 2014, before acceleration of inflation of the C1 reservoir from July 2014, shortly before the eruption in November (Ohkura et al. 2015; JMA 2016). These changes were accompanied by a sudden increase in persistent $\mathrm{SO}_{2}$ gas emission in September 2013, considered as a precursor to the 2014 - 2015 eruptive period (JMA 2016). These temporal and spatial relationships of geophysical observation and degassing activities strongly indicate the role of the deeper $\mathrm{C} 1$ reservoir during degassing. However, to sustain replenishment of the $\mathrm{Cl}$ reservoir, the magma must be supplied from an even deeper depth (greater than $10 \mathrm{~km}$; Sudo et al. 2006; Hata et al. 2016). For example, the slowing down of deflation in 2008 and subsequent inflation in 2014 can be interpreted as events relating to magma replenishment of the $\mathrm{Cl}$ reservoir (Ohkura et al. 2015, 2017).

We also found excess degassing of $\mathrm{CO}_{2}$ for this eruption period. Using the maximum pre-eruptive $\mathrm{CO}_{2}$ concentration of $340 \mathrm{ppm}$ measured in a melt inclusion of Nakadake eruption products (Saito et al. 2018), and assuming there is no pre-eruptive vapor phase approximately $1700-2700$ times more dissolved $\mathrm{CO}_{2}$ is required to account for the observed $0.77-1.2 \times 10^{6}$ tons of $\mathrm{CO}_{2}$ emission (Table 5). In the case of Aso, the gas phase must be derived from a depth greater than that of the $\mathrm{C} 1$ reservoir.

\section{$\underline{\text { Modelling degassing of the deep magma reservoir }}$}

In the sections above, the equilibrium depths of volatile concentration in magma were used to indicate magma storage depth, where stagnated-magma and gas remain at equilibrium. Equilibrium gas composition at that depth should be the source of the gas composition observed at the surface, only if the gas segregated and travelled to the surface without precipitating solids or re-dissolving gas in between. In detail, the speciation of mixed gas is a function of pressure, temperature, and oxygen fugacity, but the gas system composition can be considered closed. With this hypothesis, it is possible to determine the depth at which the observed gas composition is in equilibrium with a magma (e.g. Burton et al. 2007; Allard 2010).

Fig. 8 is a result of such a calculation using SolEx (Witham et al. 2012), showing the variations in $\mathrm{H}_{2} \mathrm{O} / \mathrm{S}, \mathrm{CO}_{2} / \mathrm{S}$, and $\mathrm{Cl} / \mathrm{S}$ molar ratios of gas in equilibrium with a magma as a function of pressure. The observed $\mathrm{H}_{2} \mathrm{O} / \mathrm{S}$ gas composition of the 2014 eruption (shown as horizontal dotted red lines) intersects with the equilibrium gas 
composition (plain lines Fig. 8) between 2.6 to 3.3 kbars. These pressures correspond to $10-13 \mathrm{~km}$ depth below the edifice. The family of curved lines represent the results of the model with varying initial $\mathrm{CO}_{2}$ concentration (400, 750, and $1000 \mathrm{ppm}$ ), as the initial $\mathrm{CO}_{2}$ concentration was unknown (but for sure higher than $340 \mathrm{ppm}$ ). For the range of degassing trajectory, the observed $\mathrm{Cl} / \mathrm{S}$ values (horizontal dotted blue line) intersect with the model calculations between 2.6 and 3.8 kbars. $\mathrm{H}_{2} \mathrm{O} / \mathrm{S}$ and $\mathrm{CO}_{2} / \mathrm{S}$ are less sensitive to the variation of the initial $\mathrm{CO}_{2}$ concentration. It should be noted that the closed system degassing path here is used to find a unique pressure condition at which the observed high temperature gas composition is at the equilibrium with a mafic magma. The systematics shows that only $\mathrm{CO}_{2}$ concentrations between 400 and $750 \mathrm{ppm}$ can produce the observed gas composition at pressures between 2.6 to $3.3 \mathrm{kbars}$, satisfying the observed ranges of $\mathrm{H}_{2} \mathrm{O} / \mathrm{S}, \mathrm{CO}_{2} / \mathrm{S}$, and $\mathrm{Cl} / \mathrm{S}$ all at once.

Therefore, the observed gas composition must have been derived from the depth of about 10 to $13 \mathrm{~km}(\sim 2.6$ to $3.3 \mathrm{~kb})$ at which it was in equilibrium with a magma with the initial magmatic $\mathrm{CO}_{2}$ concentration between 400 to $750 \mathrm{ppm}$ (Fig. 8). The determination of initial $\mathrm{CO}_{2}$ is strongly tied to the $\mathrm{Cl}$ and $\mathrm{S}$ partitioning into $\mathrm{H}_{2} \mathrm{O}-\mathrm{CO}_{2}$ fluid, and we think that these values may need to be revised once we have a better understanding of $\mathrm{Cl}$ and $\mathrm{S}$ element partitioning. Lastly, this conclusion is highly model dependent. Here, we chose to use SolEx for its agreement with the variation of $S$ in the melt inclusions. However, one must be cautious with the use of SolEx, because it is shown to fail to reproduce degassing trajectories of other volcanoes (e.g., Werner et al. 2020).

Fig. 9 shows the observed gas composition emitted from Aso volcano in the quiescent period and eruptive period. The gas data shown in Fig. 8 correspond to the eruptive period data (orange). While Fig. 8 demonstrated the occurrence of deep gas segregation, it does not explain the range of gas composition observed before and, even, during the eruption of the Nakadake cone. We modelled the variation in gas composition using (1) a degassing trend (solid line), the same model as that used in Fig. 8, and it fits the data with some scatter and (2) a mixing line (dotted line) between a deep reservoir, for example at the storage depth around $10 \mathrm{~km}$, and a shallow reservoir (C2 or top of $\mathrm{C} 1)$. Both explain the data (Fig. 9). Thus, on the one hand, it is possible to consider the variation in gas composition as the variation in gas segregation depth. On the other hand, the observed gas composition variation potentially represents the different degrees of mixing between discharged gas from NKD14 magma at shallow depth and segregated gas from a deep reservoir (i.e. gas segregation depth at 10 km; Fig. 8 and 10). Case 1 is less likely to apply here. Because of the closed-system degassing model (solid line), the ascending primitive magma would have been expected to be in equilibrium with gas all the time until it reaches near the surface. Therefore, the gas composition representing the low pressure must have been in equilibrium with the mafic magmas at the shallowest depth. However, no volcanic product of primitive composition was found during the eruption of Nakadake cone. Instead, observed volcanic products were all the result of mixing. As case 1 is unlikely, we conclude that the mixing of gases (case 2) is the process 
explaining the observed compositional variation. The gas mixing could have been possible, for example, by bubble accumulation at the roof of a magma chamber (Jaupart and Vergniolle 1988, 1989).

\section{Implications for understanding current Aso volcanic activity}

This study identified the role of a volatile-rich, primitive magma during volcanic degassing (Fig. 10). During ascent, the volatile-rich primitive magma started to degas at a depth between 11 and $13 \mathrm{~km}$ (2.8 to $3.5 \mathrm{kbars}$, SolEx) based on the initial volatile concentration. The gas and magma reached $10 \mathrm{~km}$ depth maintaining equilibrium. At that depth, the gas segregated from the magma and moved to the surface without any significant modification. The separation of gas from magma was potentially caused by stopping of magma ascent, which contributed to overpressuring of $\mathrm{C} 1$ observed by the deformation of the edifice. The magma then moved upwards and mixed with silicic magma in the $\mathrm{C} 1$ magma reservoir. While the exact depth of mixing was undetermined, the mixed magma was eventually stored at depths of $\mathrm{C} 1$ and $\mathrm{C} 2$ (for example $2 \mathrm{~km}$ (C2) for NKD14 and KKO samples, and $4 \mathrm{~km}$ (C1) for OJSU, OJSL, and KSS samples).

The segregated deep gas mixed with the shallow gases upon its ascent at shallower levels. We were unable to constrain the exact mechanism of the deep gas transport to the shallow depth without significant interaction. One possibility is the presence of porosity providing connected gas passages. However, this mechanism implies the rigid structure at a temperature lower than magmatic conditions, and this contradicts with the observation of the high temperature gas indicating magmatic degassing. Alternatively, a convection within $\mathrm{C} 1$ and $\mathrm{C} 2$ potentially serves a "gas pump". In this scenario, a shallow mixed magma (devoid of volatile elements) descends by convection to the bottom of $\mathrm{C} 1$ where gas segregation is occurring. Upon the return of such magma to shallow depth, it drags the gas component with it. Such parcel of magma may further pull gas bubbles from the shallow depth and result in a bulk system of mixed gas. If the magma degases completely, the resulting gas composition will be identical to the result of the gas mixing. This scenario would fail if some batch of magma do not degas and remain in some depth; it requires complete degassing. Shinohara (2018) proposed a model which suggested that the observed chemical variation in gases during eruption was caused by mixing of gases derived from magmas at different depths. This model is consistent with our gas mixing model. Our model furthered understanding of Aso activity, by (1) quantifying the volatile concentration of primitive mafic magma, and (2) by determining its degassing, segregation, and storage depths.

\section{Summary and conclusion}

Petrological analyses of melt inclusions in basaltic tephras from the late Holocene eruption of Aso volcano provided us with insights into the process of the persistent degassing in a magma plumbing system. 
(1) The compositions of melt inclusions in phenocrysts from recent eruption products (Nov. 2014) of Nakadake cone were homogeneous, evolved and degassed ( $<434 \mathrm{ppm}$ ), while compositions of melt inclusions in phenocrysts from Kishimadake and other related cones (ca. 3.0 - $3.7 \mathrm{ka}$ ) showed variable compositions with two extreme endmembers. One was mafic $\left(\mathrm{SiO}_{2}<55 \mathrm{wt} . \%\right)$ and volatile-rich, and the other was felsic $\left(\mathrm{SiO}_{2}>\right.$ 55wt.\%) and relatively degassed. Mafic melt inclusions were hosted in high-Fo olivine and some plagioclase, whereas felsic melt inclusions were hosted in plagioclase, clinopyroxene, orthopyroxene and low-Fo olivine.

(2) Reverse mineral zoning, and highly variable mineral and glass compositions indicated a mixing process during which volatile-rich basaltic magma was injected in a degassed shallower magma.

(3) The estimated depths of pre-eruptive magma were approximately $2 \mathrm{~km}$ (C2 magma reservoir) for Strombolian eruption of Nakadake cone (Nov. 27, 2014) and Kamikomezuka cone (3.0 ka) and approximately $4 \mathrm{~km}$ (top of C1 magma reservoir) for sub-Plinian eruption of Ojodake and Kishimadake cones in $3.5-3.7 \mathrm{ka}$. These depths corresponded to the partially melted zones characterized by geophysical investigations (e.g. Hata et al. 2016). Furthermore, volatile-rich primitive magma originated from a deeper level (greater than $10 \mathrm{~km}$ ) than these two magma reservoirs.

(4) Even with the highest S concentration of NKD14, it was impossible to account for the excess $\mathrm{S}$ gas emission. This suggests an addition of gas derived from the deep magma reservoir (greater than $10 \mathrm{~km}$ depth).

(5) Initial volatile concentrations of the volatile-rich primitive magma were determined from the systematics of melt inclusion, plagioclase compositions, and degassing model: >4.68 wt.\% $\mathrm{H}_{2} \mathrm{O}, 3750 \mathrm{ppm} \mathrm{S}, 716$ ppm Cl and 324 ppm F.

(6) Emitted gas compositions constrained the initial $\mathrm{CO}_{2}$ concentration ranges in the magma, between 400 and $750 \mathrm{ppm}$.

(7) The variation observed in volcanic gas composition was best explained by the mixing of the gas segregated at $10 \mathrm{~km}$ depth with those from the shallow reservoirs.

\section{Acknowledgements}

The authors acknowledge the in-depth reviews of K. Iacovino, N. Métrich, and D. Rasmussen. Their comments and challenging questions greatly improved this manuscript. This work received funding from JSPS KAKENHI, Grant Number 17K05682 and the Integrated Program for Next Generation Volcano Research and Human Resource Development to TH. MK acknowledges the financial support from the French Embassy in Tokyo, Japan and from the French government through a "Bourse du Gouvernement Français". Campus France helped MK get settled during his stay in France. MK also extends his thanks to Tadao Nishiyama and Hiroshi Isobe for their assistance 
806

807

808

809

810

811

812

813

814

815

816

817

818

819

820

821

822

823

824

825

826

827

828

829

830

831

832

833

834

835

836

837

838

839

840

841

842

with the electron microprobe at Kumamoto University, and to Akira Yoshiasa for his support in this international collaboration. ER-K and KTK acknowledge the financial support from Region Auvergne-Rhone-Alpes (program SCUSI) and from the Laboratory of Excellence ClerVolc. This is Laboratory of Excellence ClerVolc contribution no xxx.

\section{References}

Abe Y, Ohkura T, Shibutani T, Hirahara K, Kato M (2010) Crustal structure beneath Aso Caldera, Southwest Japan, as derived from receiver function analysis. J Volcanol Geotherm Res 195:1-12. https://doi.org/10.1016/j.jvolgeores.2010.05.011

Allard P (2010) A CO 2 -rich gas trigger of explosive paroxysms at Stromboli basaltic volcano, Italy. J Volcanol Geotherm Res 189:363-374. https://doi.org/10.1016/j.jvolgeores.2009.11.018

Anderson AT (1973) The before-eruption water content of some high-alumina magmas. Bull Volcanol 37:530-552. https://doi.org/10.1007/BF02596890

Aster EM, Wallace PJ, Moore LR, Watkins J, Gazel E, Bodnar RJ (2016) Reconstructing $\mathrm{CO}_{2}$ concentrations in basaltic melt inclusions using Raman analysis of vapor bubbles. J Volcanol Geotherm Res 323:148-162. https://doi.org/10.1016/j.jvolgeores.2016.04.028

Baker DR, Moretti R (2011) Modeling the solubility of sulfur in magmas: a 50-year old geochemical challenge. Rev Mineral Geochemistry 73:167-213. https://doi.org/10.2138/rmg.2011.73.7

Bucholz CE, Gaetani GA, Behn MD, Shimizu N (2013) Post-entrapment modification of volatiles and oxygen fugacity in olivine-hosted melt inclusions. Earth Planet Sci Lett 374:145-155. https://doi.org/10.1016/j.epsl.2013.05.033

Burdo RA, Morrison HG (1971) Table of atomic and molecular lines for spark source mass spectrometry of complex sample-graphite mixes. Materials Science Center, Cornell University, Ithaca, New York

Burton MR, Allard P, Muré F, La Spina A (2007) Magmatic gas composition reveals the source depth of slug-driven Strombolian explosive activity. Science 317:227-230

Carroll MR, Rutherford MJ (1985) Sulfide and Sulfate Saturation in Hydrous Silicate Melts. J Geophys Res Solid Earth 90:C601-C612

Carroll MR, Rutherford MJ (1988) Sulfur speciation in hydrous experimental glasses of varying oxidation state: results from measured wavelength shifts of sulfur X-rays. Am J Sci 73:845-849

Chen Y, Provost A, Schiano P, Cluzel N (2011) The rate of water loss from olivine-hosted melt inclusions. Contrib to Mineral Petrol 162:625-636. https://doi.org/10.1007/s00410-011-0616-5

Costa F, Dohmen R, Chakraborty S (2008) Time scales of magmatic processes from modeling the zoning patterns of crystals. Rev Mineral Geochemistry 69:545-594. https://doi.org/10.2138/rmg.2008.69.14

Danyushevsky L V., Della-Pasqua FN, Sokolov S (2000) Re-equilibration of melt inclusions trapped by magnesian olivine phenocrysts from subduction-related magmas: petrological implications. Contrib to Mineral Petrol 138:68-83. https://doi.org/10.1007/PL00007664

Danyushevsky L V., Sokolov S, Falloon TJ (2002) Melt inclusions in olivine phenocrysts: using diffusive re-equilibration to determine the cooling history of a crystal, with implications for the origin of olivine-phyric volcanic rocks. J Petrol 43:1651-1671. 


\section{https://doi.org/10.1093/petrology/43.9.1651}

de Moor JM, Kern C, Avard G, Muller C, Aiuppa A, Saballos A, Ibarra M, LaFemina P, Protti M, Fischer TP (2017) A new sulfur and carbon degassing inventory for the Southern Central American Volcanic Arc: the importance of accurate time-series data sets and possible tectonic processes responsible for temporal variations in arcscale volatile emissions. Geochemistry, Geophys Geosystems 18:4437-4468. https://doi.org/10.1002/2017GC007141

Dixon JE, Stolper EM, Holloway JR (1995) An experimental study of water and carbon dioxide solubilities in mid-ocean ridge basaltic liquids. Part I: calibration and solubility models. J Petrol 36:1607-1631

Edmonds M, Wallace PJ (2017) Volatiles and exsolved vapor in volcanic systems. Elements 13:29-34. https://doi.org/10.2113/gselements.13.1.29

Ferriss E, Plank T, Walker D (2016) Site-specific hydrogen diffusion rates during clinopyroxene dehydration. Contrib to Mineral Petrol 171:1-24. https://doi.org/10.1007/s00410-016-1262-8

Fortin M-A, Riddle J, Desjardins-Langlais Y, Baker DR (2015) The effect of water on the sulfur concentration at sulfide saturation (SCSS) in natural melts. Geochim Cosmochim Acta 160:100-116. https://doi.org/10.1016/j.gca.2015.03.022

Gaetani GA, O’Leary JA, Shimizu N, Bucholz CE, Newville M (2012) Rapid reequilibration of $\mathrm{H}_{2} \mathrm{O}$ and oxygen fugacity in olivine-hosted melt inclusions. Geology 40:915-918. https://doi.org/10.1130/G32992.1

Gardner JE, Rutherford M, Carey S, Sigurdsson H (1995) Experimental constraints on pre-eruptive water contents and changing magma storage prior to explosive eruptions of Mount St Helens volcano. Bull Volcanol 57:1-17. https://doi.org/10.1007/BF00298703

Ghiorso MS, Gualda GAR (2015) $\mathrm{An}_{2} \mathrm{O}-\mathrm{CO}_{2}$ mixed fluid saturation model compatible with rhyolite-MELTS. Contrib to Mineral Petrol 169:1-30. https://doi.org/10.1007/s00410-015-1141-8

Hartley ME, Bali E, Maclennan J, Neave DA, Halldórsson SA (2018) Melt inclusion constraints on petrogenesis of the 2014-2015 Holuhraun eruption, Iceland. Contrib to Mineral Petrol 173:10. https://doi.org/10.1007/s00410-017-1435-0

Hartley ME, Maclennan J, Edmonds M, Thordarson T (2014) Reconstructing the deep $\mathrm{CO}_{2}$ degassing behaviour of large basaltic fissure eruptions. Earth Planet Sci Lett 393:120-131. https://doi.org/10.1016/j.epsl.2014.02.031

Hata M, Takakura S, Matsushima N, Hashimoto T, Utsugi M (2016) Crustal magma pathway beneath Aso caldera inferred from three-dimensional electrical resistivity structure. Geophys Res Lett 43:10720-10727. https://doi.org/10.1002/2016GL070315

Hauri E, Wang J, Dixon JE, King PL, Mandeville C, Newman S (2002) SIMS analysis of volatiles in silicate glasses 1 . Calibration, matrix effects and comparisons with FTIR. Chem Geol 183:99-114. https://doi.org/10.1016/S0009-2541(01)00375-8

Helo C, Longpré M-A, Shimizu N, Clague DA, Stix J (2011) Explosive eruptions at midocean ridges driven by $\mathrm{CO}_{2}$-rich magmas. Nat Geosci 4:260-263. https://doi.org/10.1038/ngeo1104

Hirata Y, Ueta K, Miyawaki R, Iemura K, Yokoyoma T, Miyawaki A (2020) Tephra stratigraphy and an about 4000-year-old slope failure on Janoo volcano, NW Aso caldera. Trans Japanese Geomorpholotical Union 41:27-47 (in Japanese with 
904

905

906

907

908

909

910

911

912

913

914

915

916

917

918

919

920

921

922

923

924

925

926

927

928

929

930

931

932

933

934

935

936

\section{English abstract)}

Ikebe S, Watanabe K, Miyabuchi Y (2008) The sequence and style of the 1988-1955 eruption of Nakadake Aso volcano, Kyushu, Japan. Bull Volcanol Soc Japan 53:1533 (in Japanese with English abstract)

Japan Meteorological Agency (2020) Results of volcanic gas observation at Aso volcano. http://www.data.jma.go.jp/svd/vois/data/fukuoka/rovdm/Asosan_rovdm/Asosan_ro vdm.html. Accessed 20 Apr 2020

Japan Meteorological Agency (2016) Volcanic activity of Asosan volcano - October 2014-February 2015-. Rep Coord Com Predict Volcan Erupt 120:166-186 (in Japanese). http://www.data.jma.go.jp/svd/vois/data/tokyo/STOCK/kaisetsu/CCPVE/Report/1 20/kaiho_120_23.pdf

Jaupart C, Vergniolle S (1988) Laboratory models of Hawaiian and Strombolian eruptions. Nature 331:58-60

Jaupart C, Vergniolle S (1989) The generation and collapse of a foam layer at the roof of a basaltic magma chamber. J Fluid Mech 203:347-380. https://doi.org/10.1017/S0022112089001497

Jugo PJ, Wilke M, Botcharnikov RE (2010) Sulfur K-edge XANES analysis of natural and synthetic basaltic glasses: implications for $\mathrm{S}$ speciation and $\mathrm{S}$ content as function of oxygen fugacity. Geochim Cosmochim Acta 74:5926-5938. https://doi.org/10.1016/j.gca.2010.07.022

Kamata H (1998) Quaternary volcanic front at the junction of the South-west Japan Arc and the Ryukyu Arc. J Asian Earth Sci 16:67-75. https://doi.org/10.1016/S07439547(97)00044-5

Kelley KA, Cottrell E (2009) Water and the oxidation state of subduction zone magmas. Science 325:605-607. https://doi.org/10.1126/science.1174156

Kilinc A, Carmichael ISE, Rivers ML, Sack RO (1983) The ferric-ferrous ratio of natural silicate liquids equilibrated in air. Contrib to Mineral Petrol 83:136-140. https://doi.org/10.1007/BF00373086

Komazawa M (1995) Gravimetric analysis of Aso volcano and its interpretation. J Geod Soc Japan 41:17-45. https://doi.org/10.11366/sokuchi1954.41.17
Kuno H (1960) High-alumina basalt. J Petrol 1:121-145. https://doi.org/10.1093/petrology/1.1.121

Lange RA, Frey HM, Hector J (2009) A thermodynamic model for the plagioclase-liquid hygrometer/thermometer. Am Mineral 94:494-506. https://doi.org/10.2138/am.2009.3011

Le Voyer M, Cottrell E, Kelley KA, Brounce M, Hauri EH (2015) The effect of primary versus secondary processes on the volatile content of MORB glasses: an example from the equatorial Mid-Atlantic Ridge $\left(5^{\circ} \mathrm{N}-3^{\circ} \mathrm{S}\right)$. J Geophys Res Solid Earth 120:125-144. https://doi.org/10.1002/2014JB011160

Le Voyer M, Kelley KA, Cottrell E, Hauri EH (2017) Heterogeneity in mantle carbon content from $\mathrm{CO}_{2}$-undersaturated basalts. Nat Commun 8:1-8. https://doi.org/10.1038/ncomms 14062

Le Voyer M, Rose-Koga EF, Shimizu N, Grove TL, Schiano P (2010) Two contrasting $\mathrm{H}_{2} \mathrm{O}$-rich components in primary melt inclusions from Mount Shasta. J Petrol 51:1571-1595. https://doi.org/10.1093/petrology/egq030

Li C, Ripley EM (2009) Sulfur contents at sulfide-liquid or anhydrite saturation in silicate 
952

953

954

955

956

957

958

959

960

961

962

963

964

965

966

967

968

969

970

971

972

973

974

975

976

977

978

979

980

981

982

983

melts: empirical equations and example applications. Econ Geol 104:405-412. https://doi.org/10.2113/gsecongeo.104.3.405

Lloyd AS, Plank T, Ruprecht P, Hauri EH, Rose W (2013) Volatile loss from melt inclusions in pyroclasts of differing sizes. Contrib to Mineral Petrol 165:129-153. https://doi.org/10.1007/s00410-012-0800-2

Médard E, Grove TL (2008) The effect of $\mathrm{H}_{2} \mathrm{O}$ on the olivine liquidus of basaltic melts: Experiments and thermodynamic models. Contrib to Mineral Petrol 155:417-432. https://doi.org/10.1007/s00410-007-0250-4

Melekhova E, Blundy J, Martin R, Arculus R, Pichavant M (2017) Petrological and experimental evidence for differentiation of water-rich magmas beneath St. Kitts, Lesser Antilles. Contrib to Mineral Petrol 172:98. https://doi.org/10.1007/s00410017-1416-3

Métrich N, Wallace PJ (2008) Volatile abundances in basaltic magmas and their degassing paths tracked by melt inclusions. Rev Mineral Geochemistry 69:363-402. https://doi.org/10.2138/rmg.2008.69.10

Miyabuchi Y (2009) A 90,000-year tephrostratigraphic framework of Aso volcano, Japan. Sediment Geol 220:169-189. https://doi.org/10.1016/j.sedgeo.2009.04.018

Miyabuchi Y (2010) Eruption age of Komezuka at Aso volcano, Japan. Bull Volcanol Soc Japan 55:219-225 (in Japanese with English abstract)

Miyabuchi Y (2017) Eruption history of Janoo volcano in the Northwestern part of Aso caldera, Japan. Bull Volcanol Soc Japan 62:1-12 (in Japanese with English abstract)

Miyabuchi Y, Watanabe K (1997) Eruption ages of Holocene tephras from Aso volcano, southwestern Japan, inferred from ${ }^{14} \mathrm{C}$ ages of buried andisols. Bull Volcanol Soc Japan 42:403-408 (in Japanese with English abstract)

Miyoshi M, Fukuoka T, Sano T, Hasenaka T (2008a) Subduction influence of Philippine Sea plate on the mantle beneath northern Kyushu, SW Japan: an examination of boron contents in basaltic rocks. J Volcanol Geotherm Res 171:73-87. https://doi.org/10.1016/j.jvolgeores.2007.10.016

Miyoshi M, Hasenaka T, Sano T (2005) Genetic relationship of the compositionally diverse magmas from Aso post-caldera volcanism. Bull Volcanol Soc Japan 50:269283 (in Japanese with English abstract)

Miyoshi M, Shimono M, Hasenaka T, Sano T, Fukuoka T (2008b) Determination of boron and other elements in volcanic rocks by prompt gamma-ray analysis: an application to magma genesis in Kyushu island, SW-Japan. J Radioanal Nucl Chem 278:343-347. https://doi.org/10.1007/s10967-008-9607-z

Moore G, Vennemann T, Carmichael ISE (1998) An empirical model for the solubility of $\mathrm{H}_{2} \mathrm{O}$ in magmas to 3 kilobars. Am Mineral 83:36-42

Moore LR, Gazel E, Tuohy R, Lloyd AS, Esposito R, Steele-MacInnis M, Hauri EH, Wallace PJ, Plank T, Bodnar RJ (2015) Bubbles matter: an assessment of the contribution of vapor bubbles to melt inclusion volatile budgets. Am Mineral 100:806-823. https://doi.org/10.2138/am-2015-5036

Mori T, Shinohara H, Kazahaya K, Hirabayashi J, Matsushima T, Mori T, Ohwada M, Odai M, Iino H, Miyashita M (2013) Time-averaged $\mathrm{SO}_{2}$ fluxes of subduction-zone volcanoes: example of a 32-year exhaustive survey for Japanese volcanoes. J Geophys Res Atmos 118:8662-8674. https://doi.org/10.1002/jgrd.50591

Mori Y, Mashima H (2005) X-ray fluorescence analysis of major and trace elements in silicate rocks using 1:5 dilution glass beads. Bull Kitakyushu Museum Nat Hist Hum 
993

994

995

996

997

998

999

1000

1001

1002

1003

1004

1005

1006

1007

1008

1009

1010

1011

1012

1013

1014

1015

1016

1017

1018

1019

1020

1021

1022

1023

1024

1025

1026

1027

1028

1029

1030

Hist Ser A 3:1-12

Nakada S, Kamata H (1991) Temporal change in chemistry of magma source under Central Kyushu, Southwest Japan: progressive contamination of mantle wedge. Bull Volcanol 53:182-194

Narvaez DF, Rose-Koga EF, Samaniego P, Koga KT, Hidalgo S (2018) Constraining magma sources using primitive olivine-hosted melt inclusions from Puñalica and Sangay volcanoes (Ecuador). Contrib to Mineral Petrol 173:80. https://doi.org/10.1007/s00410-018-1508-8

Neave DA, Hartley ME, Maclennan J, Edmonds M, Thordarson T (2017) Volatile and light lithophile elements in high-anorthite plagioclase-hosted melt inclusions from Iceland. Geochim Cosmochim Acta 205:100-118. https://doi.org/10.1016/j.gca.2017.02.009

Ohkura T, Utsugi M, Yokoo A, Yoshikawa S, Inoue H, Kagiyama T (2015) Eruptive activities of Aso volcano, 2014-2015. Japan Geosci Union Meet 2015 SVC45-04

Ohkura T, Utsugi M, Yokoo A, Yoshikawa S, Inoue H, Kagiyama T, Yamamoto M, Oikawa J (2017) Eruptive activities of Aso Volcano, 2014-2016. Program Abstr Volcanol Soc Japan 2017 fall Meet A3-20 (in Japanese)

Ono K, Watanabe K (1985) Geological map of Aso volcano, 1:50,000. Geological Survey of Japan (in Japanese with English abstract)

Pioli L, Azzopardi BJ, Cashman K V. (2009) Controls on the explosivity of scoria cone eruptions: magma segregation at conduit junctions. J Volcanol Geotherm Res 186:407-415. https://doi.org/10.1016/j.jvolgeores.2009.07.014

Portnyagin M, Almeev R, Matveev S, Holtz F (2008) Experimental evidence for rapid water exchange between melt inclusions in olivine and host magma. Earth Planet Sci Lett 272:541-552. https://doi.org/10.1016/j.eps1.2008.05.020

Putirka KD (2008) Thermometers and barometers for volcanic systems. Rev Mineral Geochemistry 69:61-120. https://doi.org/10.2138/rmg.2008.69.3

Roberge J, Delgado-Granados H, Wallace PJ (2009) Mafic magma recharge supplies high $\mathrm{CO}_{2}$ and $\mathrm{SO}_{2}$ gas fluxes from Popocatépetl volcano, Mexico. Geology 37:107-110. https://doi.org/10.1130/G25242A.1

Roggensack K (2001) Unraveling the 1974 eruption of Fuego volcano (Guatemala) with small crystals and their young melt inclusions. Geology 29:911-914. https://doi.org/10.1130/0091-7613(2001)029<0911:UTEOFV>2.0.CO;2

Roggensack K, Hervig RL, McKnight SB, Williams SN (1997) Explosive basaltic volcanism from Cerro Negro volcano: influence of volatiles on eruptive style. Science 277:1639-1642. https://doi.org/10.1126/science.277.5332.1639

Rose-Koga EF, Koga KT, Devidal JL, Shimizu N, Voyer M Le, Dalou C, Döbeli M (2020) In-situ measurements of magmatic volatile elements, F, S, and Cl, by electron microprobe, secondary ion mass spectrometry, and heavy ion elastic recoil detection analysis. Am Mineral 105:616-626. https://doi.org/10.2138/am-2020-7221

Rose-Koga EF, Koga KT, Hamada M, Hélouis T, Whitehouse MJ, Shimizu N (2014) Volatile ( $\mathrm{F}$ and $\mathrm{Cl}$ ) concentrations in Iwate olivine-hosted melt inclusions indicating low-temperature subduction. Earth, Planets Sp 66:81. https://doi.org/10.1186/18805981-66-81

Rose-Koga EF, Koga KT, Schiano P, Le Voyer M, Shimizu N, Whitehouse MJ, Clocchiatti R (2012) Mantle source heterogeneity for South Tyrrhenian magmas revealed by $\mathrm{Pb}$ isotopes and halogen contents of olivine-hosted melt inclusions. 

Chem Geol 334:266-279. https://doi.org/10.1016/j.chemgeo.2012.10.033

Rowe MC, Kent AJR, Nielsen RL (2007) Determination of sulfur speciation and oxidation state of olivine hosted melt inclusions. Chem Geol 236:303-322. https://doi.org/10.1016/j.chemgeo.2006.10.007

Saal AE, Hauri EH, Langmuir CH, Perfit MR (2002) Vapour undersaturation in primitive mid-ocean-ridge basalt and the volatile content of earth's upper mantle. Nature 419:451-455. https://doi.org/10.1038/nature01073

Saito G, Ishizuka O, Ishizuka Y, Hoshizumi H, Miyagi I (2018) Petrological characteristics and volatile content of magma of the 1979, 1989, and 2014 eruptions of Nakadake, Aso volcano, Japan. Earth, Planets Sp 70:197. https://doi.org/10.1186/s40623-018-0970-x

Sakuyama M (1979) Evidence of magma mixing: petrological study of Shirouma-Oike calc-alkaline andesite volcano, Japan. J Volcanol Geotherm Res 5:179-208. https://doi.org/10.1016/0377-0273(79)90040-4

Sakuyama T, Nakai S, Yoshikawa M, Shibata T, Ozawa K (2014) Progressive interaction between dry and wet mantle during high-temperature diapiric upwelling: constraints from cenozoic Kita-Matsuura intraplate basalt province, Northwestern Kyushu, Japan. J Petrol 55:1083-1128. https://doi.org/10.1093/petrology/egu020

Scaillet B, Pichavant M (2003) Experimental constraints on volatile abundances in arc magmas and their implications for degassing processes. Geol Soc London, Spec Publ Spec Publ 213:23-52. https://doi.org/10.1144/GSL.SP.2003.213.01.03

Shibata T, Yoshikawa M, Itoh J, Ujike O, Miyoshi M, Takemura K (2014) Along-arc geochemical variations in Quaternary magmas of northern Kyushu Island, Japan. Geol Soc Spec Publ 385:15-29. https://doi.org/10.1144/SP385.13

Shimizu K, Saal AE, Hauri EH, Perfit MR, Hékinian R (2019) Evaluating the roles of melt-rock interaction and partial degassing on the $\mathrm{CO}_{2} / \mathrm{Ba}$ ratios of MORB: implications for the $\mathrm{CO}_{2}$ budget in the Earth's depleted upper mantle. Geochim Cosmochim Acta 260:29-48. https://doi.org/10.1016/j.gca.2019.06.013

Shimizu K, Ushikubo T, Hamada M, Itoh S, Higashi Y, Takahashi E, Ito M (2017) $\mathrm{H}_{2} \mathrm{O}$, $\mathrm{CO}_{2}, \mathrm{~F}, \mathrm{~S}, \mathrm{Cl}$, and $\mathrm{P}_{2} \mathrm{O}_{5}$ analyses of silicate glasses using SIMS: report of volatile standard glasses. Geochem J 51:299-313. https://doi.org/10.2343/geochemj.2.0470

Shinohara H (2008) Excess degassing from volcanoes and its role on eruptive and intrusive activity. Rev Geophys 46:RG4005. https://doi.org/10.1029/2007RG000244

Shinohara H (2013) Volatile flux from subduction zone volcanoes: insights from a detailed evaluation of the fluxes from volcanoes in Japan. J Volcanol Geotherm Res 268:46-63. https://doi.org/10.1016/j.jvolgeores.2013.10.007

Shinohara H, Kazahaya K, Saito G, Fukui K, Odai M (2003) Variation of $\mathrm{CO}_{2} / \mathrm{SO}_{2}$ ratio in volcanic plumes of Miyakejima: stable degassing deduced from heliborne measurements. Geophys Res Lett 30. https://doi.org/10.1029/2002g1016105

Shinohara H, Yokoo A, Kazahaya R (2018) Variation of volcanic gas composition during the eruptive period in 2014-2015 at Nakadake crater, Aso volcano, Japan. Earth, Planets Sp 70:151. https://doi.org/10.1186/s40623-018-0919-0

Sisson TW, Grove TL (1993) Temperatures and $\mathrm{H}_{2} \mathrm{O}$ contents of low-MgO high-alumina basalts. Contrib to Mineral Petrol 113:167-184

Sisson TW, Layne GD (1993) $\mathrm{H}_{2} \mathrm{O}$ in basalt and basaltic andesite glass inclusions from four subduction-related volcanoes. Earth Planet Sci Lett 117:619-635. 

https://doi.org/10.1016/0012-821X(93)90107-K

Spilliaert N, Métrich N, Allard P (2006) S-Cl-F degassing pattern of water-rich alkali basalt: modelling and relationship with eruption styles on Mount Etna volcano. Earth Planet Sci Lett 248:772-786. https://doi.org/10.1016/j.epsl.2006.06.031

Straub SM, Layne GD (2003) The systematics of chlorine, fluorine, and water in Izu arc front volcanic rocks: implications for volatile recycling in subduction zones. Geochim Cosmochim Acta 67:4179-4203. https://doi.org/10.1016/S00167037(03)00307-7

Sudo Y, Kong LSL (2001) Three-dimensional seismic velocity structure beneath Aso volcano, Kyushu, Japan. Bull Volcanol 63:326-344. https://doi.org/10.1007/s004450100145

Sudo Y, Tsutsui T, Nakaboh M, Yoshikawa M, Yoshikawa S, Inoue H (2006) Ground deformation and magma reservoir at Aso volcano: location of deflation source derived from long-term geodetic surveys. Bull Volcanol Soc Japan 51:291-309 (in Japanese with English abstract)

Sugawara T (2000) Empirical relationships between temperature, pressure, and $\mathrm{MgO}$ content in olivine and pyroxene saturated liquid. J Geophys Res Solid Earth 105:8457-8472. https://doi.org/10.1029/2000jb900010

Takada H (1989) Preliminary report on tephra from Aso central cones. J Kumamoto Geosci Assoc 90:8-11 (in Japanese)

Teplow W, Marsh B, Hulen J, Spielman P, Kaleikini M, Fitch D, Rickard W (2009) Dacite melt at the Puna Geothermal Venture wellfield, Big Island of Hawaii. Geotherm Resour Counc Trans 33:989-994

Toplis MJ (2005) The thermodynamics of iron and magnesium partitioning between olivine and liquid: criteria for assessing and predicting equilibrium in natural and experimental systems. Contrib to Mineral Petrol 149:22-39. https://doi.org/10.1007/s00410-004-0629-4

Tsuchiyama A (1985) Dissolution kinetics of plagioclase in the melt of the system diopside-albite-anorthite, and origin of dusty plagioclase in andesites. Contrib to Mineral Petrol 89:1-16

Tsutsui T, Sudo Y (2004) Seismic reflectors beneath the central cones of Aso Volcano, Kyushu, Japan. J Volcanol Geotherm Res 131:33-58. https://doi.org/10.1016/S0377-0273(03)00315-9

Tucker JM, Hauri EH, Pietruszka AJ, Garcia MO, Marske JP, Trusdell FA (2019) A high carbon content of the Hawaiian mantle from olivine-hosted melt inclusions. Geochim Cosmochim Acta 254:156-172. https://doi.org/10.1016/j.gca.2019.04.001

Van den Bleeken G, Koga KT (2015) Experimentally determined distribution of fluorine and chlorine upon hydrous slab melting, and implications for $\mathrm{F}-\mathrm{Cl}$ cycling through subduction zones. Geochim Cosmochim Acta 171:353-373. https://doi.org/10.1016/j.gca.2015.09.030

Wallace PJ (2005) Volatiles in subduction zone magmas: concentrations and fluxes based on melt inclusion and volcanic gas data. J Volcanol Geotherm Res 140:217-240. https://doi.org/10.1016/j.jvolgeores.2004.07.023

Wallace PJ (2001) Volcanic $\mathrm{SO}_{2}$ emissions and the abundance and distribution of exsolved gas in magma bodies. J Volcanol Geotherm Res 108:85-106. https://doi.org/10.1016/S0377-0273(00)00279-1

Wallace PJ, Carmichael ISE (1994) S speciation in submarine basaltic glasses as 

determined by measurements of SK $\alpha$ X-ray wavelength shifts. Am Mineral 79:161167

Wallace PJ, Edmonds M (2011) The sulfur budget in magmas: evidence from melt inclusions, submarine glasses, and volcanic gas emissions. Rev Mineral Geochemistry 73:215-246. https://doi.org/10.2138/rmg.2011.73.8

Wallace PJ, Kamenetsky VS, Cervantes P (2015) Melt inclusion $\mathrm{CO}_{2}$ contents, pressures of olivine crystallization, and the problem of shrinkage bubbles. Am Mineral 100:787-794. https://doi.org/10.2138/am-2015-5029

Wanless VD, Behn MD, Shaw AM, Plank T (2014) Variations in melting dynamics and mantle compositions along the Eastern Volcanic Zone of the Gakkel Ridge: insights from olivine-hosted melt inclusions. Contrib to Mineral Petrol 167:1005. https://doi.org/10.1007/s00410-014-1005-7

Wanless VD, Shaw AM (2012) Lower crustal crystallization and melt evolution at midocean ridges. Nat Geosci 5:651-655. https://doi.org/10.1038/ngeo1552

Wanless VD, Shaw AM, Behn MD, Soule SA, Escartín J, Hamelin C (2015) Magmatic plumbing at Lucky Strike volcano based on olivine-hosted melt inclusion compositions. Geochemistry Geophys Geosystems 16:126-147. https://doi.org/10.1002/2014GC005517

Watanabe K (2001) History and activity of Aso volcano (Japanese title "Aso kazan no oitachi"). Ichinomiya-cho, Japan (in Japanese)

Watanabe K (1991) Volcanic activity of Nakadake, Aso volcano. J Kumamoto Geosci Assoc 98:2-13 (in Japanese)

Watanabe K, Itaya T, Ono K, takada (1989) K-Ar ages of dike rocks in the Southwestern region of Aso caldera, Kyushu, Japan. Bull Volcanol Soc Japan 34:189-195 (in Japanese with English abstract)

Webster JD, Mandeville CW, Goldoff B, Coombs ML, Tappen C (2010) Augustine Volcano-The influence of volatile components in magmas erupted A.D. 2006 to2,100 years before present. In: Power JA, Coombs ML, Freymueller JT (eds) The 2006 eruption of Augustine Volcano, Alaska: U.S. Geological Survey Professional Paper 1769

Witham F, Blundy J, Kohn SC, Lesne P, Dixon J, Churakov S V., Botcharnikov R (2012) SolEx: a model for mixed COHSCl-volatile solubilities and exsolved gas compositions in basalt. Comput Geosci 45:87-97. https://doi.org/10.1016/j.cageo.2011.09.021

Yamamoto M, Kawakatsu H, Kaneshima S, Mori T, Tsutsui T, Sudo Y, Morita Y (1999) Detection of a crack-like conduit beneath the active crater at Aso volcano. Geophys Res Lett 26:3677-3680

Yasuda A (2014) A new technique using FT-IR micro-reflectance spectroscopy for measurement of water concentrations in melt inclusions. Earth, Planets Sp 66:34. https://doi.org/10.1186/1880-5981-66-34

Yasuda A, Nakada S, Fujii T (2001) Sulfur abundance and redox state of melt inclusions from Miyake-jima 2000 eruption products. Bull Volcanol Soc Japan 46:165-173 (in Japanese with English abstract)

Yokoo A, Miyabuchi Y (2015) Eruption at the Nakadake 1st crater of Aso volcano started in November 2014. Bull Volcanol Soc Japan 60:275-278 (in Japanese) 
1171

1172

1173

1174

1175

1176

1177

1178

1179

1180

1181

1182

1183

1184

1185

1186

1187

1188

1189

1190

1191

1192

1193

1194

1195

1196

1197

1198

1199

1200

1201

1202

1203

1204

1205

1206

1207

1208

1209

1210

1211

\section{Figure caption}

Fig. 1 Locations of volcanic cones and sampling sites of the study. Main map shows topography of Aso volcano with a $50 \mathrm{~m}$ contour interval. Volcanic cones are indicated by solid triangles. Sampling sites are indicated by solid circles. Location of Aso volcano is indicated in an inset in the top left corner, showing Japanese islands with plate boundaries: solid line, active subduction plate boundary, and dashed line, diffused plate boundary. Stratigraphic log shows corresponding eruption stages and nature of volcanic deposits in A9418 site (Miyabuchi and Watanabe 1997). Kishimadake scoria (KSS) and Ojodake scoria (OJSL and OJSU) were collected at the indicated units. Kamikomezuka scoria (KKO) and Nakadake scoria (NKD14) were collected at the location indicated by field symbols. KKO in parenthesis indicates the relative eruption age (top of N4 stage).

Fig. 2 Microscope photographs (a-d) and backscatter electron images (e, f) of representative phenocrysts and textures from Holocene basaltic tephra products in Aso central cones. (a) Plagioclase (Pl) phenocrysts with honeycomb texture in KKO, under cross-polarized light. Clinopyroxene (Cpx) and olivine (Ol) phenocrysts also present. (b) An orthopyroxene (Opx) phenocryst with reaction rim consisted of clinopyroxene and olivine in KSS, under cross-polarized light. (c) An aggregate of phenocryst consisted of plagioclase, clinopyroxene and olivine in KSS, under cross-polarized light. (d) A microlite-rich part of groundmass in KSS with abundant crystals, under plain-polarized light. (e) High-Fo olivine phenocryst and its melt inclusions observed in KSS. (f) A texture of plagioclase phenocryst with (optically) dusty zone, in the middle part of the crystal, observed in NKD14.

Fig. 3 Major element and volatile concentrations in melt inclusions from Holocene basaltic tephra products in Aso central cones. Melt inclusion data from minerals other than olivine are shown as open symbols. The melt inclusion data are compared to bulk tephra and average groundmass glass compositions, solid circles, and solid squares, respectively. The distribution of Fo content in all olivine cores is shown as a relative density function on the left side of (a). The dashed line in Figure $3 a$ and $3 b$ indicates the value Fo72. Bulk lava compositions of late-Holocene volcanic products, reported previously, are also shown as solid grey circles in (c) (Miyoshi et al. 2005; Miyabuchi 2010, 2017; Saito et al. 2018). All oxide concentrations were normalized to $100 \mathrm{wt}$ \%, excluding volatile element abundance.

Fig. 4 Ratios of volatiles $/ \mathrm{K}_{2} \mathrm{O}$ vs. $\mathrm{K}_{2} \mathrm{O}$ in melt inclusions and groundmass glasses (the same symbols as Fig. 3). All volatile elements showed a systematic decrease (a, $\mathrm{H}_{2} \mathrm{O} / \mathrm{K}_{2} \mathrm{O} ; \mathrm{b}, \mathrm{S} / \mathrm{K}_{2} \mathrm{O} ; \mathrm{c}, \mathrm{Cl} / \mathrm{K}_{2} \mathrm{O}$ ) with respect to increasing $\mathrm{K}_{2} \mathrm{O}$. High volatile $/ \mathrm{K}_{2} \mathrm{O}$ corresponds to high volatile concentration as well as low $\mathrm{K}_{2} \mathrm{O}$. 
1212 Fig. 5 (a) Variations in $\mathrm{S}$ and total $\mathrm{FeO}$ concentrations of melt inclusions and groundmass

1213 glasses. Symbols are the same as Fig. 3. Melt inclusions hosted in olivine show abrupt 1214 decrease in $\mathrm{S}$ content, and the change lacks correlation with FeO. (b) Measured S 1215 concentration in olivine-hosted melt inclusions as a function of sulfur concentration at 1216 sulfide saturation (SCSS). In this figure, the samples at the saturation can be seen on the 1217 solid grey line (1:1 line). The dashed line shows the SCSS corrected for abundance of $\mathrm{S}^{2-}$, 1218 which was 0.85 , the maximum value. All data plots below the corrected SCSS. SCSS is 1219 calculated according to Fortin et al. (2015) using the trapping temperature ( $\left.\mathrm{T}_{\text {trap }}\right)$ of the 1220 melt inclusion (Table S1) at $0.05 \mathrm{GPa}$ (for NKD14) and 0.1 GPa (for KKO, OJSU, OJSL, 1221 and KSS) based on estimated volatile saturation pressure of the pre-eruptive magma

1222

1223

1224 reservoir. For melt inclusions without measured $\mathrm{H}_{2} \mathrm{O}$ concentration, we attributed average $\mathrm{H}_{2} \mathrm{O}$ concentrations (by SIMS) of NKD14 and KSS.

Fig. 6 Variations in $\mathrm{Cl}$ and $\mathrm{F}$ concentrations of melt inclusions (KSS and NKD14) plotted in decadic log scale. The KSS and NKD14 data are compared with the volatile rich mafic primitive magma, represented by a large blue diamond. The two areas are indicated to show the $\mathrm{Cl}$ and $\mathrm{F}$ concentrations in primitive arc basalt and MORB, which were measured in olivine-hosted melt inclusions (taken from Van den Bleeken and Koga 2015). MORB melt inclusions were plotted as solid light-grey circles (Saal et al. 2002; Wanless and Shaw 2012; Wanless et al. 2014, 2015; Le Voyer et al. 2017; Shimizu et al. 2019) including Cl-rich data of assimilated MORB samples by seawater derived component. Melt inclusions from Iwate volcanoes, one of low $\mathrm{F}$ concentration arc lava from Japan arc, is shown as an example of a cold subduction zone (red plus sign, Rose-Koga et al. 2014). The lines show the constant $\mathrm{Cl} / \mathrm{F}$ values, and the values are indicated above the line.

Fig. 7 Pre-eruptive temperatures and water concentrations calculated from the compositions of plagioclase rim and groundmass glass. The squares represent the estimated range of temperature and $\mathrm{H}_{2} \mathrm{O}$ concentration. The calculation was based on a combination of a plagioclase-olivine-liquid hygrometer (Lange et al. 2009) and olivinesaturated liquid geothermometer (Sugawara 2000; Médard and Grove 2008) according to Sakuyama et al. (2014), assuming the crustal conditions (0.1 - 0.5 GPa). Standard deviations $(1 \sigma)$ of the difference in temperature and $\mathrm{H}_{2} \mathrm{O}$ concentration between estimation and expectations using this method were $23{ }^{\circ} \mathrm{C}$ and 0.6 wt. $\%$, respectively. The dashed lines represent water saturation isobars for groundmass glass composition of KSS calculated according to Moore et al. (1998); the corresponding pressures (kbar) and the depths $(\mathrm{km})$ are indicated to the left of the line. The depth in the crust was calculated assuming a density of $2200 \mathrm{~kg} / \mathrm{m}^{3}$ for less than $1 \mathrm{~km}$ depth and a density of $2700 \mathrm{~kg} / \mathrm{m}^{3}$ for depth greater than $1 \mathrm{~km}$ (Komazawa 1995). The red and blue colors show the range of the magma storage depths: red, C1 from 3 to $10 \mathrm{~km}$ depth, and blue, C2 from 1 to 4 km depth beneath Nakadake's first crater (Sudo and Kong 2001; Sudo et al. 2006; Hata 
et al. 2016).

Fig. 8 Evolution of $\mathrm{H}_{2} \mathrm{O} / \mathrm{S}, \mathrm{CO}_{2} / \mathrm{S}$, and $\mathrm{Cl} / \mathrm{S}$ molar ratios of magmatic gases in equilibrium with the primitive basaltic melt plotted against pressure. Horizontal dotted lines indicate measured gas compositions of $\mathrm{H}_{2} \mathrm{O} / \mathrm{S}=22.5, \mathrm{CO}_{2} / \mathrm{S}=6$, and $\mathrm{Cl} / \mathrm{S}=0.07$ ( $\mathrm{S}$ as total sulfur) with the variation observed with propagated measurement uncertainties shown by shaded regions. The values correspond to high-pressure gas component A reported in previous studies (Shinohara 2013; Shinohara et al. 2018). $\mathrm{SO}_{2}$ and $\mathrm{H}_{2} \mathrm{~S}$ components were added to calculate the total S. Horizontal colored bars at the top of the panel show pressure ranges corresponding to the $\mathrm{C} 1, \mathrm{C} 2$, and LVL. To evaluate the evolution of the gas composition of the basaltic magma from a great depth, we modelled the equilibrium compositions of gas and magma for a closed system magma ascent using SolEx (Witham et al. 2012). Grey field indicates the pressure range of $2.3-2.9 \mathrm{kbars}$, at which conditions the modeled gas compositions (solid and dashed curves) intersect with measured gas ratios. Thus, the observed gas composition potentially originated at these depths. We chose the primitive magma composition (discussed in the text) with values of FMQ+1.4 and $1090{ }^{\circ} \mathrm{C}$ based on the individual melt analyses. We tested initial $\mathrm{CO}_{2}$ contents of 400,750 and $1000 \mathrm{ppm}$ for the calculation, as the $\mathrm{CO}_{2}$ concentration was unknown to us. In combination with $\mathrm{H}_{2} \mathrm{O} / \mathrm{S}$ and $\mathrm{Cl} / \mathrm{S}$, the initial $\mathrm{CO}_{2}$ concentration from 400 to $750 \mathrm{ppm}$ produced the gas composition evolution curves that agree at a similar depth.

Fig. 9 Observed volcanic gas compositions emitted from Aso volcano compared with modelled variation in $\mathrm{CO}_{2} / \mathrm{SO}_{2}$ and $\mathrm{H}_{2} \mathrm{O} / \mathrm{CO}_{2}$ molar ratios. Observed gas compositions are those during quiescent periods (fumarole and lake gases) and during eruptive periods (Shinohara et al. 2018). Some data points were reported as poor quality observations due to atmospheric $\mathrm{H}_{2} \mathrm{O}$, and they are plotted as smaller symbols. Solid curve is a modeled gas composition of closed-system ascent of primitive magma with $750 \mathrm{ppm}$ initial $\mathrm{CO}_{2}$ concentration, which is the same as that used in Fig. 8. The gas compositions on the curve indicate the different depths of gas segregation, and thus, the variation among observations can be attributed to a variation in segregation depths. Dashed curve shows a mixing curve between a $\mathrm{CO}_{2}$-rich gas in equilibrium with the deep primitive magma at $2.6 \mathrm{kbar}$ (crossed circle) and a gas discharged from NKD14 magma at shallow depth (asterisk) representing the gas stored at the shallow reservoir. The shallow gas component was calculated from the difference in volatile concentrations between pre-eruptive melt and groundmass glass.

Fig. 10 Schematic summary of the magma and gas evolution in the Aso plumbing system. Magma passage is indicated by the color ranging red-orange-yellow. The gas is white, and the grey zone corresponds to the conductivity anomaly (Hata et al. 2016). C1, C2, and LVL (black thick bars) are the zones of magma stagnations determined by geophysical methods (Yamamoto et al. 1999; Sudo and Kong 2001; Tsutsui and Sudo 
1

2 3 4 5 6 7 8 10 11 12 13 14 15 16 17 18 19 20 21 22 23 24 25 26 27 28 29 30 31 32 33 34 35 36 37 38 39 40 41 42 43 44 45 46 47 48 49 50 51 52 53 54 55 56 57 58 59 60 61 62 63 64 65

1294 2004; Sudo et al. 2006; Abe et al. 2010; Hata et al. 2016). 


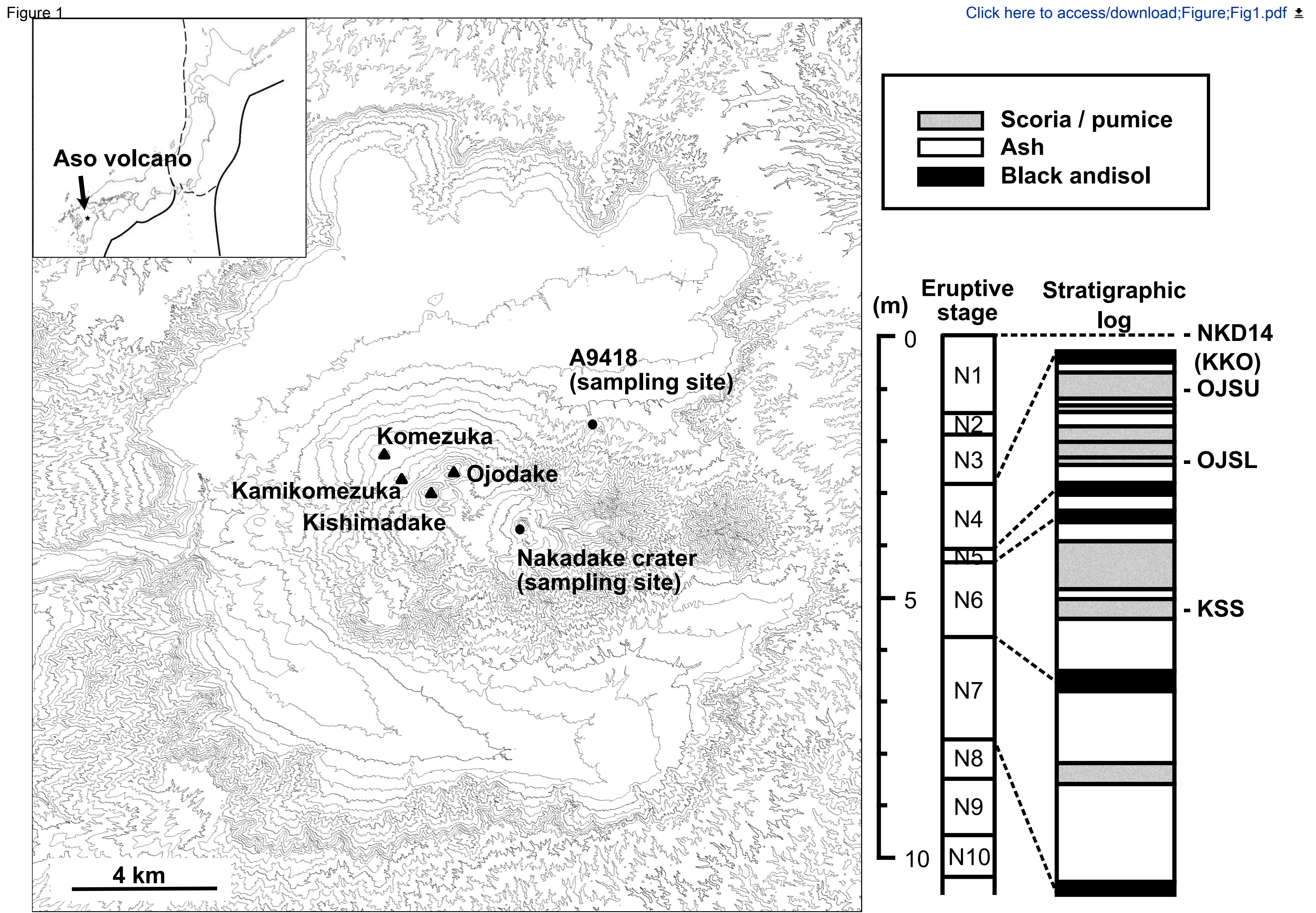



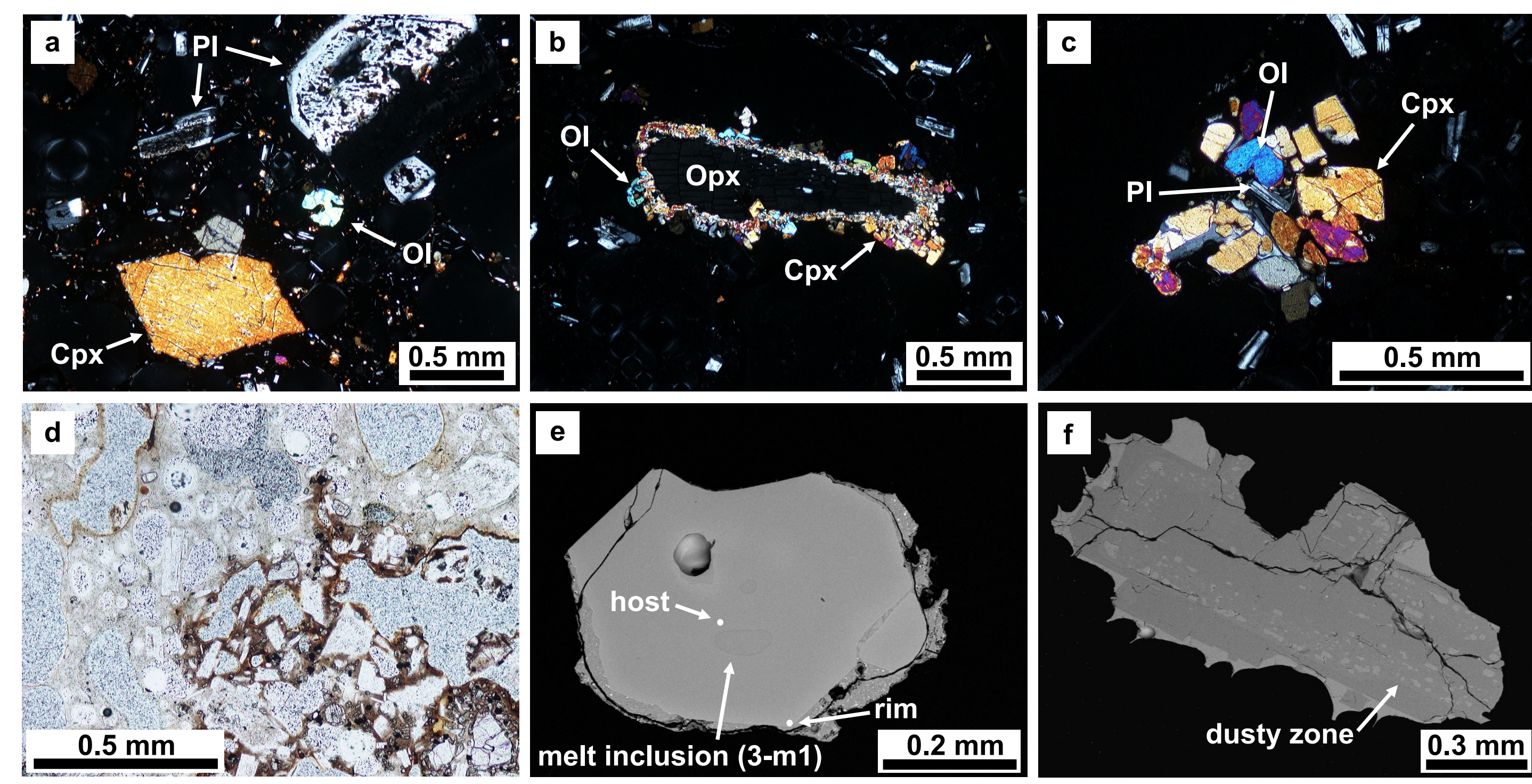
$\Delta \quad$ Clinopyroxene

$\diamond$ Olivine

○ Orthopyroxene

$\square$ Plagioclase
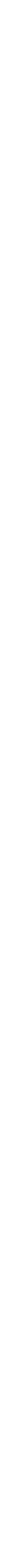


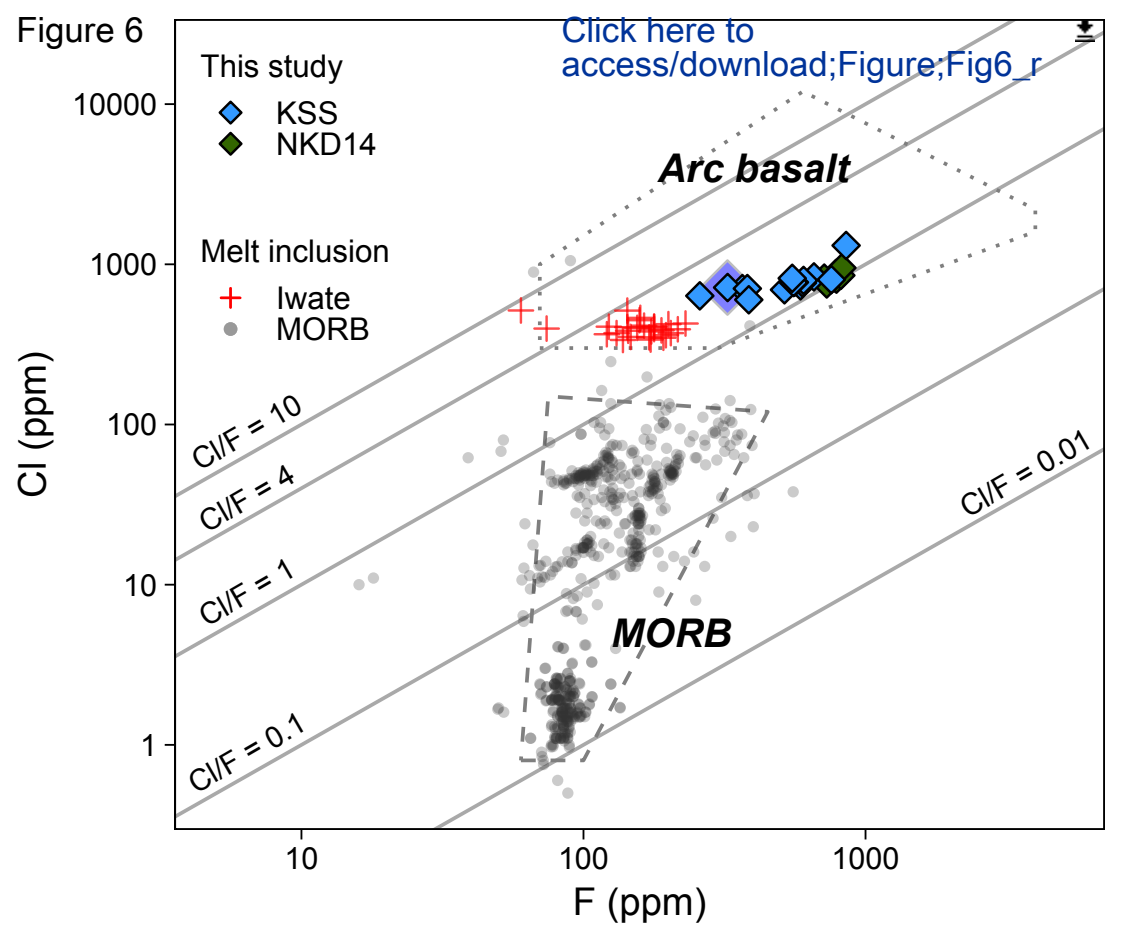




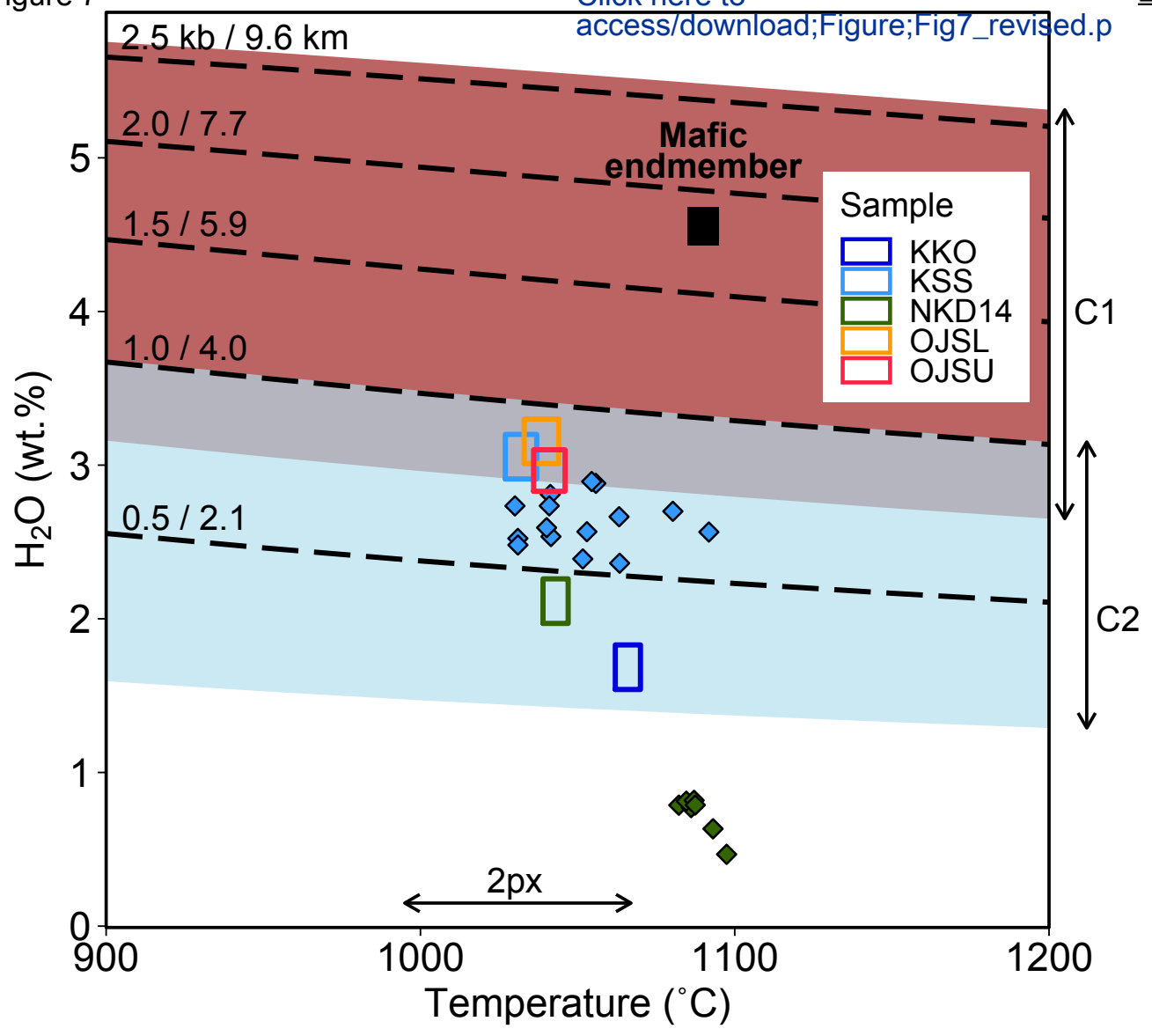


Figure 8

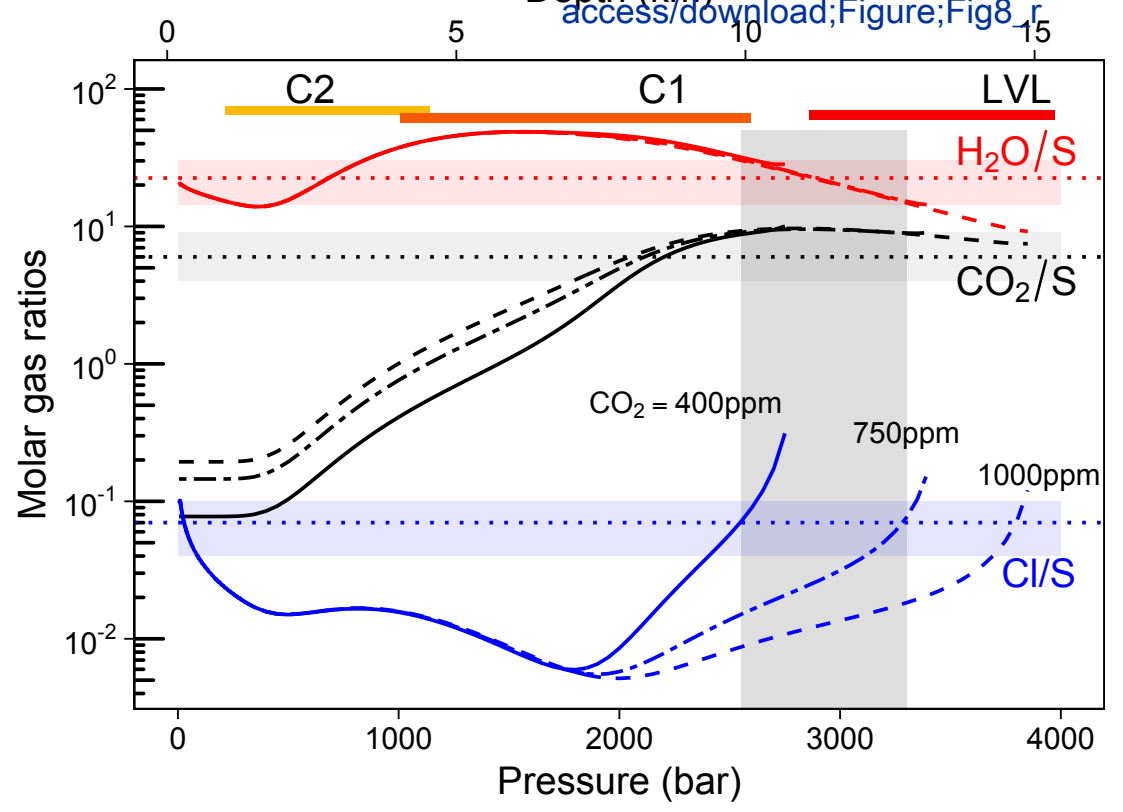



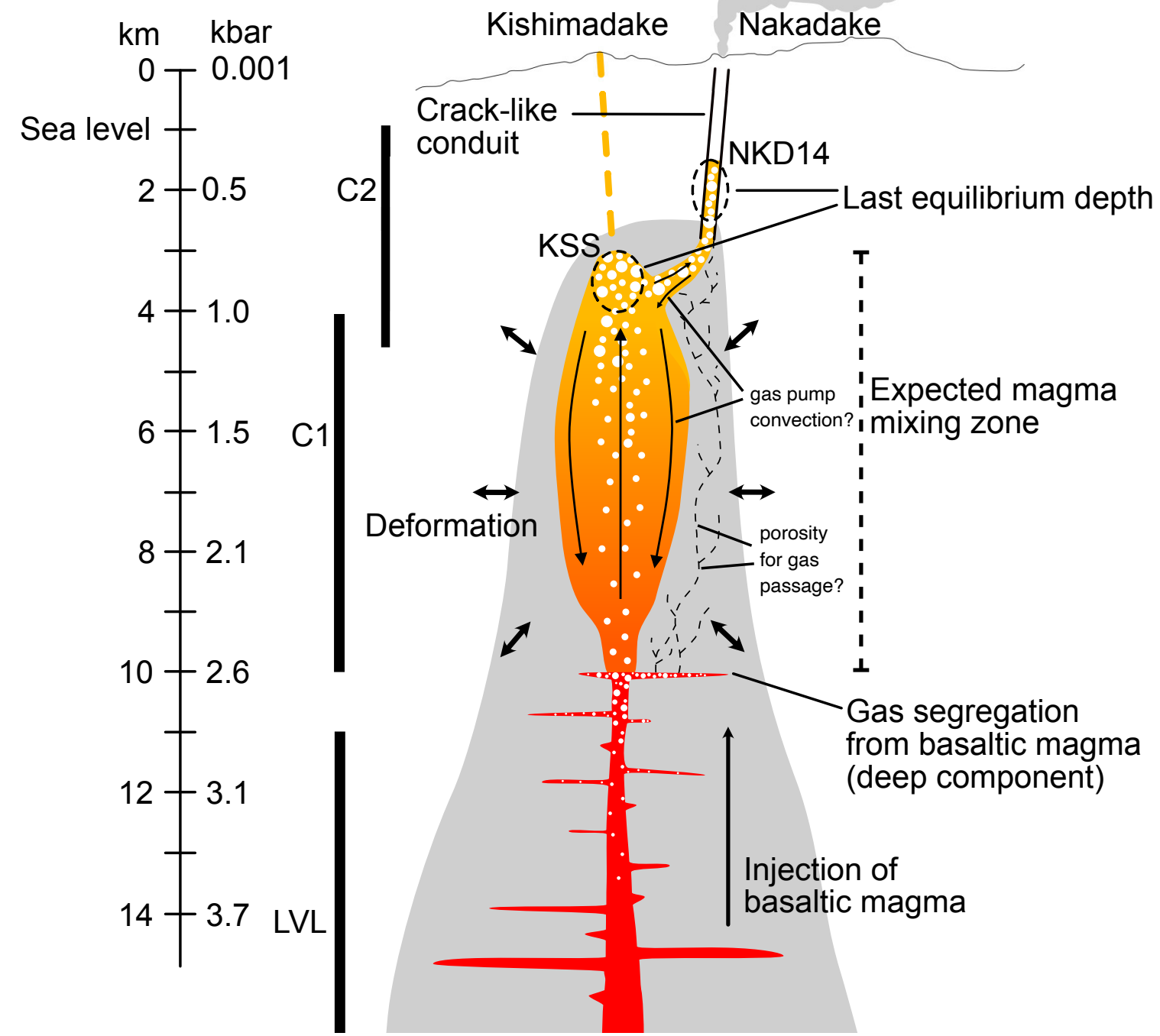
Table 1 Major and trace element compositions of bulk tephra samples.

\begin{tabular}{|c|c|c|c|c|c|}
\hline \multicolumn{2}{|c|}{ Volcanic con $\epsilon$ Nakadake } & \multirow{2}{*}{$\begin{array}{l}\text { Kamikomezuka } \\
\text { KKO }\end{array}$} & Kishimadake & \multirow[b]{2}{*}{$\operatorname{RSTD}(\%)^{\mathrm{D}}$} & \multirow[b]{2}{*}{ Detection limit } \\
\hline Sample & NKD14 & & KSS & & \\
\hline \multicolumn{6}{|c|}{ Majore elements (wt.\%) ${ }^{a}$} \\
\hline $\mathrm{SiO}_{2}$ & 54.26 & 51.49 & 53.22 & 0.1 & \\
\hline $\mathrm{TiO}_{2}$ & 0.94 & 0.94 & 1.00 & 0.3 & \\
\hline $\mathrm{Al}_{2} \mathrm{O}_{3}$ & 17.84 & 18.52 & 18.48 & 0.1 & \\
\hline $\mathrm{FeO}^{*}$ & 8.78 & 10.07 & 9.62 & 0.1 & \\
\hline $\mathrm{MnO}$ & 0.16 & 0.18 & 0.17 & 0.3 & \\
\hline $\mathrm{MgO}$ & 3.91 & 5.56 & 4.45 & 0.1 & \\
\hline $\mathrm{CaO}$ & 8.77 & 9.38 & 8.71 & 0.1 & \\
\hline $\mathrm{Na}_{2} \mathrm{O}$ & 3.05 & 2.49 & 2.61 & 0.2 & \\
\hline $\mathrm{K}_{2} \mathrm{O}$ & 2.00 & 1.16 & 1.51 & 0.3 & \\
\hline $\mathrm{P}_{2} \mathrm{O}_{5}$ & 0.28 & 0.21 & 0.22 & 0.4 & \\
\hline Total $* *$ & 99.75 & 99.93 & 99.50 & & \\
\hline \multicolumn{6}{|c|}{ Trace elements (ppm) } \\
\hline $\mathrm{Sc}$ & 26 & 31 & 30 & 2.4 & 4.6 \\
\hline V & 260 & 320 & 283 & 0.5 & 5.4 \\
\hline $\mathrm{Cr}$ & n.d. & 11 & 12 & 8.9 & 3.7 \\
\hline $\mathrm{Ni}$ & n.d. & 21 & 18 & 6.2 & 5.1 \\
\hline $\mathrm{Cu}$ & 209 & 202 & 131 & 0.7 & 5.3 \\
\hline $\mathrm{Zn}$ & 81 & 88 & 81 & 0.7 & 2.9 \\
\hline $\mathrm{Rb}$ & 58 & 31 & 45 & 0.7 & 1.4 \\
\hline $\mathrm{Sr}$ & 566 & 588 & 598 & 0.2 & 2.7 \\
\hline$Y$ & 26 & 21 & 23 & 2.3 & 2.5 \\
\hline $\mathrm{Zr}$ & 139 & 88 & 121 & 0.6 & 2.4 \\
\hline $\mathrm{Nb}$ & 7 & 5 & 7 & 6.3 & 1.5 \\
\hline $\mathrm{Ba}$ & 369 & 277 & 328 & 0.7 & 9.8 \\
\hline $\mathrm{La}$ & 18 & 13 & 15 & 11.2 & 6.1 \\
\hline $\mathrm{Ce}$ & 82 & 33 & 33 & 4.2 & 5.4 \\
\hline $\mathrm{Nd}$ & 25 & 16 & 18 & 7.3 & 5.5 \\
\hline $\mathrm{Pb}$ & 13 & 7 & 18 & 3.8 & 2.4 \\
\hline
\end{tabular}

${ }^{\mathrm{a}}$ All oxides were normalized to $100 \mathrm{wt} . \%$.

${ }^{\mathrm{b}}$ Relative standard deviation (RSTD) of major elements were from Mori and Mashima (2005). RSTD of trace elements were calculated for KSS using the relationship between RSTD and concentration reported in Mori and Mashima (2005).

* Total iron as $\mathrm{FeO}$ calculated by following equation: $\mathrm{FeO}=0.8998 * \mathrm{Fe}_{2} \mathrm{O}_{3}$. ** Total of the raw data. 
Table 2: PEC corrected and normalized to $100 \%$, major element and volatile concentrations in representative melt inclusions.

\begin{tabular}{|c|c|c|c|c|c|c|c|c|c|c|c|c|c|c|c|c|c|}
\hline Sample & $\overline{\text { NKD14 }}$ & & & & & & KKO & & & & & & OJSU & & & & \\
\hline Host mineral $^{\mathrm{a}}$ & $\mathrm{OL}$ & $\mathrm{OL}$ & $\mathrm{OL}$ & PL & CPX & OPX & $\mathrm{OL}$ & $\mathrm{OL}$ & PL & PL & CPX & OPX & $\mathrm{OL}$ & $\mathrm{OL}$ & PL & PL & CPX \\
\hline Melt ID & $1-\mathrm{m} 1$ & $2-\mathrm{m} 1$ & 4-m4 & a3-m1 & c5-m1 & $4-m 6$ & $2-\mathrm{m} 1$ & $3-m 3$ & a2-m1 & Cb3-m1 & $\mathrm{d} 2-\mathrm{m} 1$ & $1-\mathrm{m} 2$ & $1-\mathrm{m} 5$ & $1-\mathrm{m} 13$ & $1-\mathrm{m} 1$ & $1-\mathrm{m} 4$ & $1-\mathrm{m} 2$ \\
\hline $\mathrm{SiO}_{2}(\text { wt. } \%)^{\mathrm{V}}$ & 59.21 & 56.44 & 57.22 & 57.71 & 60.22 & 59.88 & 48.53 & 49.29 & 57.65 & 52.53 & 61.65 & 59.09 & 59.68 & 54.30 & 59.11 & 55.74 & 57.45 \\
\hline $\mathrm{TiO}_{2}$ & 1.33 & 1.01 & 1.35 & 1.48 & 1.45 & 1.25 & 0.86 & 1.07 & 1.15 & 1.25 & 1.39 & 1.36 & 0.97 & 1.15 & 1.10 & 1.33 & 1.60 \\
\hline $\mathrm{Al}_{2} \mathrm{O}_{3}$ & 14.43 & 14.82 & 14.33 & 14.61 & 14.23 & 14.37 & 18.08 & 19.52 & 17.10 & 13.35 & 13.69 & 14.90 & 14.42 & 16.77 & 16.91 & 15.34 & 15.47 \\
\hline $\mathrm{FeO}^{1 \text { otal }}$ & 10.08 & 11.63 & 10.63 & 11.16 & 10.06 & 9.45 & 11.85 & 10.50 & 8.34 & 13.85 & 9.31 & 9.24 & 9.45 & 9.88 & 7.39 & 10.14 & 10.04 \\
\hline $\mathrm{MnO}$ & 0.23 & 0.22 & 0.21 & 0.23 & 0.18 & 0.24 & 0.13 & 0.19 & 0.15 & 0.28 & 0.21 & 0.19 & 0.19 & 0.17 & 0.14 & 0.21 & 0.19 \\
\hline $\mathrm{MgO}$ & 3.10 & 3.59 & 3.23 & 2.68 & 2.05 & 2.33 & 6.88 & 5.60 & 2.48 & 5.90 & 1.86 & 2.76 & 2.98 & 3.87 & 2.50 & 3.84 & 2.17 \\
\hline $\mathrm{CaO}$ & 5.13 & 6.50 & 6.38 & 5.83 & 4.90 & 5.24 & 10.37 & 10.60 & 6.86 & 8.85 & 4.71 & 5.87 & 5.72 & 8.50 & 5.92 & 7.51 & 5.27 \\
\hline $\mathrm{Na}_{2} \mathrm{O}$ & 2.86 & 3.49 & 3.03 & 2.55 & 2.97 & 3.63 & 2.61 & 2.48 & 2.44 & 1.81 & 3.16 & 3.40 & 3.02 & 3.10 & 3.49 & 3.11 & 3.09 \\
\hline $\mathrm{K}_{2} \mathrm{O}$ & 3.16 & 1.94 & 3.09 & 3.23 & 3.36 & 3.35 & 0.53 & 0.58 & 3.62 & 1.98 & 3.78 & 2.78 & 3.14 & 1.95 & 2.97 & 2.46 & 4.07 \\
\hline $\mathrm{P}_{2} \mathrm{O}_{5}$ & 0.48 & 0.37 & 0.53 & 0.52 & 0.57 & 0.26 & 0.16 & 0.17 & 0.21 & 0.20 & 0.23 & 0.40 & 0.44 & 0.31 & 0.46 & 0.31 & 0.64 \\
\hline S (EPMA) & 0.010 & 0.044 & 0.022 & 0.009 & 0.013 & 0.019 & 0.378 & 0.251 & 0.004 & 0.097 & 0.022 & 0.014 & 0.019 & 0.143 & 0.011 & 0.041 & 0.021 \\
\hline Cl (EPMA) & 0.087 & 0.122 & 0.085 & 0.099 & 0.131 & 0.096 & 0.054 & 0.098 & 0.053 & 0.070 & 0.104 & 0.074 & 0.090 & 0.072 & 0.094 & 0.073 & 0.217 \\
\hline $\mathrm{H}_{2} \mathrm{O}$ (SIMS) & - & - & 0.48 & - & - & - & - & - & - & - & - & - & - & - & - & - & - \\
\hline S ppm (SIMS) & - & - & 199 & - & - & - & - & - & - & - & - & - & - & - & - & - & - \\
\hline Cl ppm (SIMS) & - & - & 835 & - & - & - & - & - & - & - & - & - & - & - & - & - & - \\
\hline F ppm (SIMS) & - & - & 727 & - & - & - & - & - & - & - & - & - & - & - & - & - & - \\
\hline $\mathrm{H}_{2} \mathrm{O} / \mathrm{K}_{2} \mathrm{O}$ & - & - & 0.154 & - & - & - & - & - & - & - & - & - & - & - & - & - & - \\
\hline $\mathrm{S} / \mathrm{K}_{2} \mathrm{O}$ & 0.003 & 0.022 & 0.006 & 0.003 & 0.004 & 0.006 & 0.711 & 0.434 & 0.001 & 0.049 & 0.006 & 0.005 & 0.006 & 0.073 & 0.004 & 0.017 & 0.005 \\
\hline $\mathrm{Cl} / \mathrm{K}_{2} \mathrm{O}$ & 0.028 & 0.063 & 0.027 & 0.031 & 0.039 & 0.029 & 0.101 & 0.170 & 0.015 & 0.035 & 0.028 & 0.027 & 0.028 & 0.037 & 0.032 & 0.029 & 0.053 \\
\hline $\mathrm{F} / \mathrm{K}_{2} \mathrm{O}$ & - & - & 0.024 & - & - & - & - & - & - & - & - & - & - & - & - & - & - \\
\hline $\mathrm{PEC} \%{ }^{\circ}$ & 1.3 & 1.6 & 1.4 & - & - & - & 5.6 & 0.1 & - & - & - & - & 0.7 & 0.1 & - & - & - \\
\hline Host Mg\#/An ${ }^{\mathrm{u}}$ & 66.2 & 66.0 & 65.6 & 66.8 & 69.6 & 69.2 & 80.7 & 79.0 & 66.7 & 89.6 & 69.2 & 68.9 & 67.7 & 74.5 & 65.7 & 80.8 & 69.6 \\
\hline
\end{tabular}


Table 2 (continued)

\begin{tabular}{|c|c|c|c|c|c|c|c|c|c|c|c|c|c|c|c|c|}
\hline Sample & & OJSL & & & & & & & KSS & & & & & & & \\
\hline Host mineral $^{\mathrm{a}}$ & OPX & $\mathrm{OL}$ & OL & PL & PL & CPX & CPX & OPX & OL & OL & OL & PL & PL & CPX & CPX & OPX \\
\hline Melt ID & $1-\mathrm{m} 2$ & $1-\mathrm{m} 2$ & $1-\mathrm{m} 3$ & $1-\mathrm{m} 1$ & 1-m6 & $1-\mathrm{m} 6$ & O1-m7 & $1-\mathrm{m} 8$ & 2-m1 & $3-m 4$ & 4-m6 & $\mathrm{c} 1-\mathrm{m} 1$ & $\mathrm{~d} 2-\mathrm{m} 1$ & a2-m1 & b5-m1 & $3-m 2$ \\
\hline $\mathrm{SiO}_{2}$ (wt.\%) & 61.75 & 52.24 & 61.21 & 56.12 & 59.57 & 58.65 & 60.87 & 62.08 & 48.18 & 56.92 & 60.40 & 59.81 & 67.77 & 55.90 & 59.58 & 58.78 \\
\hline $\mathrm{TiO}_{2}$ & 0.76 & 1.08 & 0.79 & 1.48 & 1.19 & 1.24 & 1.27 & 1.21 & 0.99 & 0.56 & 1.25 & 0.98 & 1.01 & 1.37 & 1.41 & 1.36 \\
\hline $\mathrm{Al}_{2} \mathrm{O}_{3}$ & 14.16 & 16.91 & 13.34 & 16.56 & 16.37 & 15.31 & 15.22 & 14.53 & 17.89 & 13.04 & 12.71 & 16.61 & 15.89 & 16.09 & 14.99 & 14.51 \\
\hline $\mathrm{FeO}^{1 \text { otal }}$ & 8.68 & 11.50 & 9.60 & 9.41 & 8.01 & 9.66 & 7.55 & 7.67 & 11.72 & 10.28 & 10.56 & 7.31 & 4.20 & 10.25 & 9.44 & 10.48 \\
\hline $\mathrm{MnO}$ & 0.16 & 0.16 & 0.20 & 0.20 & 0.13 & 0.18 & 0.16 & 0.16 & 0.18 & 0.17 & 0.27 & 0.20 & 0.10 & 0.23 & 0.24 & 0.17 \\
\hline $\mathrm{MgO}$ & 2.45 & 4.63 & 2.74 & 2.82 & 2.13 & 2.44 & 2.18 & 2.11 & 6.58 & 3.13 & 3.16 & 3.19 & 0.83 & 3.55 & 1.99 & 1.92 \\
\hline $\mathrm{CaO}$ & 5.45 & 9.35 & 5.49 & 7.01 & 5.78 & 5.50 & 4.59 & 4.68 & 10.99 & 6.14 & 5.97 & 6.94 & 2.99 & 7.28 & 5.09 & 5.27 \\
\hline $\mathrm{Na}_{2} \mathrm{O}$ & 3.91 & 2.77 & 2.89 & 2.78 & 3.36 & 2.96 & 3.58 & 3.40 & 2.50 & 2.81 & 3.15 & 2.24 & 2.04 & 3.16 & 2.79 & 3.08 \\
\hline $\mathrm{K}_{2} \mathrm{O}$ & 2.55 & 1.08 & 3.25 & 2.76 & 3.11 & 3.50 & 4.12 & 3.74 & 0.73 & 1.84 & 2.10 & 2.42 & 4.77 & 1.84 & 3.87 & 3.83 \\
\hline $\mathrm{P}_{2} \mathrm{O}_{5}$ & 0.12 & 0.29 & 0.49 & 0.86 & 0.36 & 0.56 & 0.45 & 0.41 & 0.23 & 0.35 & 0.43 & 0.30 & 0.41 & 0.34 & 0.60 & 0.60 \\
\hline S (EPMA) & 0.033 & 0.203 & 0.006 & 0.026 & 0.007 & 0.021 & 0.008 & 0.013 & 0.180 & 0.068 & 0.017 & 0.008 & 0.006 & 0.081 & 0.042 & 0.038 \\
\hline $\mathrm{Cl}$ (EPMA) & 0.045 & 0.058 & 0.101 & 0.078 & 0.071 & 0.103 & 0.143 & 0.096 & 0.071 & 0.153 & 0.085 & 0.067 & 0.143 & 0.109 & 0.123 & 0.118 \\
\hline $\mathrm{H}_{2} \mathrm{O}$ (SIMS) & - & - & - & - & - & - & - & - & 2.62 & 2.52 & 2.58 & - & - & - & - & - \\
\hline S ppm (SIMS) & - & - & - & - & - & - & - & - & 2962 & 1075 & 164 & - & - & - & - & - \\
\hline Cl ppm (SIMS) & - & - & - & - & - & - & - & - & 731 & 1311 & 801 & - & - & - & - & - \\
\hline F ppm (SIMS) & - & - & - & - & - & - & - & - & 331 & 853 & 578 & - & - & - & - & - \\
\hline $\mathrm{P}_{2} \mathrm{O}_{5}(\mathrm{SIMS})$ & - & - & - & - & - & - & - & - & 0.22 & 0.40 & 0.50 & - & - & - & - & - \\
\hline $\mathrm{H}_{2} \mathrm{O} / \mathrm{K}_{2} \mathrm{O}$ & - & - & - & - & - & - & - & - & 3.591 & 1.375 & 1.232 & - & - & - & - & - \\
\hline $\mathrm{S} / \mathrm{K}_{2} \mathrm{O}$ & 0.013 & 0.188 & 0.002 & 0.009 & 0.002 & 0.006 & 0.002 & 0.003 & 0.406 & 0.059 & 0.008 & 0.003 & 0.001 & 0.044 & 0.011 & 0.010 \\
\hline $\mathrm{Cl} / \mathrm{K}_{2} \mathrm{O}$ & 0.018 & 0.054 & 0.031 & 0.028 & 0.023 & 0.030 & 0.035 & 0.026 & 0.100 & 0.071 & 0.038 & 0.028 & 0.030 & 0.059 & 0.032 & 0.031 \\
\hline $\mathrm{F} / \mathrm{K}_{2} \mathrm{O}$ & - & - & - & - & - & - & - & - & 0.045 & 0.047 & 0.028 & - & - & - & - & - \\
\hline $\mathrm{PEC} \%{ }^{\circ}$ & - & 2.3 & 0.1 & - & - & - & - & - & 8.7 & 1.3 & 0.3 & - & - & - & - & - \\
\hline Host Mg\#/An ${ }^{u}$ & 70.4 & 74.9 & 64.5 & 81.8 & 66.4 & 71.1 & 69.2 & 66.7 & 81.0 & 66.1 & 66.0 & 76.7 & 56.8 & 76.4 & 69.4 & 66.2 \\
\hline
\end{tabular}

${ }^{\mathrm{a}}$ OL: olivine, PL: plagioclase, CPX: clinopyroxene, OPX: orthopyroxene. ${ }^{\mathrm{b}}$ All major oxides were normalized to $100 \mathrm{wt} \%$ as volatile-free. ${ }^{\mathrm{c}}$ Degree of post-entrapment crystallization (wt.\%) based on the addition of equilibrium olivine. Oxide concetrations presented in this table were corrected values. ${ }^{\mathrm{d}}$ $\mathrm{Mg} \#=\mathrm{Mg} /(\mathrm{Fe}+\mathrm{Mg}), \mathrm{An}=\mathrm{Ca} /(\mathrm{Ca}+\mathrm{Na})$, in mole $\%$. 
Table 3 Major element and volatile contents in groundmass glasses.

\begin{tabular}{lrrrrrrrrrr}
\hline \multicolumn{2}{l}{$\begin{array}{l}\text { Volcanic cone Nakadake } \\
\text { Sample }\end{array}$} & \multicolumn{4}{c}{ NKD14 } & \multicolumn{3}{c}{ KKO } & \multicolumn{3}{c}{ OJSU } & \multicolumn{3}{c}{ OJSL } & \multicolumn{3}{c}{ Kishimadake } \\
& Avr. & \multicolumn{1}{c}{ Std. } & Avr. & \multicolumn{1}{c}{ Std. } & Avr. & Std. & Avr. & Std. & Avr. & Std. \\
\hline $\mathrm{N}^{\mathrm{a}}$ & 17 & & 8 & & 14 & & 13 & & 18 & \\
$\mathrm{SiO}_{2}$ (wt.\%) & 58.94 & 0.30 & 57.58 & 0.46 & 56.19 & 0.95 & 55.03 & 0.33 & 57.15 & 0.63 \\
$\mathrm{TiO}_{2}$ & 1.39 & 0.05 & 1.56 & 0.06 & 1.32 & 0.06 & 1.30 & 0.05 & 1.24 & 0.05 \\
$\mathrm{Al}_{2} \mathrm{O}_{3}$ & 14.66 & 0.35 & 14.14 & 0.23 & 15.01 & 0.43 & 15.40 & 0.55 & 15.77 & 0.32 \\
$\mathrm{FeO}^{1 \text { 10tal }}$ & 9.60 & 0.26 & 12.11 & 0.43 & 10.36 & 0.35 & 10.87 & 0.42 & 9.40 & 0.36 \\
$\mathrm{MnO}$ & 0.21 & 0.02 & 0.23 & 0.02 & 0.21 & 0.02 & 0.22 & 0.02 & 0.21 & 0.02 \\
$\mathrm{MgO}$ & 2.70 & 0.15 & 3.28 & 0.15 & 3.80 & 0.19 & 3.96 & 0.22 & 3.55 & 0.17 \\
$\mathrm{CaO}$ & 6.05 & 0.23 & 6.67 & 1.12 & 7.29 & 0.34 & 7.84 & 0.28 & 7.29 & 0.36 \\
$\mathrm{Na}$ & 2.87 & 0.23 & 2.15 & 0.66 & 3.33 & 0.18 & 3.28 & 0.31 & 2.73 & 0.22 \\
$\mathrm{~K}_{2} \mathrm{O}$ & 3.09 & 0.09 & 2.01 & 0.45 & 2.22 & 0.10 & 1.86 & 0.29 & 2.30 & 0.15 \\
$\mathrm{P}_{2} \mathrm{O}_{5}$ & 0.48 & 0.04 & 0.28 & 0.05 & 0.26 & 0.04 & 0.23 & 0.03 & 0.36 & 0.05 \\
$\mathrm{~S}$ & 0.008 & 0.011 & 0.003 & 0.005 & 0.012 & 0.018 & 0.006 & 0.008 & 0.006 & 0.006 \\
$\mathrm{Cl}$ & 0.088 & 0.013 & 0.062 & 0.016 & 0.065 & 0.014 & 0.048 & 0.008 & 0.072 & 0.012 \\
\hline
\end{tabular}

${ }^{\mathrm{a}}$ Number of analyses.

${ }^{\mathrm{D}}$ All major oxides were normalized to $100 \mathrm{wt} . \%$ excluding $\mathrm{S}$ and $\mathrm{Cl}$. 
Table 4 Results of thermo-barometric calculation for mixed magma

\begin{tabular}{|c|c|c|c|c|c|}
\hline Volcanic cone & Nakadake & Kamikomezu & ake & & madake \\
\hline Sample & NKD14 & $\mathrm{KKO}$ & JJSU & JSSL & KSS \\
\hline & 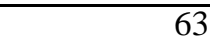 & 70 & 77 & 7 & \\
\hline & & & & & 1037 \\
\hline $\mathrm{H}_{2} \mathrm{O}$ in melt (wt.\%) & -2.26 & $1.54-1.83$ & $2.83-3.10$ & $3.01-3.30$ & $2.91-3.20$ \\
\hline
\end{tabular}

${ }^{\mathrm{a}}$ Mode of plagioclse-rim composition

${ }^{\mathrm{b}}$ Temperature and $\mathrm{H}_{2} \mathrm{O}$ content are estimated based on groundmass glasses and plagioclase compositions after Sakuyama et al. (2014). Ranges of estimated values corespond with the range of assuming crustal condition (0.1 - $0.5 \mathrm{GPa})$. 
Table 5 Comparison of the measured volatile emission with petrological estimation for Nakadake 2014 eruption

\begin{tabular}{|c|c|c|c|c|}
\hline & $\mathrm{H}_{2} \mathrm{O}$ & $\mathrm{CO}_{2}$ & $\mathrm{SO}_{2}$ & $\mathrm{HCl}$ \\
\hline Total emitted mass (ton $)^{a}$ & $1.2 \times 10^{\circ}$ & $7.7 \times 10^{3}$ & $1.4 \times 10^{5}$ & $5.6 \times 10^{5}$ \\
\hline Pre-eruptive concentration in melt ( & 1.08 & 0.034 & $0.069 *$ & $0.196^{*}$ \\
\hline Exsolved volatile from magma (ton) & 14000 & 440 & 1600 & 1400 \\
\hline
\end{tabular}

${ }^{a}$ Total mass of each volatile species were computed from observed gas composition of $\mathrm{CO}_{2} / \mathrm{SO}_{2}=$ $8, \mathrm{H}_{2} \mathrm{O} / \mathrm{SO}_{2}=30$ and $\mathrm{HCl} / \mathrm{SO}_{2}=0.07$ in mole (Shinohara 2013, 2018) assuming observed average $\mathrm{SO}_{2}$ emission rate of 2000 - 3100 ton/day from November 18, 2014 to Janurary 9, 2015 (JMA 2016, 2020) for 70 days.

${ }^{b}$ Pre-eruptive volatile concentrations were estimated for an average $\mathrm{K}_{2} \mathrm{O}$ concentration of groundmass glass times the maximum volatiles $/ \mathrm{K}_{2} \mathrm{O}$ ratios of NKD14 melt inclusions. For preeruptive $\mathrm{CO}_{2}$ concentration, we chose the highest reported value (340 ppm) of Nakadake eruption products (Saito et al. 2018).

${ }^{c}$ Total masses of exsolved volatiles from erupted magma were calculated using the total mass of erupted products of $2.0 \times 10^{6}$ ton during the eruption of $2014-2015$ (Yokoo and Miyabuchi 2015) assuming all $\mathrm{S}$ degassed as $\mathrm{SO}_{2}$.

*Values with asterisk are shown as $\mathrm{S}$ and $\mathrm{Cl}$. 


\section{Reply to reviewer's comments}

First of all, we thank the reviewers for detailed and insightful comments. We carefully read the comments and answered to all in this reply summary. To distinguish the comments from replies, we quoted the comment as an indented paragraph or in double quotation marks in italic. Please note that the reviewer comments refer to the page and line numbers of our initial submitted document, while our replies refer to line numbers of the newly revised document. The modified text as it reads now in the revised manuscript is quoted in blue.

Our manuscript got three reviews and four major points were raised by all the reviewers so we are making a common response to the three issues that were:

1) Regarding the choice of magma degassing model, some reviewers were skeptical about the accuracy of SolEx. They have asked if we can explain, provide arguments in favor of, the choice of SolEx? Why not D-Compress?

2) The term felsic and mafic correspond to two groups of samples that are not well defined. This makes the text hard to follow and consequently some parts of discussion appear ad hoc.

3) The concentration of volatile elements in the volatile-rich end-member is re-assessed in the middle section of the discussion. The reason for the re-calculation of the volatile concentration in mafic endmember is not clear, especially for $\mathrm{H}_{2} \mathrm{O}$ concentration.

4) The authors have measured $\mathrm{CO}_{2}$ by SIMS and although they argue it could be contaminated by prior carbon coating for EMPA analysis, yet the authors claim they are low in the text. These values should be reported in the tables.

In addition to these points, we realized that our discussion may have been unclear. Because of this, we have added a new figure (Fig. 10), summarizing the conclusion derived from the discussion. We sincerely hope that the paper improved the clarity.

Response to (1): In this paper, we compared published Aso volcanic gas composition with modelled gas composition at depths. Here, we used the SolEx model to achieve such comparison. As pointed out by all reviewers, $\mathrm{S}$ behavior during magmatic degassing is a complex process and it appears that there is no one model applicable for all volcanic degassing, and accuracy of some models were questioned as well. It is possible that our approach to apply an existing model may be premature and misleading. In this revision, we investigated further and came to a conclusion that SolEx still suits our situation best. "Lastly, this conclusion is highly model dependent. Here, we chose to use SolEx for its agreement with the variation of $S$ in melt inclusions. However, one must be cautious with the use of SolEx, because it is shown to fail to reproduce degassing trajectories in other volcanoes (e.g., Werner et al. 2020)" [see Line 692-695].

As suggested by the reviewers, we now have calculated the compositional variations modelled by the model D-compress (Burgisser et al. 2015), and compared the results with the observed compositional trend (the figure shown below). The degassing paths modelled by D-compress (red lines) show moderate decrease of $\mathrm{S}$ with a decrease of $\mathrm{H}_{2} \mathrm{O}$ (left panel), whereas the paths of SolEx (black lines) show dramatic depression of sulfur with the initial decrease of $\mathrm{H}_{2} \mathrm{O}$, and fits globally with the observed trend. The SolEx results indicate negligible degassing of $\mathrm{Cl}$ (right panel), which is also consistent with our observation. However, some previous studies reported the inconsistency between SolEx paths and observed melt compositions (e.g. Werner et al. 2020). Furthermore, unlike D-compress, which accounts for chemical potential of gas species, SolEx treats the behavior of $S$ with variable partition coefficient with pressure while not accounting for other parameters, such as oxygen fugacity change with decompression. Lastly, because the compositional trend of volatile elements in the melt inclusions is a result of degassing, mixing, and probably crystal fractionation, the disparity of melt composition from the degassing path is likely due to such processes. On top of this, diffusive $\mathrm{H}$-loss of melt inclusion can reduce $\mathrm{H}_{2} \mathrm{O}$ while keeping $\mathrm{S}$ concentration. Similarly, many $\mathrm{Cl}$ points are shifted to a higher value 
compared to the SolEx path, which can be explained by mixing and crystal fractionation as $\mathrm{Cl}$ is incompatible in minerals. Here, our point is that the trend of the volatile element depletion is better explained by SolEx than D-compress, while it is far from a perfect fit.

An ideal case, would be to use the method for predicting gas evolution using pressure-dependent bulk partitioning coefficients derived from the observed trend (Werner et al. 2020; Johnson et al. 2010; Sisson and Layne 1993; Spilliaert et al. 2006). However, this method requires a well-documented sample set representing the degassing and crystallization, but without mixing. In our case, the variation of major and some volatile elements is clearly controlled by mixing, while $\mathrm{H}_{2} \mathrm{O}$ and $\mathrm{CO}_{2}$ are degassed. It was not possible to separate these processes, and derive degassing controlled $\mathrm{S}$ partition coefficient, like in those studies. Thus, we did not pursue this approach, and accepted to use SolEx for the degassing modelling of our sample.
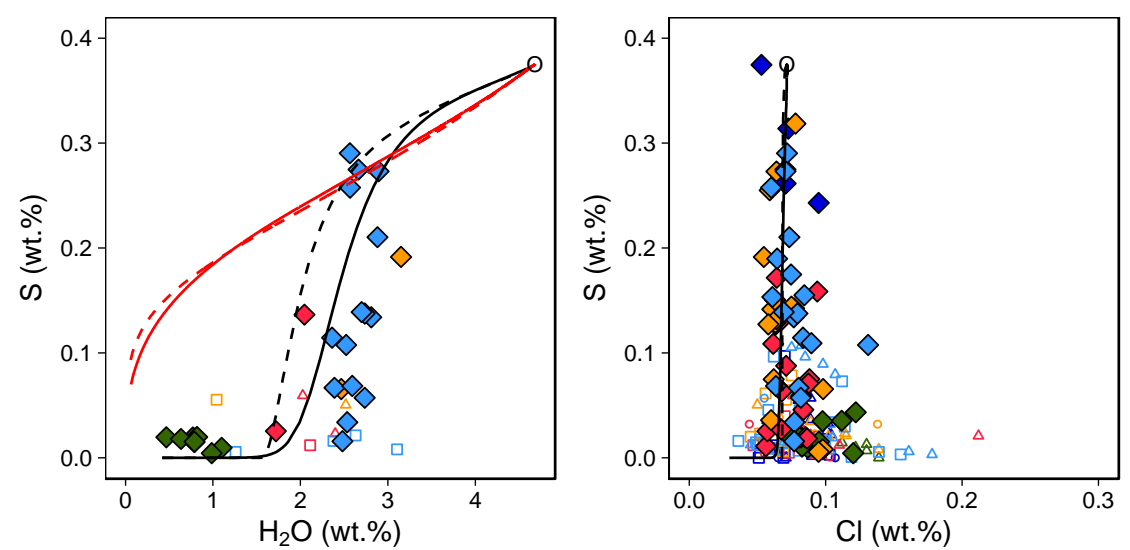

Figure caption: Red and black lines correspond to the modelled degassing paths of D-compress and SolEx, respectively. Solid and dashed line indicates the closed-system and the open-system degassing, respectively. Initial volatile concentration used for the degassing model is plotted as an open circle, with $\mathrm{H}_{2} \mathrm{O}=4.68 \%, \mathrm{~S}=3750 \mathrm{ppm}, \mathrm{Cl}=716 \mathrm{ppm}$ (Our mafic endmember composition before degassing). The paths shown in the figures is the case with $650 \mathrm{ppm}$ initial $\mathrm{CO}_{2}$. Changing the initial $\mathrm{CO}_{2}$ concentration did not change the paths significantly. Measured volatile concentrations of individual melt inclusion and average values of groundmass glasses are plotted as the same symbols as in Figure $3 . \mathrm{H}_{2} \mathrm{O}$ concentrations of groundmass glasses are assumed to be $0.01 \mathrm{wt} . \%$.

Response to (2): The definition of the two groups, mafic and felsic, is based on their host olivine composition. In our sample set, the core composition of the host olivines are clearly divided into two groups with Fo72 representing the divide (see the histogram below). We interpreted that olivines are grown from two distinctively different lavas, which we called mafic and felsic. Based on the anticorrelation of $\mathrm{SiO}_{2}$ concentration in olivine-hosted melt inclusions with host Fo content, we concluded that magma composition can be divided into two groups above and below $55 \mathrm{wt}$. $\% \mathrm{SiO}_{2}$. The high $\mathrm{SiO}_{2}$ corresponds to low-Fo olivine and low $\mathrm{SiO}_{2}$ corresponds to high-Fo olivine. Thus, we grouped all melt inclusions lower than $55 \mathrm{wt} . \% \mathrm{SiO}_{2}$ in a mafic group, and others in a felsic group. 


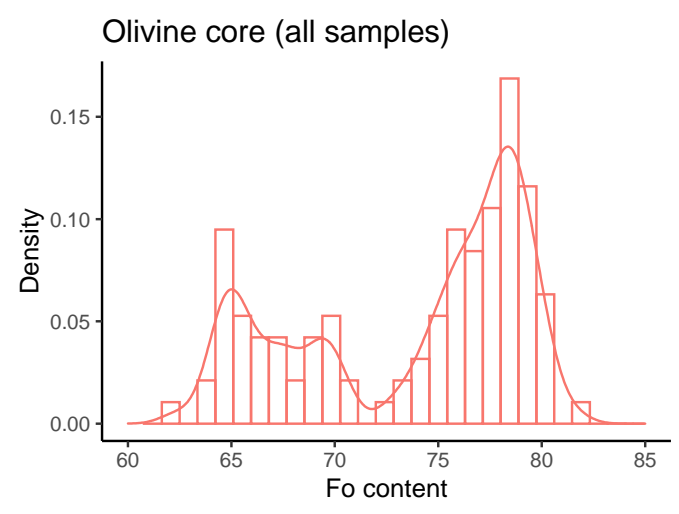

Thank you for pointing out the cut-off value of Fo74 as being unclear. While we mention the value in the text that was misquoted (as Fo74), the correct value is Fo72. We corrected the Fo value in the main texts to "... as low-Fo (62 to 72) and high-Fo (72 to 82)..." [Line 328] . In addition, we modified Figure $3 \mathrm{a}$ to include the relative density distribution of olivine core composition. On top of it, a dashed line representing Fo72 is added to Figure $3 \mathrm{a}$ and $3 \mathrm{~b}$ to indicate the separation between the two MI groups. In the caption of Figure 3, we added the sentence, "The distribution of Fo content in all olivine cores is shown as a relative density function on the left side of (a). The dashed line in Figure $3 \mathrm{a}$ and $3 \mathrm{~b}$ indicates the value Fo72.".

To clarify the definition of the groups, we added a new passage in the manuscript. The new text now reads [L 351-358], "In our sample set, the core composition of host olivines were clearly divided into two groups with Fo72 representing the divide (Fig. 3a). We interpreted that olivines have grown from two distinctively different lavas, which we called mafic and felsic. Based on the anti-correlation of $\mathrm{SiO}_{2}$ concentration in olivine-hosted melt inclusions with host Fo content, we concluded that magma composition can be divided into two groups above and below 55 wt.\% $\mathrm{SiO}_{2}$. The high $\mathrm{SiO}_{2}$ corresponded to low-Fo olivine and low $\mathrm{SiO}_{2}$ corresponded to high-Fo olivine. Thus, in the following we grouped all the melt inclusions lower than 55 wt.\% $\mathrm{SiO}_{2}$ in a mafic group, and others in a felsic group."

Response to (3): The volatile concentration of the mafic endmember is defined based on the hygrometer of the plagioclase - melt - olivine equilibrium. This is necessary because MI data are influenced by magma degassing as $\mathrm{H}_{2} \mathrm{O}$ concentration in melt inclusion is easily modified by diffusion of $\mathrm{H}^{+}$through host olivine (Portnyagin et al. 2008, Chen et al. 2011, Gaetani et al. 2012, Bucholz et al. 2013). Thus, water content in MI is re-equilibrated to a degassed magma after entrapment. The measured water content in melt inclusions does not represent the water concentration at the depth of the deep magma chamber. To clarify, we rearranged the section "Characterization of mixing endmembers" and added sentences to better express what we meant. The exact changes are as follow:

- First these comments made us realise that the source of confusion originates from the mixing calculation applied to $\mathrm{H}_{2} \mathrm{O}$ concentration while we were clearly aware of the post-entrapment loss. In retrospect, the mixing model does not need to include $\mathrm{H}_{2} \mathrm{O}$. In the revised manuscript, we suppressed all the discussions concerning the $\mathrm{H}_{2} \mathrm{O}$ in the context of mixing. Furthermore, to clarify the definition of the mafic endmember, we change the order of sections. Now "Characterization of mixing endmembers" is followed by "volatile concentrations of the primitive magma" then "storage depth of magma mixture"

- We also addressed the issue by re-organizing a section of the discussion, "Characterization of mixing endmembers", by separating the discussion concerning the endmember compositions in major elements and volatile elements. Then, in the paragraphs discussing the characterization of the end-member of volatile elements, we explicitly discussed the effect of degassing in melt inclusions and why MI volatile data are not used.

- In the section "Characterization of mixing endmembers" in the discussion, "former" page 10 line $15-17$, the sentences "For volatile elements, ... during/after magma mixing." are deleted from the paragraph and moved to the end of this section. This separates the discussion of major elements from volatile elements. The new paragraph now reads: "The mixing trend among 
volatile elements is present and generally consistent with the trend of major elements. However, in detail, there are systematic disparities from the mixing curve (Supplementary document S4). Notably, abundances of $\mathrm{H}_{2} \mathrm{O}, \mathrm{S}$, and $\mathrm{Cl}$ for NKD14 samples are depleted compared to the mixing trend traced by KSS melt inclusions (Fig. S4-5). This is best explained by significant degassing occurring during/after magma mixing. Furthermore, there is no single melt inclusion uniquely representing suitable mafic endmember volatile concentrations. The sample KSS-2$\mathrm{m} 1$ is selected as the major element endmember, but its $\mathrm{H}_{2} \mathrm{O}$ contents are not the highest values. From the inspection of the trend, we inferred that mafic endmember must have higher volatile content thus most likely lost water after its entrapment. If melt inclusions formed at a deeper depth were stored in a shallower magma chamber, it is expected that $\mathrm{H}+$ diffusion through olivine equilibrates melt inclusion with surrounding magma (Portnyagin et al. 2008, Chen et al. 2011, Gaetani et al. 2012, Bucholz et al. 2013, Ferris et al., 2016). Complete re-equilibration of the melt inclusions would have erased the mixing trend. However, we have found suitable endmember volatile element concentrations that satisfy the general trend. Because the mafic endmember magma is expected to be volatile-rich, it's $\mathrm{H}_{2} \mathrm{O}$ concentration has to be higher than the $\mathrm{H}_{2} \mathrm{O}$ of the mixed magma (e.g. melt inclusions). The maximum estimated $\mathrm{H}_{2} \mathrm{O}$ concentration (4.68 wt. \%) based on the hygrometer discussed above is therefore taken as the concentration for the volatile-rich mafic endmember. This value of $4.68 \mathrm{wt} . \% \mathrm{H}_{2} \mathrm{O}$ is higher, by about 2 wt. \%, than the highest $\mathrm{H}_{2} \mathrm{O}$ concentration measured in the melt inclusion. Sakuyama's method implicitly ignores the $\mathrm{CO}_{2}$ activity in magma, and predict lower $\mathrm{H}_{2} \mathrm{O}$ content when considering $\mathrm{CO}_{2}$-bearing system (by 0.9 wt. \% less, assessed from an experimental result of Melekhova et al., 2017). Furthermore, this volatile content is the value at the condition of olivine - plagioclase crystallization, most likely of the cooling magma in the crust. At this point we have no other constraint on the $\mathrm{H}_{2} \mathrm{O}$ concentration of the mafic endmember and the primary magma could have an even higher $\mathrm{H}_{2} \mathrm{O}$ content." [Line 448-475].

- The discussion concerning the volatile element concentration in the mafic endmember appears in two other sections, "Storage depth of the magma mixture", and "Volatile concentrations of primitive basaltic melt". We carefully examined redundancy, paid extra attention to improve the clarity of our interpretation.

- Lastly, we added a sentence in the supplementary material $\mathrm{S} 4$ " $\mathrm{H}_{2} \mathrm{O}$ concentration of mafic endmember was taken from the maximum plagioclase-olivine-liquid hygrometer-estimated value (4.68 wt.\%) rather than from the measured melt inclusion because of possible diffusive H-loss (e.g. Portnyagin et al. 2008)."

Response to (4): the $\mathrm{CO}_{2}$ measurements by SIMS were added to Table 2 and $\mathrm{S} 1$. The $\mathrm{CO}_{2}$ concentrations measured in the melt inclusions vary from 10 to $411 \mathrm{ppm}$. Although we wrote that these concentrations are generally low, we have doubts on the higher $\mathrm{CO}_{2}$ values. We advise for caution interpreting the values in the range of a few hundreds ppm because of possible carbon contamination, since the EMP analyses (therefore carbon coating) were performed prior to volatile measurements by SIMS. In any case we did not use the melt inclusion measured $\mathrm{CO}_{2}$ data in the discussion.

\section{Specific replies to reviewer's comments:}

\section{Reviewer \#1: Kayla lacovino}

K. Iacovino review of "Persistent gas emission originating from a deep basaltic magma reservoir of an active volcano: the case of Aso volcano, Japan" by Kawaguchi et al. for Contributions to Mineralogy and Petrology.

Dear Editor, 
This manuscript represents an increasingly important approach to understanding volcanic degassing; that is, it is one of a growing number of studies to look in depth at both the petrology of erupted products (petrography; compositional analysis of matrix glass and phenocrysts; and major and volatile element compositional analysis of melt inclusions) as well as modeling of the surface gas data. The data collected in this work seem to be of top quality, and I have no qualms with the results of chemical analyses (including the descriptions of the analyses performed). However, I find that key sections of this paper are complicated in ways that make it impossible to understand the use of these data. For example, while melt inclusion volatile concentrations are measured, key volatile concentrations of various magma reservoirs are also calculated in multiple ways. It is unclear why the authors have calculated so many of these values, instead of relying more heavily on their hard-won and quite thorough dataset.

Below I detail specific areas of concern where I think the manuscript could be improved with additional clarity in both a.) what samples are being referred to when; and b) why certain choices were made by the authors. Overall, the body of work is impressive, and I find the final analyses intriguing. But, I cannot comment intelligently on whether I am convinced with the final argument, since I am so confused by key details along the way. I recommend that this manuscript be accepted pending major revisions to the text. Some new calculations may be required OR the authors must better justify the values they chose for various modeling exercises.

Response: We thank you very much for the support of the paper and the model. We took your comment carefully into account, and revised the discussion section as detailed in the following replies, especially examining what we have stated what is referred to and why certain choices are made.

\section{Specific comments}

Volatile concentrations: which are which?

The authors present a large number of values for $\mathrm{H} 2 \mathrm{O}, \mathrm{CO} 2, \mathrm{~S}, \mathrm{~F}$, and $\mathrm{Cl}$ concentrations in various magma reservoirs. Some of these are based on measured values in melt inclusions, while others are based on various calculated values. It is unclear to me throughout the text which reservoir is being referred to at any given time. I *think* there are three main reservoirs: a shallow region which contains a mixed magma created by the mixing of a mafic end-member and a silicic end-member plus a deeper region which is referred to as either a primitive or primary source region. I attempted to keep a running tally of the values ascribed to each of these magma bodies as I read the text but was unable to accurately do so. I think a table AND a figure showing the values broken down based on these three reservoirs with symbols for measured (MI) and calculated (hygrometer, K2O ratio modeling...) values would be very helpful.

The different "sets" of values that I encountered include:

1. Measured melt inclusion values for various subsets of the data (although it is never made clear which samples within each sample number are grouped into which of the three reservoirs listed above)

2. Primitive reservoir values modeled using the plagioclase hygrometer (some of which are discounted by the authors)

3. Primitive reservoir values modeled using the ratio of volatiles to $\mathrm{K} 2 \mathrm{O}$ concentration

4. Values from another paper (Saito et al., 2018) that show up and which are used in the final analysis despite new values presented in this paper

Response: The reason why we constantly mention different sets of values, volatile concentration in particular, is the reflection of the complexity of the processes. On the one hand, we have the measured 
values, yet these are the results of modifications due to magma transport and storage. As we develop the discussion to distinguish processes (mixing, deep and shallow storages), inevitably we need to introduce other geochemical indications that may be the reflections of our model hypothesis.

We acknowledge that our discussion was not organized enough to present our idea clearly. Especially since the issues mentioned here were also pointed out by other reviewers. We addressed it as one of the four points listed at the beginning of this summary.

\section{Introduction and methods sections}

These sections are fantastic and well written, and I suggest no changes here.

\section{Results section}

Section on host mineral compositions: Here is where my confusion begins. The MI-bearing olivines (e.g., those shown in figure 3) come from 5 different sampled locations (the five sample numbers) and are grouped into two groups: high Fo_olivine with low SiO2_MI and low Fo_olivine with high SiO2_MI. These groups are separated at Fo=74. However, figure 3 a does not seem to indicate that there are two distinct groups of ol, and it makes me wonder why the authors chose this seemingly arbitrary Fo value to define their groups.

Response: We wrote a common reply for the three reviewers at the beginning of the document. This is addressed in "Response to (2)" of the list.

Section on major and volatile elements in melt inclusions: As with the previous section, this one details volatile concentrations in two "groups": mafic and felsic. It is not immediately clear to me which samples in Fig 3 fall into which groups. Specific volatile concentrations are called out here, but for example, which sample in Fig 3 represents the "felsic volatile-poor magma" with $S<1069$ ppm? Since the distinction between these groups seems arbitrary to me, I lose the meaning of the most volatile-rich sample from the felsic group.

Response: As we have revised the presentation of the mafic and felsic groups (see "Response to (2)), we hope the discussion on volatile elements is clearer. We also modified figure 3, adding a background color to identify immediately the mafic and felsic groups.

Section on storage depth of magma mixture: Here it is very unclear as to which samples are being referred to at any given time.

Response: we revised the text carefully to be more specific about what sample we were talking about. We hope that the section now reads well. Also, we switched the position of two sections, "Volatile concentrations of primitive basaltic melt" now comes before "Storage depth of the magma mixture" for clarity of discussion.

A plagioclase hygrometer is used here to calculate the $\mathrm{H}_{2} \mathrm{O}$ concentration of the mixed magma (I think?). I think I understand the rationale for this, although it should be more clearly stated. E.g., MI measured values give $\mathrm{H}_{2} \mathrm{O}$ in end-member magmas, so the hygrometer calculated values using feldspar rims and matrix glass should correspond to the mixed value.

Response: Measurements of $\mathrm{H}_{2} \mathrm{O}$ in melt inclusions are not used for determining the $\mathrm{H}_{2} \mathrm{O}$ concentrations of the endmembers. Instead, the $\mathrm{H}_{2} \mathrm{O}$ determined by the hygrometer is the $\mathrm{H}_{2} \mathrm{O}$ concentration of the mixed magma, because plagioclase rim - melt are equilibrated after mixing. The $\mathrm{H}_{2} \mathrm{O}$ concentration of the endmember has to be higher than the $\mathrm{H}_{2} \mathrm{O}$ of the mixed magma, therefore higher than the $\mathrm{H}_{2} \mathrm{O}$ determined by the hygrometer. The $\mathrm{H}_{2} \mathrm{O}$ concentration of the volatile-rich endmember is $4.68 \mathrm{wt} . \%$ (and this is still a minimum value) corresponding to the highest calculated value with the hygrometer determined from the plagioclase core. To clarify the significance of the results of the hygrometers, we 
added a sentence in (former) page 11, line 13. It reads: "For example, measured volatile concentrations of melt inclusions are considered to be re-equilibrated to a condition of a magma storage. Alternatively, it is also possible to determine $\mathrm{H}_{2} \mathrm{O}$ concentrations estimated from plagioclase rim and groundmass glass pairs (geo-hygrometer, Lange et al. 2009), likely corresponding to the value of the mixed magma during the plagioclase rim growth. The $\mathrm{H}_{2} \mathrm{O}$ concentration of such mixed magmas are, $\sim 2$ wt. $\%$ for NKD14 and KKO, and 3 wt.\% for OJSU, OJSL and KSS (Table 4)." [Line 554-560]

H2O concentrations are converted to storage depths. VERY IMPORTANT: which model was used to calculate saturation pressures?

Response: The conversion from $\mathrm{H}_{2} \mathrm{O}$ concentrations to saturation pressure was based on the water solubility model of Moore et al. (1998). Estimated $\mathrm{H}_{2} \mathrm{O}$ concentrations and temperatures were plotted in Figure 4, then saturation pressures were read from solubility contours. The corresponding depths of these pressures were calculated based on the reported crustal density structure in the Aso area (2200 $\mathrm{kg} / \mathrm{m} 3$ for depths $<1 \mathrm{~km}$ and $2700 \mathrm{~kg} / \mathrm{m} 3$ for greater depths; Komazawa, 1995). We have revised and made sure that all the information is explicitly cited in the text.

Line 22-23 on this page: 1) "Melt inclusion $\mathrm{H} 2 \mathrm{O}$ measurements ranged from 0.47 to $2.97 \mathrm{wt} \%$ (SIMS) " For which samples? 2) In table 2, measured H2O in MI goes up to 4.57 (measured by FTIR). Do you discount this FTIR value? 3) Also noteworthy that I think the authors should decide how to compare FTIR and SIMS data. Currently, both are presented, but it is unclear if one method is favored over another?

Response: (1) The sample names are NKD14-Olivine-4-m4 corresponding to $0.47 \mathrm{wt}$. $\% \mathrm{H}_{2} \mathrm{O}$ and KSSOlivine-4-m11 corresponding to 2.89 wt. \%. Sample names are added to the sentence [Line 369]. (2) The comparison of $\mathrm{H}_{2} \mathrm{O}$ measurements by FTIR and SIMS data: although we reported $\mathrm{H}_{2} \mathrm{O}$ concentrations done with both methods, FTIR by reflectance is prone to overestimation of $\mathrm{H}_{2} \mathrm{O}$ concentration due to the baseline correction of spectra. Therefore, in the entire manuscript only the SIMS $\mathrm{H}_{2} \mathrm{O}$ measurements are used for discussion and considered reliable. As some inclusions are only measured by FTIR, we couldn't compare them with SIMS measurements and we do not have a concrete reason to discard the data neither. So we decided to report the data with a caution of potentially large uncertainty close to a factor of 2 . We added the following sentence as a footnote to the Table S1 "In this study, we did not find satisfactory agreement between $\mathrm{H}_{2} \mathrm{O}$ determined by FTIR and by SIMS (uncertainty of FTIR measurements is close to $40 \%$ ) so in the following, we only consider $\mathrm{H}_{2} \mathrm{O}$ concentrations measured by SIMS, based on the better detection limit and precision of the method." [Line 262-265]. (3) Regarding the measurements of $\mathrm{H}_{2} \mathrm{O}$ concentration, FTIR and SIMS measurements are unusually in weak agreement (within $40 \%$, see first figure below), with one obvious outlier (KSSOL-4-m7). As already written in (2), one explanation to this disagreement is overestimation of $\mathrm{H}_{2} \mathrm{O}$ in reflectance FTIR analysis due to the contamination of reflective components derived from the host minerals. Again in response to this, we only consider SIMS $\mathrm{H}_{2} \mathrm{O}$ measurements in the entire manuscript, for the sake of consistency, and the range of $\mathrm{H}_{2} \mathrm{O}$ cited everywhere in the text is always that of SIMS measurements. 


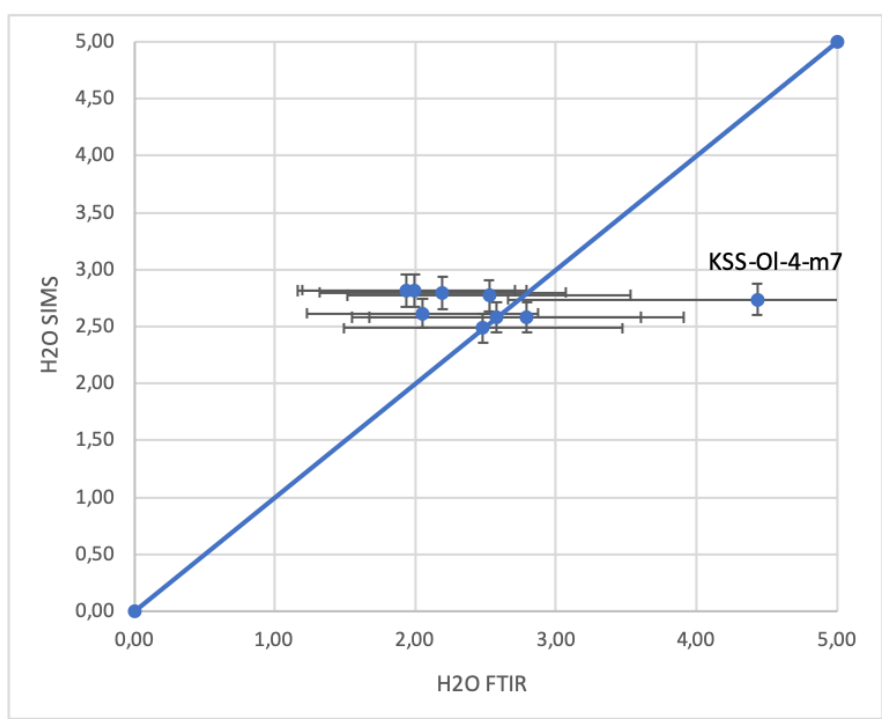

Lines 26-28 on this page: I don't understand why the $\mathrm{CO}_{2}$ concentration in the matrix glass has any meaning here. The matrix glasses are completely degassed. If anything, the $\mathrm{CO}_{2}$ concentration in the MI should be considered (even given the presence of vapor bubbles). By the way, how is $\mathrm{CO}_{2}$ measured in glasses? It seems like it is not measured, but here it is reported that matrix glasses have very low $\mathrm{CO}_{2}$.

Response: Yes, your remark is absolutely correct. It was our error. We deleted the text referring to $\mathrm{CO}_{2}$ measurements in the matrix. The section of "Storage depth and . . " is completely re-written, suppressing such incoherence.

Second paragraph in this section: 1) Why is $\mathrm{H}_{2} \mathrm{O}$ concentration calculated using the plagioclase hygrometer for the mafic end-member? Surely it makes more sense to rely on measured MI concentrations here? 2) Also, why Is a $\mathrm{CO}_{2}$ value of $200 \mathrm{ppm}$ used to model the saturation pressure? 3) What is the rationale for the crustal densities of $2400 \mathrm{~kg} / \mathrm{m} 3$ and $2700 \mathrm{~kg} / \mathrm{m} 3$ ?

Response:

1) The reason that we calculated using the plagioclase-olivine-melt hygrometer is to have the $\mathrm{H}_{2} \mathrm{O}$ concentration of the mixed magma. The risk with $\mathrm{H}_{2} \mathrm{O}$ measurements in olivine-hosted melt inclusion as we already explained, is that melt inclusions could have suffered $\mathrm{H}_{2} \mathrm{O}$ loss by proton diffusion (e.g. Portnyagin et al. 2008). We modified the text accordingly to explain this. Considering that olivineplagioclase crystallization comes after olivine-only crystallization, the value from the plagioclase hygrometer cannot be the primary concentration (at most its maximum value represents a minimum $\mathrm{H}_{2} \mathrm{O}$ of the endmember). It represents a deep magma saturation value but not the $\mathrm{H}_{2} \mathrm{O}$ concentration before crystallization.

2) In the revised text, we have changed completely how we refer to measured $\mathrm{CO}_{2}$ data. This is mainly due to the fact that our measurements are potentially influenced by carbon contamination of the EMP carbon coating and we do not have any good way to discriminate the bad data. While we incorporated $\mathrm{CO}_{2}$ data in the supplementary data, in the text we only mention them as the indication of low $\mathrm{CO}_{2}$ abundance. The concentration referred to here, is suppressed.

3) Both crustal densities of $2200 \mathrm{~kg} / \mathrm{m} 3$ and $2700 \mathrm{~kg} / \mathrm{m} 3$ were the reported values based on the gravimetric analysis of Aso volcano by Komazawa (1995). To avoid any confusion, we have explicitly cited the source and provided a complete description how we converted the entrapment pressure to depth. "note the depth is calculated using a density of $2200 \mathrm{~kg} / \mathrm{m} 3$ for the first $1 \mathrm{~km}$ and $2700 \mathrm{~kg} / \mathrm{m} 3$ for the crust at greater depths (Komazawa, 1995), by solving for the depth, $\mathrm{h}[\mathrm{m}], \mathrm{P}=\mathrm{g}\{2200$ (1000) + 2700 (h-1000)\}." [Line 564-566]

Section on volatile concentrations of primitive basaltic melt: (1)It is unclear to me why new volatile concentrations are calculated here, since some of the language here makes it seem like 
the most mafic MI are used as representative of this primitive reservoir. Did I misunderstand? (2) Please provide a rationale for why $\mathrm{K} 2 \mathrm{O}$ is used as the index of fractionation. In calculating the volatile contents of this primitive reservoir, why is a value of $0.71 \mathrm{wt} \% \mathrm{~K} 2 \mathrm{O}$ used? This seems random. (3) Further, $\mathrm{H} 2 \mathrm{O}$ is calculated here to be only $2.55 \mathrm{wt} \%$, a value which is discounted immediately since some MI have up to $4.5 \mathrm{wt} \%$. If this value is so wrong, how can you trust the calculations for other volatiles? More discussion is needed here.

Response: (1) The $\mathrm{H}_{2} \mathrm{O}$ and $\mathrm{CO}_{2}$ measurements in the melt inclusions from the mafic group are not interpreted as representing the volatile composition of the mafic endmember, after the revision, because melt inclusions have been affected by degassing. We hope the message is clear now that we reorganized this section.

(2) The choice of $\mathrm{K}_{2} \mathrm{O}$ concentration was on the basis of the lowest concentration. However, such estimates create significant disparities with $\mathrm{F}$ and $\mathrm{Cl}$ concentration measured. We chose to simplify the discussion regarding the determination of mafic endmember composition, during the revision. We now tie the endmember composition of $\mathrm{S}, \mathrm{Cl}$, and $\mathrm{F}$ to the melt inclusion values.

(3) $\mathrm{H}_{2} \mathrm{O}$ was measured by 2 methods FTIR (reflectance) and SIMS. We reported both in the table but the agreement between the 2 methods is poor because the FTIR method overestimates $\mathrm{H}_{2} \mathrm{O}$ concentrations. To remain conservative, we only trust and consider the $\mathrm{H}_{2} \mathrm{O}$ measurements that were obtained by SIMS.

Second paragraph in this section and Figure 6: the calculation of SCSS is very confusing to me. Based on the text, it seems like the first calculation (at a reduced condition?) was incorrectly calculated. If fO2 is known, why are curves for two different fO2 values plotted? Then, I don't understand how these data are plotted; were SCSS values calculated independently for each MI sample? Finally, why are the S concentrations in "undersaturated oxidized melt" considered to represent primary concentrations? What does "primary" mean in this context? The deepest primitive reservoir? Which $S$ concentrations correspond this "undersaturated oxidized melt"?

Response: SCSS equation of Fortin et al. (2015) does not include the term of $\mathrm{fO}_{2}$ explicitly. Rather, the author specifies he determines $\mathrm{FeO}$ abundance from the total $\mathrm{FeO}$ with the correct redox state while the sulfur concentration in the melt is as $\mathrm{S}^{2-}$. As commented here, we could calculate the fO2 corrected line but it would be a deviation from Fortin's equation. For the clarity, we decided to develop the discussion in this manner. We revised the figure 5 caption to include more detail about these points. SCSS can be calculated with melt composition, P, and T. This allows us to plot SCSS vs. measured S content. The grey line on the figure thus indicates the 1:1 line. When measured $\mathrm{S}$ is equal to SCSS, such melt inclusion would plot on the line. The word primary is used to state that magma did not experience sulfur phase saturation and fractionation since the formation of the magma.

Figure 4: This might be a good place to plot all of the various $\mathrm{H} 2 \mathrm{O}$ concentrations (measured and calculated).

Response: Figure 4 was modified accordingly with plotting individual measured melt inclusions and calculated $\mathrm{H}_{2} \mathrm{O}$ concentrations. FTIR data is excluded.

Section on persistent degassing from a deeper magma reservoir (>10km): Here, some new volatile concentrations are introduced, but I'm not sure where they are from. An "initial $S$ concentration" of 690 ppm and a "maximum pre-eruptive CO2 concentration" of 340 ppm are given. Are both of these values from Saito et al., (2018)? I can understand using CO2 values from this work, as it appears those were not measured in this study (although this should be explicitly stated earlier in the manuscript), but why use that value for $S$ ? What reservoir does it correspond to? The deep primitive reservoir? Odd, since the $S$ concentrations measured in this study are much greater than 690 ppm. 
Response: Reading the comment, we realised that our organization of the discussion was too meandering. In this revision, we simply tied $\mathrm{CO}_{2}$ budget to a result from a previous study (Saito et al., 2018), as our measurements of $\mathrm{CO}_{2}$ content is only reliably concluded as low (0-77 ppm) among the mixed magmas (inclusions with intermediate compositions).

In line 357-379, we have a revised paragraph discussing $\mathrm{CO}_{2}$ concentration mafic endmember. Now, we state clearly here that we do not know the exact value, and consider $340 \mathrm{ppm}$ as the observed high value, probably indicating the depth of equilibration. Later in the section "Modelling degassing of the deep magma reservoir", we make further advances on possible source $\mathrm{CO}_{2}$ contents by comparing with the gas observation. In this paper, one of our goals is to demonstrate the possible $\mathrm{CO}_{2}$ constraints in such a complex system.

There is another passage (line 381, section "Excess degassing of $\mathrm{SO}_{2}$ and $\mathrm{CO}_{2}$ from Nakadake 2014 eruption") where we introduce a different volatile content (Table 5). The point of this discussion simply illustrates the occurrence of excess degassing by investigating recent 2014 eruption with its magmatic product and observed gas output. The magma of the 2014 eruption is the mixed magma. Therefore, the corresponding possible source composition is independently assessed (supplementary S4). As we considered this part as a passage to support the needs of deep gas sources, we did not see the importance of developing a full discussion, and in consequence caused confusion. As it is mentioned in the footnote of Table 5, the value of $690 \mathrm{ppm} \mathrm{S}$ was calculated for NKD14 based on their maximum S/K $\mathrm{K}_{2} \mathrm{O}$ ratios and average $\mathrm{K}_{2} \mathrm{O}$ concentration of the groundmass glass because we explained the excess degassing of NKD14 magma in this first section "Excess degassing of $\mathrm{SO}_{2}$ and $\mathrm{CO}_{2}$ from Nakadake 2014 eruption" in "Persistent degassing from a deeper magma reservoir $(>10 \mathrm{~km})$ ".

One of the reasons making confusion is the usage of the term "initial volatile concentration". To distinguish from the "initial" meaning volatile concentrations in primary magma, we changed to use "pre-eruptive" for volatile concentration at the pre-eruptive magma reservoir and modified the text accordingly.

Section on modelling degassing of the deep magma reservoir: It is never stated here which model is used to perform these calculations, which is paramount. DCOMPRESS?

Response: Indeed, thank you, we forgot to specify the model we used. The modified text now reads: "Fig. 8 is the result of such a calculation using SolEx (Witham et al. 2012), showing the variations in $\mathrm{H}_{2} \mathrm{O} / \mathrm{S}, \mathrm{CO}_{2} / \mathrm{S}$ and $\mathrm{Cl} / \mathrm{S}$ molar ratios of gas in equilibrium with a magma as a function of pressure." [Line 671-673]

"Equilibrium gas composition at depth should be the same as the gas composition observed at the surface, if the gas segregated and travelled to the surface without any modification in between." Senso stricto, this is not true. Due to P-dependent fugacity coefficients, the speciation of a gas will change from depth to surface (even at constant fO2). This does not matter for this study if and only if surface gas measurements were made in terms of total $S$. Based on the information in the supplement, it appears that $S$ may have been measured as SO2. Technically, if total $\mathrm{C}$ in the gas was measured as $\mathrm{CO}$, this also presents a problem as a gas will speciate between (primarily) $\mathrm{CO} 2$ and $\mathrm{CO}$ (plus other probably minor C species). However, the amount of $\mathrm{CO}$ is usually quite low, so I am okay with this approximation for carbon. For sulfur, however, the fO2 of the system can have a big effect on SO2 concentration, since $S$ is split primarily between SO2 and H2S (plus other probably minor S species). I can't say off the top of my head weather the bulk gas composition will be significantly affected, but this felt worthy of pointing out.

Response: Absolutely. We have completely overseen the changes of gas speciation between the depth and the surface, and indeed Shinohara et al. (2018) reports measurements of $\mathrm{SO}_{2} / \mathrm{H}_{2} \mathrm{~S}$, but not $\mathrm{CO}_{2} / \mathrm{CO}$. We revised and made sure to calculate the gas ratios as molar $\mathrm{H}_{2} \mathrm{O} /\left(\right.$ total S), $\mathrm{CO}_{2} /$ (total S), and $\mathrm{Cl} /$ (total S), and rewrote the discussions, and modified Fig. 8, and 9 where gas compositions were compared with magmatic sulfur input. 
Overall, I find it difficult to comment on the conclusions drawn in this section, since I am unclear as to which dissolved volatile concentrations were used to represent which magma reservoirs. I think an additional table AND a figure showing the various volatile concentrations measured or calculated for these reservoirs will help alleviate this, PLUS some necessary clarification in the text. Other than this confusion, the manuscript was well written. I think that some more thought into how to organize and present the volatile data can go a long way toward strengthening the manuscript.

This work is very interesting to me, and I am available to re-review this manuscript should that be desired.

Response: We thank the reviewer again for the positive encouragement. In conclusion, we have added a figure (Fig10) summarising the discoveries made in this study using a schematic diagram. We hope this would improve the readability of the paper.

\section{Reviewer \#2: Daniel Rasmussen}

\section{Summary}

Kawaguchi et al. provide a detailed study of melt inclusions from Aso volcano. They evaluate compositions of melt inclusions, host crystals, and bulk tephras, as well as phenocryst textures. They find that melt inclusion major elements give evidence of magma mixing as the primary means of variation in melt composition. Volatile elements were used to investigate magma storage depths, and the authors argue for shallow, preeruptive storage at depths of 2 and $4 \mathrm{~km}$, and they suggest that mafic magmas feeding the system originate at depths $>10 \mathrm{~km}$. They use SolEx to model magma degassing paths, and a comparison of their model results with observed gas emissions indicates that mixing of shallow and deep gases occurs.

This paper was a pleasure to read, and it will be an important contribution. The authors have conducted a careful, thorough study. The dataset presented here represents a monumental effort (200 melt inclusions!). The data are robust. The writing is very clear, and I was amazed by the level of polish. Broadly, the authors have been careful in their interpretation of the data. However, I have identified some areas that need improvement or further clarification below. Specifically, the main findings of the paper relate to magma mixing, magma storage depth, and origins of gas emissions. In all three of these areas, there are weaknesses in some aspects of the arguments.

\section{Major comments}

1. The authors rely heavily on a model of magma mixing ("liquid"-"liquid" mixing) to describe the chemical compositions and textures of minerals, and the major-element trends in melt inclusions. No consideration is given for alternative scenarios (magma-crystal mixing, crystallization). The paper would benefit from the authors making a stronger case for the mixing scenario they consider and/or describing some of the alternatives. More information on my concerns can be found in my specific comments on Pages 8 and 9 of the manuscript. 
Response: This was the point we contemplated for the organization of the paper. We absolutely agree that magma evolution is complex and it is rarely controlled only by a single process. With this in mind, our choice to place mixing as a central process to explain the magma transport may have appeared too simplistic. However, we maintain the idea that the major compositional variation reflects that of mixing, while crystallization contributes to a minor dispersion. The mixing might have been a mixing process of magma crystal mixture, certainly, but melt inclusion is expected to represent magma only. Even if magma-crystal mixtures had been present, inclusions probably record only the mixing of magma. In the revision, we paid attention to discuss competing magmatic processes, while insisting on why we prefer the magma-magma mixing model.

2. There are weak arguments that surround the suggested shallow region of magma storage. The authors discuss saturation pressures that are relevant for a pure- $\mathrm{H} 2 \mathrm{O}$ system when the system in question is a mixed-volatile (i.e., $\mathrm{H} 2 \mathrm{O}$ and $\mathrm{CO} 2$ ) system. Pressures derived using assuming the melt and vapor only had $\mathrm{H} 2 \mathrm{O}$ are minimums. If $\mathrm{CO} 2$ is added to the melt (and coexisting vapor), the saturation-pressure estimates increase. The authors state that there was no CO2 in the systems when the crystals formed because at the depths of the imaged reservoirs, CO2 solubility is low (Page 11, lines 26-28). That may be true. However, then the petrological data are not being used as an independent confirmation of the geophysically determined magma storage depths. Rather, the interpretation of the petrological data relies on the assumption that the depths recorded by the samples are the same as the geophysical depths. Their data could be used as an independent constraint on magma depth if they can convincingly argue that the magma did not have much CO2 in it at the time the crystals in question formed without relying on the geophysical data.

Response: First of all, we insist that the abundance of $\mathrm{CO}_{2}$ in the melt inclusions were low especially for the felsic group melt inclusion $(0-77 \mathrm{ppm})$. While we agree with all the points raised here by the reviewer, because of the low $\mathrm{CO}_{2}$ in the melt inclusions, the change of the pressure of equilibration is minor. As with the presence of bubbles in the inclusions, the concentration of volatile element in melt is equilibrated with the pressure condition just before the eruption, thus the shallow storage in this case, and as it is not the discussion of the entrapment pressure, it is unnecessary to account for the $\mathrm{CO}_{2}$ in the bubble.

Ultimately, as commented here, the weakness of our argument was rooted in luck of independent evidence showing low $\mathrm{CO}_{2}$. In this revision, we decided to include $\mathrm{SIMS} \mathrm{CO}_{2}$ data, with a cautionary note for high concentration measurements for potential $\mathrm{C}$ contamination. However, it is clearly shown that the mixed magmas are low in $\mathrm{CO}_{2}$. We added a sentence stating "Because $\mathrm{CO}_{2}$ concentrations in the felsic group melt inclusions are notably low (0 - $77 \mathrm{ppm}$, Table S1), it makes negligible changes to the calculated equilibrium pressure." [Line 566-568].

3. The authors base several of their interpretations on modeling that was performed using melt inclusion $\mathrm{H} 2 \mathrm{O}$ contents without adequately exploring the potential role of diffusive exchange of $\mathrm{H}^{+}$(i.e., water loss or gain) between the melt inclusion and exterior melt. The authors indicate that they selected samples to minimize the effects of this process during quench, and they indicate the possibility of water loss in page 11. However, there are ample opportunities for the process to have occurred prior to quench. Are the measured $\mathrm{H} 2 \mathrm{O}$ contents consistent with their mixing model? Or could they be described by a model of ascent, degassing, and crystallization? Diffusive exchange of $\mathrm{H}^{+}$is a widely 
known and understand challenge when working with melt inclusion data which must be very clearly addressed.

Response: This point was raised by all reviewers. We addressed this at the beginning of this reply letter, point (3).

4. The authors argue that the "initial" CO2 contents of the magma is 250-500 ppm. This is very low for an arc magma. The basis for this argument is the comparison of observed gas emissions with the results of SolEx modeling. Degassing model predictions are highly dependent on the model, the parameters, and the scenario. The authors do not adequately justify their modeling. For further information, see my comments on page 15.

Response: Again, we can only accept this comment. The discussion surrounding $\mathrm{CO}_{2}$ strongly depends on the choice model as pointed out here. As for the reply to this, we examined the alternative model available at this moment (see the beginning of this reply document, point 1). As we found that SolEx after all, appears to follow our compositional trend better, we decided to keep the original interpretation. However, we revised the section of "degassing" and carefully described the limit of our interpretation.

5. If the paper goes back to review, it would be helpful for the authors to make the line numbers continuous (i.e., not start over at the beginning of each page).

Response: We apologize for the inconvenience caused by the line numbering and our revised manuscript now has continuous line numbering

\section{Line comments}

Abstract: The authors have been very consistent with their use of verb tense. From what I can tell, the entire paper is written in past tense. I do not recommend the authors change any of the tenses in this paper. However, for future papers, the authors should consider using other tenses. Here is a general guideline from Nature: "In your scientific paper, use verb tenses (past, present, and future) exactly as you would in ordinary writing. Use the past tense to report what happened in the past: what you did, what someone reported, what happened in an experiment, and so on. Use the present tense to express general truths, such as conclusions (drawn by you or by others) and atemporal facts (including information about what the paper does or covers). Reserve the future tense for perspectives: what you will do in the coming months or years. Typically, most of your sentences will be in the past tense, some will be in the present tense, and very few, if any, will be in the future tense."

(https://www.nature.com/scitable/topicpageleffective-writing-13815989/)

Response: We appreciate very much the advice here. In fact, correct usage of verb tense is difficult to master.

Page 2, Line 11: Melt inclusions.

Response: Corrected, thank you. [new line, Line 45] Also we have re-examined the singular-plural usage carefully throughout the manuscript.

Page 2, Line 12: Phenocrysts. What was their Fo?

Response: Corrected thank you. [Line 46]

Page 2, Line 34: Suggest replacing "characterized" with "governed". 
Response: Corrected thank you. [Line 69]

Page 2, Line 38: Suggest replacing "melt inclusion" with "the study of melt inclusions".

Response: Corrected thank you. [Line 73]

Pages 2-3, Lines 37-1: Today, it is very well known that melt inclusions are not completely isolated from chemical interaction with their host crystal and the external melt. The authors should make a brief comment of this here with one or two references.

Response: Yes indeed, we added the following sentence and references in the text [Line 76-80] : "In fact, melt inclusions are not perfectly isolated from surrounding magmas since $\mathrm{H}^{+}$can diffuse through the host olivine (e.g. Gaetani et al., 2012) and $\mathrm{CO}_{2}$ can be redistributed in shrinkage bubbles (e.g. Tucker et al., 2019). Therefore, $\mathrm{H}_{2} \mathrm{O}$ and $\mathrm{CO}_{2}$ measurements in melt inclusions are regarded as minimum values indicating the conditions of last equilibration."

Page 3, Lines 1-6: The excess sulfur problem has been known for a long time, and several studies have given explanations to explain the observation. Some should be cited here.

Response: We agree and we cited more references for example: Métrich and Wallace 2008, Wallace and Edmonds 2011, de Moor et al. 2017 [Line 83-84]

Page 3, Line 20: Suggest replacing “magma” with "glass".

Response: Corrected thank you. [Line 100]

Page 4, Lines 27-29: It is great that you have made note of your consideration for posteruptive cooling. It is also important that you describe the clast size of the tephra samples you worked with. Did you focus on loose crystals in the ash size fraction of tephra samples?

Response: Yes, indeed. The clast size of the tephra sample is written in the following paragraph [Line 160 - 181]. We only used lapilli-size scoria (up to $6 \mathrm{~cm}$ ) [Line 185-186].

Page 4, Lines 32-33: Do you have a sense of the relative abundance of each of these phases?

Response: We have no data about the relative abundance of these minerals in our samples. However, Miyoshi et al. (2005) reported the phenocryst mode of basalt - basaltic andesite lava ( $<54 \mathrm{wt} . \% \mathrm{SiO} 2)$ erupted from Kishimadake, Ojodake, Komezuka, and Nakadake volcanoes: $32-39$ vol.\% plagioclase, $7-9$ vol. \% clinopyroxene, <1 vol.\% orthopyroxene, $1-2$ vol.\% olivine, $1-2$ vol. $\%$ opaque minerals. To point the reader to the right information, we added "Detailed descriptions of these tephras are found in Miyabuchi et al. (2005).” [Line 158 - 159]

Page 4, Line 36 (and throughout): In some cases, the authors use the Oxford comma. In others, they do not. Its use should be systematic. I would recommend using it.

Response: Thank you for pointing out the inconsistency. We have revised all the occurrences and corrected accordingly.

Page 5, Line 5: Suggest changing "was not identified today" to "has not been identified presently." 
Response: Corrected thank you.

Page 5, Lines 34-35: It would be better to express the accuracies as percent errors. An uncertainty of 5-25 ppm may be a lot more significant for an element like $\mathrm{Nb}$ than it is for something like $\mathrm{Sr}$.

In the text we cited the range to indicate the standard deviations. The detailed variations are in fact in Table 1 . For this revision, we decided to report relative standard deviations.

Page 6, Lines 19-27: Do you have a sense of the detection limit for the reflectance technique? It probably depends somewhat on the specifics of the sample, but a rough estimate would be helpful to include here.

Response: Our understanding of the reflectance technique for FTIR made us realised how difficult and how user-dependent the estimation of the baseline of FTIR spectra is. As already explained, we therefore took the conservative decision to only trust the SIMS data for $\mathrm{H}_{2} \mathrm{O}$ measurements. We nonetheless reported the FTIR $\mathrm{H}_{2} \mathrm{O}$ measurement in the supplementary material. While the detection limit of the method strongly depends on the sample, we estimated detection limits as $0.14 \mathrm{wt} \%$ [Line 233-235].

Page 6, Lines 19-27: It appears that you performed SIMS on some of the same melt inclusions that you obtained water content measurements using FTIR. It is important to describe how the two measurements compare. It appears that, in some cases, the agreement is good, while in others is pretty poor.

Response: Like we replied to the reviewer 1, we adopted SIMS $\mathrm{H}_{2} \mathrm{O}$ values rather than FTIR. Similarly, we systematically favored SIMS volatile data to EMPA measurements, SIMS being more precise.

Pages 6-7, Lines 28-6: Did you measure secondary (check) standards? Do you have a sense of the precision and accuracy of the SIMS analyses?

Response: Yes, we measured a secondary standard, EPR-G3 an aphyric basalt from the East Pacific Rise. We added the sentence "Repeated analysis of a secondary basaltic glass standard from East Pacific Rise EPR-G3 (Shimizu et al., 2017) yielded a relative standard deviation for $\mathrm{H}_{2} \mathrm{O}, \mathrm{CO}_{2}, \mathrm{~F}, \mathrm{Cl}$, and $\mathrm{S}$ of $1.4,3.2,1.5,2.5$, and $0.9 \%$, respectively". [Line 252-255].

Page 7, Lines 34-37: Are the FeO concentrations significantly elevated about the bulk rock?

Response: We realised our writing raised this question. In fact, $\mathrm{FeO}$ in the inclusions is mostly the same as the bulk rock or higher. High $\mathrm{FeO}$ melt inclusions were also lower in $\mathrm{SiO}_{2}$ consistent with magma evolution. As it was not our aim to develop the discussion regarding the precision of $\mathrm{FeO}$ content in the melt inclusion, we did not elaborate more information here. Instead, we changed the sentence to "The melt inclusions were not corrected for post-entrapment diffusive Fe-loss (Danyushevsky et al. 2000), as total $\mathrm{FeO}$ concentrations in melt inclusions are either the same or higher than those in bulk rocks." [Line 294-296]

Page 8, Lines 5-6: How was equilibrium with the host tested?

Response: The melt inclusions that are in equilibrium with their host were identified by filtering our data. Specifically, the melt inclusion - host pair must satisfy an expected range of Kd, typical for basaltic compositions. The modified text now reads: "Among these samples, only the melt inclusions in equilibrium with host minerals were used for the magmatic temperature calculation, in which the 
exchange coefficients were within expected range of basaltic composition: $(\mathrm{KD}(\mathrm{Fe}-\mathrm{Mg}) \mathrm{cpx}$-liq $=0.28$ $\pm 0.08, \mathrm{KD}(\mathrm{Fe}-\mathrm{Mg}$ )opx-liq $=0.29 \pm 0.06$, and $\mathrm{KD}(\mathrm{An}-\mathrm{Ab}$ ) pl-liq $=0.27 \pm 0.01$ or $0.1 \pm 0.05$ (depending on the calculated temperature; Putirka 2008).” [Line 303-307]

Page 8, Lines 9-10: Suggest changing wording to "major and volatile element concentrations".

Response: Corrected thank you.

Page 9, Line 16: Here and elsewhere "olivine-hosted" should be hyphenated.

Response: Corrected thank you.

Page 9, Line 30: Normally zoned olivine phenocrysts are not described in the "Host mineral compositions section". Are these common? Does normal zoning occur in the high-Fo olivine only?

Response: Yes, all high-Fo olivine observed in KKO, OJSU, OJSL, and KSS are normally zoned and common. As described in former page 8 line 37, some plagioclase phenocrysts were also normally zoned. In conclusion, normal zoning occurred in the high-Fo olivine and high-An plagioclase only. We added the sentence into former page 8 line 30: "All high-Fo olivine phenocrysts were normally zoned." [Line 333]
Page 9, Lines 29-34: I wonder if describing the mixing as something that occurs between two "liquids" is too reductive. (1) Does the mixing need to be between two liquids? Could you have one magma carrying some crystals interact with xenocrysts or antecrysts? In other words, could you explain the observations listed in lines 31-34 with a mafic magma bearing crystals interacting with a more evolved pile of crystals? Also, if the "liquids" are suggested to be bearing crystals (and/or other phases), I would recommend calling them "magmas".

Response: Yes indeed, it is better to use "magma" and we changed the text accordingly. In fact, we don't have a clear evidence to judge if mixing was just between "liquids". As the reviewer said, we can not exclude the incorporation of xenocrysts or antecrysts into the ascending magma. However, given the presence of banded pumice in ACP-1 (e.g. Miyabuchi 2017) erupted prior KSS eruption, it seems conceivable that melt would have been present. Even if the silicic endmember magma was the remnant of such mixed ACP-1, the mixing of two distinct extreme magmas is not geochemically wrong. Furthermore, considering the high temperature of the silicic endmember and the fact inclusion traps the liquid only, we stand by our choice of mixing liquids. Thanks to the reviewer's comment we leave this possibility open for food for thoughts without having any good argument here to constrain it. In any case, for the flow of discussion it is not the right place to state "liquid" here [Line 372-384]. Reference to liquid-liquid mixing is suppressed here and moved further down in the discussion.

We modified the text to clarify our interpretation in this discussion, "It is important to note that there is a surface expression of this silicic endmember in the Aso eruption products, while the mixing endmember is set by a melt inclusion. Major element compositions of ACP1 dacitic pumice (Miyabuchi 2017), the only Holocene felsic product erupted three hundred years before that of KSS, are similar to the felsic endmember, and this indicates the presence of the silicic magma. Furthermore, the presence of a banded pumice was reported in ACP1 prior to KSS (Miyabuchi 2017). This banded texture is evidence of magma mingling and therefore the mixing trend is unlikely a result of assimilation and crystal fractionation of single parental magma." [Line 408-415] 
Page 10, Lines 4-6: Perhaps you could make a brief statement why the two types of magmas that mix are proposed to not be derived from a single parent. It is easy to imagine a scenario where magma mixing occurs between two magmas that have a similar parent.

Response: Certainly. We modified the first paragraph of the discussion expanding to mention the point raised here. "While the major variance of concentration variations was explained by a simple mixing process, in close inspection of trends, it is likely that crystal fractionation contributed to the dispersion from the mixing model. It should also be noted that the mixing model required the presence of independent mixing endmembers, it does not constrain their origin." [Line 403-407]

Page 10, Lines 16-17: Some of the variation in water could be due to diffusive equilibration of $\mathrm{H}^{+}$, right?

Response: Yes for example most MI from KSS have $\mathrm{H}_{2} \mathrm{O}$ concentrations between 2.36 and 2.89 wt.\%, with the exception of one Mi (KSS 3-m3) which has probably suffered diffusive equilibration of proton and has a lower $\mathrm{H}_{2} \mathrm{O}$ concentration (1.52 wt.\%). For this reason, we did not include $\mathrm{H}_{2} \mathrm{O}$ in the mixing model.

Page 10, Lines 9-17: Can the major elements be described by a crystallization model? In the major element data alone, is mixing required? Mixing requires linear trends on major element plots. Some major element plots (see below, note these were made used the uncorrected major element data of melt inclusions) do not seem to show linear trends. Rather, there is some evidence of "kinked" paths, which are commonly attributed to crystallization.
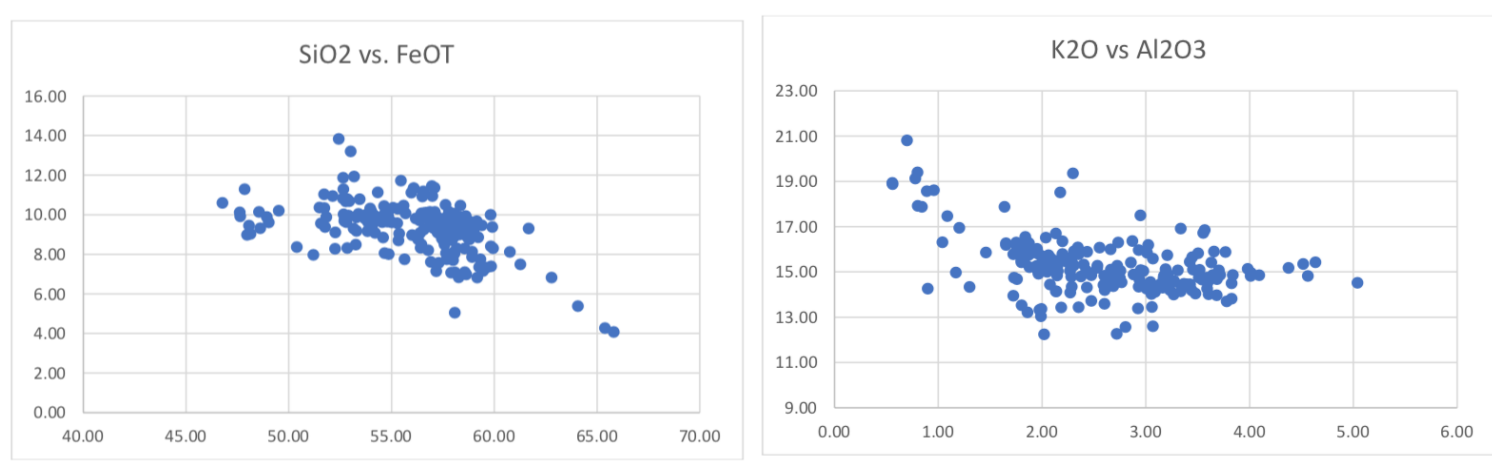

Response: Thank you. We tested the idea of a fractional crystallization on the figure the reviewer produced but with the corrected MI data and we added the fractional crystallization model. The trend in corrected major element $\mathrm{FeO}$ vs $\mathrm{SiO}_{2}$ is closer to linear now (no kink, figure below). However, a simple cristallisation trend (produced by Rhyolite MELTS, fractional crystallization from $1150{ }^{\circ} \mathrm{C}$ ) disagrees with the composition variation here. So maybe fractional crystallization happens but it is not the main process justifying the composition variation. Therefore, we maintain our mixing model to explain the melt inclusion variations but we now mention the fractional crystallization because we can not rule it out entirely, but we add that it does not play an essential role in this variation. 


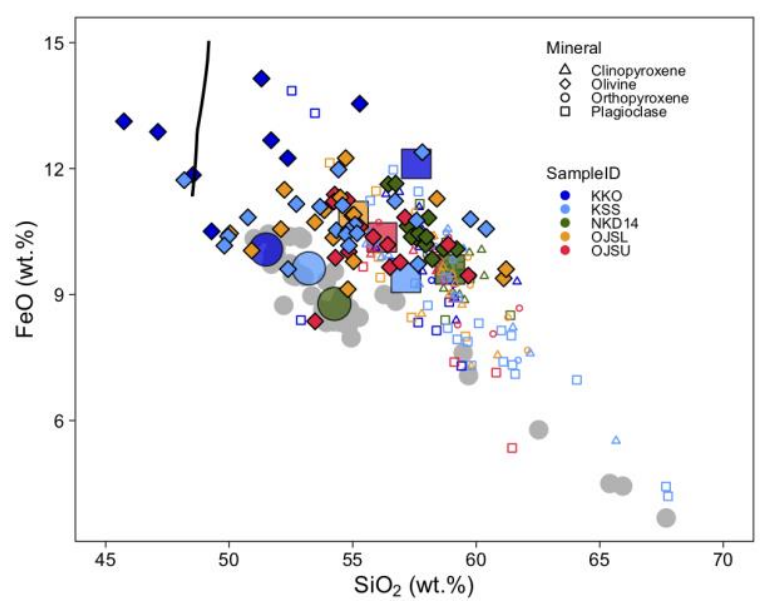

Page 10, Line 21: It appears that the stated uncertainty is the standard deviation of your temperature estimates? Does the thermometer have an associated uncertainty (i.e., standard error of the estimate)? What is that?

Response: Yes, indeed. The cited uncertainty is of the sample variations. The standard error of Putirka's two pyroxene thermometer is $\pm 38^{\circ} \mathrm{C}$. The text is modified as " . . . are $1010-1025^{\circ} \mathrm{C}$ for $\mathrm{KKO}$, OJSU, OJSL, and $\mathrm{KSS}\left( \pm 13^{\circ} \mathrm{C} 1 \sigma\right.$ of samples, while standard error of the thermometer is \pm 38 ${ }^{\circ} \mathrm{C}$; Table 4)". [Line 419-421]

Page 10, Lines 22-27: Do you have a possible explanation for your high temperatures? Is there a big difference in the water content of your magmas relative to the lowtemperature dacites?

Response: Yes, the low temperature $\left(770-915^{\circ} \mathrm{C}\right)$ found for the dacitic magma from Mount St Helens might have been due to higher $\mathrm{H}_{2} \mathrm{O}$ contents (4 to 5 wt.\%) compared to $\mathrm{H}_{2} \mathrm{O}$ range that we have in this study ( 0.5 to $2.9 \mathrm{wt} . \%)$. Actually, our temperature estimates $\left(1010-1025^{\circ} \mathrm{C}\right)$ are in between that found for this previous hydrous dacite (Mount St Helens) and that found for an anhydrous dacite (Puna Geothermal Venture Wellfield, Hawaii; Teplow et al. $2009 ; 1050^{\circ} \mathrm{C}$ ). We modified the text accordingly. [Line 422-428]

For volcanological sense, we do not have a concrete explanation on what would cause the production of the high temperature magmas. We just report here that it does exist beneath Aso.

Pages 10-11, Lines 32-8: The thermometry is highly dependent on water contents. The authors have not discussed diffusive water exchange. What is the evidence that the basaltic melt inclusions have retained their original water contents throughout the course of mixing, ascent, and cooling in the plume? At high temperatures (i.e., >1000 or 1100 C), melt inclusions hosted in olivine will likely loose some water while cooling in an eruptive plume if they are in lapilli clasts (although, this does depend on several factors). I imagine the eruptive temperature of these magmas is lower?

Response: Yes, this was certainly our point as well. First, we discussed the diffusive water exchange of olivine-hosted melt inclusion and stressed that melt inclusions have lost water. In the revision, we wrote more statements recognising this. Furthermore, Sakuyama's method exactly recognizes the issue and is based on the major element composition of melt inclusion and plagioclase. Using the latter method, temperature and $\mathrm{H}_{2} \mathrm{O}$ concentration are calculated simultaneously. Lastly, we also applied a simple olivine thermometer to the melt inclusion with the highest water content to have a comparable value to Sakuyama's method. We think that the convergence of these two methods is an indication of the successful determination of magma temperature. 
Page 11, Lines 11-28: The saturation pressures presented are the pressure of saturation of a pure- $\mathrm{H} 2 \mathrm{O}$ vapor. However, this is a mixing volatile system. If you start to add $\mathrm{CO} 2$ to the melt (and coexisting vapor), the pressures presented become minimums. The authors argue that if magma storage occurs at 2 and $4 \mathrm{~km}$, then it is unlikely that the system contained much $\mathrm{CO} 2$ because the saturation pressures calculated for an $\mathrm{H} 2 \mathrm{O}$-only system are consistent with those depths. That may be true. However, that means that the petrological data are not being used as an independent constraint on those depths. Rather, the authors are just arguing that their data can be consistent with it if no (or very little) CO2 existed in the melt (and coexisting vapor) that the samples record. This problem could be resolved by presenting measurements of $\mathrm{CO}$, which the authors say they performed using SIMS, yet there is no mention of the results of these analyses.

Response: The SIMS $\mathrm{CO}_{2}$ measurements were done after the EMP analyses, and we conservatively thought that the carbon coating contamination could have ruined the data. However, the $\mathrm{CO}_{2}$ we measured in the melt inclusions is low ( $<450 \mathrm{ppm}$; mostly 10-30 ppm for mixed felsic magmas). We decided to follow the reviewers' request and reported the $\mathrm{CO}_{2}$ SIMS measurements in the supplementary material. Table $\mathrm{S} 1$ is modified to include $\mathrm{CO}_{2}$.

Page 11, Lines 27-28: The CO2 content of the groundmass is irrelevant. Clearly, the groundmass has degassed its CO2. What is more important is determining the CO2 that existed in the melt at the conditions of the entrapment of your melt inclusions (or formation of plagioclase).

Response: yes absolutely, we agree. We deleted this erroneous sentence from our text.

Page 12, Line 22: The first clear demonstration of rapid water equilibration in olivinehosted melt inclusions is Portnyagin et al. (2008). The most up-to-date reference on the diffusivity of $\mathrm{H}^{+}$in olivine is Ferriss et al. (2016). Both references should be cited here.

Response: Yes thank you, we added the references.

Page 12, Lines 29-31: SCSS was calculated using the pressures of the shallow reservoir, but the high $S$ contents are observed in melt inclusions hosted in high-Fo olivine (i.e., Fo 80) that I thought were entrapped at much greater depths? The depth of the "pre-eruptive magma reservoir" is not important here. The depth of melt inclusion entrapment is key.

Response: There can be a pressure effect but here we think the higher $\mathrm{S}$ concentrations in melt inclusions reflects mainly a change in redox conditions. The pressure change does not affect $\mathrm{S}$ solubility as much as the oxidation change. The melt are oxidised and have more dissolved S.

We added a sentence to clarify such limitations: "The elevated S concentrations in the undersaturated oxidized melt are therefore considered to represent, less-degassed, non-sulfide-fractionated, S concentrations, at least at the condition of the shallow storage depth." [Line 513-516]

Page 13, Lines 2-3: The authors are considering the sulfur contents of the melt inclusions relative to saturation of an S-bearing phase. It is not clear to me how they are arguing that their $S$ contents are primary. If you are below SCAS (or SCSS), S can still degas. $S$ partitions strongly into vapor. What is the evidence that $S$ has not degassed from the high-S melt inclusions? 
Response: We have no counter argument against this point. We were too eager to extend the interpretation. We dropped the claim that we demonstrated the undegassed S content. The value was rather the best we could find.

Page 14, Lines 13-14: I thought the authors were arguing that their least-degassed melt inclusions recorded primary $S$ contents (e.g., page 13, lines 2-3)? Here they indicate that they need a "deeper, volatile-rich basaltic magma" to assess the $S$ excess. Can this be assessed using their deep, volatile- rich melt inclusions?

Response: As pointed here, that is exactly how we would like to develop our discussion. In the paragraph in question, we are just establishing S-excess to illustrate the necessity of the deep source.

Pages 13-15, Lines 37-7: The discussion here is very interesting. I think it would benefit from further discussion of possible mechanisms of degassing (e.g., second boiling, magma ascent and decompression) and the relationship of observed $\mathrm{SO} 2$ and $\mathrm{CO} 2$ emissions.

Response: At this point of the discussion, our goal was to establish the observation of excess degassing. Instead, we introduced the mechanism of degassing in the revised conclusion.

Page 15, Lines 16-31: SolEx is often inaccurate and unreliable (e.g., Werner et al., 2020). The issue is that SolEx uses an extremely limited range of experimental data to model the degassing of $S$, which is a complex function of melt composition, fO2, temperature, pressure, etc. The authors need to justify their use of SolEx. One way the authors could do this would be by comparing SolEx predictions for volatile contents of the melt with their observations (i.e., melt inclusions). Have the authors considered using D-compress? There are a lot more knobs to turn when performing modeling with D-compress, but I think many would consider that model capable of producing results that are more accurate.

Response: Refer to the answers at the beginning of the reply.

Figure 8: The authors model degassing as "closed system", yet they suggest excess sulfur is derived from a deeper magma. This would mean that the gas that exsolved from the deep melt become decoupled from its melt. The authors acknowledge this when they discuss the segregation of a deep gas (e.g., page 15, line 35). Later (page 16, lines 18-20) the authors suggest that at $9 \mathrm{~km}$, the system changes from open to closed. Therefore, their modeled degassing path does not apply at depths of $<9 \mathrm{~km}$. Regardless, the authors have not justified the assumption that degassing occurs in a closed system at depths $>9 \mathrm{~km}$.

Response: Based on our idea of Fig. 8, the closed system model is used to find a unique condition at which observed gas compositions agree with the prediction of the model. Chemically, we envisioned the scenario to decouple the deep gas from the magma at depth, and thus the system became open. Because our intention was to find thermodynamic equilibrium, we did not justify why degassing should be closed below $9 \mathrm{~km}$. Rather we consider that even if magma might have gone through some kind of open system degassing below $9 \mathrm{~km}$, if the gas became stagnant at $9 \mathrm{~km}$ and re-equilibrated with magma, we can still argue for the condition of equilibrium.

Figure 8: Perhaps the authors could add a second $x$-axis that indicates depth? It would be helpful for the reader. 
Response: Fig. 8 was modified and the depth tick marks are added.

Page 15, Lines 27-29: By "initial magmatic CO2 concentration", do the authors mean the primary $\mathrm{CO} 2$ contents (i.e., CO2 concentration of the melt when it entered the lower crust)? If so, this would be very low for an arc magma. Most would argue that, in general, primary arc magmas have at least 1000s of ppm CO2. The modeling the authors present here does not seem robust enough to make such a bold claim. The results of the degassing model are highly sensitive to several factors, such as choice of model (e.g., SolEx vs. D-compress), style of degassing (e.g., open, closed), degassing scenario (e.g., second-boiling, ascent), whether or not the gas emitted at the surface reflects gas derived from a single depth or if it is a mix of gases from multiple depths, etc. Most of these factors are not discussed with relation to the estimate of initial CO2 contents.

Response: It seems we did not express ourselves better here. First, $\mathrm{CO}_{2}$ content should be considered as an estimate highly dependent on the model. We think our deduction is correct as long as the model works. In the revision, we stress this point. As for low $\mathrm{CO}_{2}$ in Aso, we think it is possible as total $\mathrm{CO}_{2}$ flux of Aso appears to be lower than other arc volcanoes. Certainly, this maybe a transient, only contemporary, observation. Again, we agree that we do not have a constraint to say anything definitive about primitive $\mathrm{CO}_{2}$ content, contrary to what we stated initially. We have revised the point: "Therefore, the observed gas composition must have been derived from the depth of about 9 $\mathrm{km}(\sim 2.4 \mathrm{~kb})$ at which it was in equilibrium with a magma with the initial magmatic $\mathrm{CO}_{2}$ concentration between 400 to $750 \mathrm{ppm}$ (Fig. 8). The total $\mathrm{CO}_{2}$ flux of Aso is described to be lower than of other arc volcanoes, and this may be an indication why our estimated $\mathrm{CO}_{2}$ content in Aso magma is lower than those of many other arcs (e.g. 1000 - 2000 ppm; Wallace 2005). The determination of initial $\mathrm{CO}_{2}$ is strongly tied to the $\mathrm{Cl}$ and $\mathrm{S}$ partitioning into $\mathrm{H}_{2} \mathrm{O}-\mathrm{CO}_{2}$ fluid, and we think that these values may need to be revised once we have a better understanding of $\mathrm{Cl}$ and $\mathrm{S}$ element partitioning. Lastly, this conclusion is highly model dependent. Here, we chose to use SolEx for its agreement with the variation of $S$ in the melt inclusions. However, we must be careful with the use of SolEx, because it is shown to fail to reproduce degassing trajectories in other volcanoes (e.g., Werner et al. 2020)." [Line 687-695]

Page 16, Lines 9-12: If gas mixing occurred, how does this impact the interpretations of Figure 8?

Response: We think the conclusion of Fig. 9 holds independently of Fig. 8. The key is to explain the mechanism at which the deep gas travels to the surface without experiencing significant modifications. Such discussion is added to the end. [Line 733-751]

Pages 16-17, Lines 35-3: It would be helpful to use ranges of chemical compositions to elaborate on terms like "mafic" and "felsic". Also, it would be helpful to show the ranges of crystal endmember mole fractions for the olivine, plag, cpx, and opx hosts.

Response: A lack of explicit definition of mafic and felsic was pointed out by other reviewers, and addressed in the beginning of this reply (point 2).

Figure 8: The authors indicate that the observed gas component they investigate is "high-pressure gas component A". Was there also a low-pressure gas component identified in the Shinohara studies?

Response: Yes, Shinohara et al. (2018) reported low-pressure gas component B and C having low $\mathrm{CO}_{2} / \mathrm{SO}_{2}$ molar ratio of 1.6 observed during eruption. All these gas components were also plotted in Figure 9. 


\section{Reviewer \#3: Nicole Métrich}

Comments on the manuscript entitled "Persistent gas emission originating from a deep basaltic magma reservoir of an active volcano: the case of Aso volcano, Japan", submitted to Contributions to Mineralogy and Petrology by Masataka Kawaguchi and co-authors.

The authors have conducted a standard study of the mineralogy and melt inclusions for modelling the magma differentiation and degassing at Aso, a very active volcano. The tephra samples which have been studied cover a span of time from $\sim 4$ ka to presentday.

Major elements, $\mathrm{S}$ and $\mathrm{Cl}$ were analyzed with electron microprobe and $\mathrm{H}_{2} \mathrm{O}$ by FTIRin melt inclusions hosted in olivine, cpx and plagioclase. Water, $\mathrm{S}, \mathrm{Cl}$ and $\mathrm{F}$ were also analyzed by SIMS in a subset of MIs hosted in olivine. Magma mixing well explains the evolution trends recorded by MIs and the mineral zoning. The possible depths of magma storage at Aso have been assessed from the dissolved $\mathrm{H}_{2} \mathrm{O}$ amounts ( $\mathrm{P}_{\mathrm{H} 2 \mathrm{O}}$ is calculated using Volatilecalc), and from literature data for $\mathrm{CO}_{2}$. The petrological results are discussed and compared to the seismic records. Both support Aso magma ponding at various levels in the crust beneath Aso. The last part of the manuscript is dedicated to the modelling of the gas emissions. This paper deserves to be published in Contributions to Mineralogy and Petrology and fits well with the objectives of the journal. The data are of high quality and the target volcano of interest. My main comments are related to the sulfur degassing, the modelling of the magma mixing, and the pressure determinations. In my point of view the manuscript could be improved in its form, and some references could be added that would strengthen the discussion.

My comments are detailed hereafter. I suggest moderate revisions.

\section{Comments}

P3, ll. Excess degassing is known at open -vent systems (i.e., Stromboli, Etna, Villarica, Popo..) and the approach using melt inclusions to describe and quantify the degassing path of magmas is widely discussed as reviewed, as an example by Métrich and Wallace (2008, RiMG69), and Wallace and Edmonds (2011; RiMG 73). There is also a nice paper on sulfur degassing (gas and MIs measurements) at Erta Ale and Masaya by de Moor et al., (2017, Gcubed).

Response: The reviewer is correct, we added the proposed citations in the introduction to this wellknown "sulfur excess degassing" question. We hadn't given enough credit to previous work.

P7. "SIMS analysis was conducted after EPMA analysis". Could $\mathrm{H}_{2} \mathrm{O}$ have been lost and the SIMS analyses of $\mathrm{H}_{2} \mathrm{O}$ biased to some extents? It could explain the low concentrations measured in olivine KSS-4-m7: 4.4 wt\% (FTIR) vs 2.74 (SIMS) as an example. 
Response: To our knowledge it has never been reported that $\mathrm{H}_{2} \mathrm{O}$ analysis by SIMS is affected by prior EPMA measurements. We take notes of beam position in the melt inclusion and are careful not to reposition the beam of the SIMS on or near the EPMA beam spot. Therefore, we do not think this is the right argument to explain the FTIR vs SIMS measurement discrepancy for some of the samples. However, it is true that in this study, we heavily rely on the SIMS measurements due to the disappointing correlation between EMP and SIMS (within 25\%) and basically the no correlation between FTIR and SIMS. We now have clearly stated our position regarding our analytical preference in the "analytical methods" section, "major and volatile elements in melt inclusions".

\section{P8, 127. Remove Fo before 62-74}

Response: Thank you, we have suppressed Fo.

P9. Section major and volatile elements.

-1. A few words to describe how $\mathrm{H} 2 \mathrm{O}$ and halogens are evolving as written for sulfur could be informative.

Response: Thank you for the suggestion. We added the following text, " $\mathrm{F}$ and $\mathrm{Cl}$ correlates with $\mathrm{SiO}_{2}$ and $\mathrm{K}_{2} \mathrm{O}$ and anti-correlate with host Fo content." [Line 367-368]

-2. "The tephra samples of this study were basaltic to basaltic andesite with SiO2 .. (large circles in Fig. 3c). Melt composition in inclusions varied significantly more than that of the bulk tephra composition...". This sentence could be easily re-arranged in order to present Figure 3 first. This Figure 3 is very important for the understanding of the paper. Adding two plots with $\mathrm{Cl}$, and $\mathrm{H} 2 \mathrm{O}$ vs $\mathrm{MgO}$ could be worth.

Response: we added in figure $3, \mathrm{Cl}$ and $\mathrm{S}$ versus $\mathrm{SiO}_{2}$ and $\mathrm{Fo}$ of host olivine, respectively.

-3. It is written, in the description of the mixing model (ESM2), that MIs in plagioclase and cpx were not considered in the modelling of mixing. However, in Fig.3b most MIs in olivine, plagioclase and cpx form a cluster. For the NKD 14 sample these MIs and the matrix glasses have similar compositions. It means that the post-entrapment evolution is minimum and that these mineral phases crystallized in the same magma batch or in closely similar magma batches. It is fully consistent with the NKD 14 sample which would result from the mixing between basalt and dacite and in which the crystals are in equilibrium with the residual melt.

Response: We apologize for the confusing story. Actually, we tested all melt inclusions including those hosted in plagioclase and pyroxenes, and we now wrote "All melt inclusions (even those hosted in other crystals than olivine), whole rocks, groundmass glasses and everything plots along the linear trend of olivine-hosted melt inclusions (Fig. S4-3)." Figures were just showing the results of olivine hosted melt inclusion only. However, the sentence we were using might have been unclear. Therefore, we modified text and figures to include the results of melt inclusions hosted in other minerals.

We replaced the text in the second paragraph "It should be noted that the model was verified by the melt compositions of melt inclusions hosted in olivine and hosted in other minerals. However only olivine hosted melt inclusions have an established procedure for the correction of the post-entrapment 
crystallization.", and now reads: "The major element variation was well reproduced with the mixing model for melt inclusions of all host minerals (Fig. S4-5)" [Line 402-403] Furthermore, we exchanged captions of Fig. S4-3 and Fig. S4-4 because it was inverted.

-4. From Fig. 3d MIs in KSS olivine record a significant depletion in sulfur (from $\sim 0.3$ wt\% down to $<0.05$ wt\% @ nearly constant $\mathrm{MgO}$ that is not due to mixing (at least in my point of view). I am wondering if KSS-MIs recording such a trend are fully enclosed. Could they be instead embayments?

Response: thank you, yes indeed after your comment we double checked the "melt inclusion" and found that there were three embayments (KSS-OL-3-m3, KKO-OL-3-m1, and KKO-OL-OP2-m2) We verified visually that they were indeed embayments. We now signal that all embayment data are suppressed from the Table S1 of the supp. material.

In this figure there are two trends of evolution: one is due but most likely to degassing since sulfide immiscibility is not observed, without crystallization and the other to mixing of magma batches differing by their composition and extent of degassing. Adding a transmitted light photomicrograph of a typical olivine-hosted melt inclusion would be important.

Response: As we have acknowledged in the reply to the reviewer 2, we were too assertive about the mixing process without carefully evaluating other processes. In the revision, for the simplicity of the discussion we decided not to discuss the mixing process for $\mathrm{H}_{2} \mathrm{O}$ and $\mathrm{CO}_{2}$. For $\mathrm{S}, \mathrm{Cl}$, and $\mathrm{F}$, we retained the presence of the mixing trend, however we also mentioned the role of degassing, and crystallisation.

Three images of olivine hosted-melt inclusions are added to the supplementary documents S4.

Fig .2e shows that the olivine and its MI have been carefully prepared but does provide any information on the MI itself (bubble size, morphology..). Moreover looking at the Table S1, the analysis of this olivine (KSS 3-m1) is not so good (total $=96.5 \%), \mathrm{MgO}$ is most likely underestimated.

Response: Unfortunately, the textural information of melt inclusions were not recorded during the preparation. This work started during the second year Master of the first author Kawaguchi and was done in Kumamoto University. It is now a posteriori not possible to provide information regarding bubble size. The form of inclusions were consistent with the type of primary inclusions, meaning not align in a plane with many other melt inclusions.

Olivine host composition is measured by EPMA with WDS mode. In fact, we see the total is generally poor. Here, we accepted the data with the total more than $98 \%$ and less than $102 \%$. Since stoichiometry is good, we now reported only cation for poor total olivine data set and only used Fo content for PEC correction. The table does not include the other worse totals now.

-5. For clarity it could be written that the volatile (at least $S$ ) concentrations that are considered are the SIMS data (even if in the Table only the SIMS data are reported after PEC correction).

Response: As we replied in previous question of reviewer 1, we added the sentence in the main text to clarify that we adopted SIMS values because of high analytical precision. 
What could justify the difference between SIMS and EMP analyses of sulfur whereas for SIMS and EMP data for Cl are in good agreement? As an example the $S$ content of the MI (KSS-2m1) chosen as the basaltic end-member is $0.31 \mathrm{wt} \%$ (SIMS) and $<0.2$ $w t \%(E M P A)$.

Response: As we already answered, the measured values for $\mathrm{S}$ between EPMA and SIMS analysis agree within $25 \%$. When melt inclusions are measured by both method EMP and SIMS, we favored SIMS data because of high analytical precision.

\section{What about $\mathrm{H}_{2} \mathrm{O}$ ?}

Response: we adopted SIMS $\mathrm{H}_{2} \mathrm{O}$ values because of high precision of analysis, they are the only $\mathrm{H}_{2} \mathrm{O}$ measurements we trust here.
P9. Discussion: evidence of magma mixing. What is the significance of the MIs compositions (major and volatile elements) in reversely zoned crystals? A short description of the MIs in the dedicated section should be inserted to describe a little bit better these MIs. Is there any evidence of cracks and overpressure, of melting/crystallization at the glass/mineral interface. Are calculations of PEC\% relevant in the case of reversely zoned olivine crystals?

Response: We scrutinized the olivine and inclusions and checked for cracks and decrepitation, but to the best of our knowledge we did not identify any of those. While we did not make an explicit reference, there is a correlation between olivine zoning and the inclusion composition. Normally zoned olivine has high-Fo core (Fig. 3), thus the mafic group on the basis of our grouping $\left(<55 \% \mathrm{SiO}_{2}\right)$. Reversely zoned olivine has low-Fo and belong to the felsic group. As the revised the text, we described the compositional correlation carefully, we believe it illustrates the systematics better now.

PEC is calculated between the melt inclusion and small immediate vicinity of the surrounding olivine. The fact that the olivine is reversely zoned has nothing to do with the correction at the time of the eruption. The reverse zoning likely happened sometimes after the entrapment of the melt inclusion.

\section{P10, l10-13. Could the calculated mixing curves be reported in the plots $\left(\mathrm{H}_{2} \mathrm{O}-\mathrm{S}-\mathrm{Cl}\right)$ of Fig. 5?}

Response: In the revised text, we decided not to include volatile elements in the mixing model, mainly due to difficulty separating degassing from mixing. Fig. 5 was kept but the mixing line was not added.

P10, 135. "The mafic endmember magma is expected to be volatile- rich, notably in sulfur (up to 4000 ppm; Fig. 3)." Yes but the end-member which has been chosen for the modeling of the magma mixing process contains 0.29 wt\% S? Moreover, in the Figure $3 d$ and as it is written $p 9$ and in the abstract, the $S$ concentration reaches 3745 ppm in one MI (KKO sample) and most of them are <3745 ppm.

Response: The reviewer is right. The value of " $4000 \mathrm{ppm}$ " written in the text was a mistake, "3750 ppm" is right. Thus, we replaced the number in the text with " $3750 \mathrm{ppm}$ ". This corresponds to the highest S concentration measured in a KKO olivine-hosted melt inclusion and we took this value as the $\mathrm{S}$ composition of the mafic endmember. We explicit this in the text. 


\section{P11, l14-17. I think that it is important to write here that $P_{H 2 O}$ is assumed to be equivalent to the total pressure of fluids, neglecting the role of $\mathrm{CO}_{2}$.}

Response: Yes absolutely. Now it reads "Here the total pressure of fluids is in fact equivalent to $\mathrm{PH}_{2} \mathrm{O}$, neglecting the role of $\mathrm{CO}_{2}$." [Line 560-561]

P1, l25. Are the depths of 2 and $4 \mathrm{~km}$, below sea level? or below the vents?

Response: Yes these 2 numbers are below sea level every time because they come from the magnetotelluric work of Hata. When we calculated the lithostatic pressure we did it from the vent so we added $1 \mathrm{~km}$ which corresponds to the height of the volcano (so 3 to $5 \mathrm{~km}$ below the vent). In the revised document, the depths are referenced to the common point $=$ the vent.

P11, 135. VolatileCalc is calibrated for MORB at low pressure. The authors could make their pressure calculations using Shishkina et al., (Chem Geol 2014), who provide an extensive experimental dataset on the $\mathrm{CO}_{2}$ concentrations in basalts. As fully proved in this paper the solubility of $\mathrm{CO}_{2}$, contrary to $\mathrm{H}_{2} \mathrm{O}$, widely varies with the melt compositions.

Response: As pointed out here, we have explored alternative saturation pressure calibration available in the community (Supplementary material S4). In the revision, we mention the range of pressure that we found. SolEx and MagmaSat (Ghiorso and Gualda 2015) are shown to be comparable. [Line 582$583]$

P11, 135: " the mafic-endmember $\mathrm{H}_{2} \mathrm{O}$ concentration as $4.43-4.68$ wt.\%. Thus, the initial primitive $\mathrm{H}_{2} \mathrm{O}$ concentration is at least $4.5 \mathrm{wt} . \%$.". In the modeling of mixing reported in ESM2 the end-member are KSS-2m1 and KSS-2d-m1. The former contains $2.9 \mathrm{wt}_{\mathrm{H}} \mathrm{H}_{2} \mathrm{O}$ and $0.29 \mathrm{wt} \% \mathrm{~S}$ (SIMS corrected data). I am confused here.

Response: Yes indeed, our writing was not clear enough. We used the maximum $\mathrm{H}_{2} \mathrm{O}$ determined with the hygrometer (4.68wt.\%) as the $\mathrm{H}_{2} \mathrm{O}$ concentration of the mafic endmember. The $\mathrm{S}$ concentration of the mafic endmember is the maximum $\mathrm{S}$ concentration measured in the melt inclusion $3750 \mathrm{ppm}$. We modified the text accordingly.

P11, 138. " $2400 \mathrm{~kg} / \mathrm{m}^{3}$ for the first $\mathrm{km}$ and... " first $\mathrm{km}$ of what?

Response: we meant the first $1 \mathrm{~km}$ of crust. We modified text and it reads " $2200 \mathrm{~kg} / \mathrm{m}^{3}$ for less than 1 $\mathrm{km}$ deep in the crust" to clarify. Furthermore, we have revised the near surface density to $2200 \mathrm{~g} / \mathrm{m}^{3}$ after carefully inspecting Komazawa's figure. [Line 564]

P11-12. "Gas bubbles in MIs...increases the pressure entrapment...". Not the bubble, the $\mathrm{CO}_{2}$ trapped in the bubble because the total fluid pressure $=P_{\mathrm{H} 2 \mathrm{O}}+P_{\mathrm{CO}}$.

Response: We modified text, and now reads: "As gas bubbles were seen in melt inclusions, large amounts of $\mathrm{CO}_{2}$ incorporated in such shrinkage bubbles significantly increases the entrapment pressure estimation (e.g. Moore et al. 2015)." [Line 585-587]

More than 40-90\% of the initial $\mathrm{CO}_{2}$ that was dissolved in the melt inclusions at the time of trapping was lost to shrinkage bubbles, with an average loss of 75-80\% (Wallace et al., 2015; Moore et al. 2015; Hartley et al., 2014). Hence the initial dissolved amount of $\mathrm{CO}_{2}$ in Aso MIs could imply a much higher total fluid pressure 
$\left(\mathrm{PCO}_{2}+\mathrm{PH}_{2 \mathrm{O}}\right)$ than $300 \mathrm{MPa}(\sim 10 \mathrm{~km}$ depth equivalent $)$. The discussion needs to be more elaborated here to demonstrate that there is a good agreement between the petrology and the depth of the seismic-low velocity layer at Aso. I also suppose that the magma ponding zone is not unique between 10 and $24 \mathrm{~km}$ beneath Aso, and that magma batches could mix altogether at various depths?

Response: The argument of the reviewer is correct and we took it into account in our discussion. On former page 12 line 3, we added the following text "Recent melt inclusion studies reported more than $40-90 \%$ of the initial $\mathrm{CO}_{2}$ that was dissolved in the melt at the time of entrapment was lost to shrinkage bubbles, with an average loss of 75-80 \% (Wallace et al. 2015; Moore et al. 2015; Hartley et al. 2014). If $90 \%$ of initial $\mathrm{CO}_{2}$ is present in the shrinkage bubble and a maximum $\mathrm{CO}_{2}$ value of $340 \mathrm{ppm}$ is assumed in the melt (from Saito et al. 2018), then the expected initial value of the melt would reach $3400 \mathrm{ppm}$. This value is in the same order of magnitude as the initial $\mathrm{CO}_{2}$ concentration in a typical primary arc magma (Aster et al. 2016), and saturation pressure would exceed $5 \mathrm{kbar}$ ( 19 km depth equivalent) However, at the time of this study, bubble sizes were not documented with impossibility to go back to measuring them a posteriori since most are now polished away. In this case we chose not to use the $\mathrm{CO}_{2}$ data of the melt inclusions." [Line 589-599]

Regarding the magma ponding zone, we don't have any information to argue for multiple ponding zones. Therefore, further discussion is currently difficult.

P12, 135. As written above, the $S$ concentration reaches 3745 ppm in one MI (KKO sample) and most of them are <3745 ppm (not 4000 pm). Such an amount is not higher but typical of subduction-related magmas -related basalt in which sulfur is dissolved dominantly or totally dissolved as sulfate. As another example, the $\mathrm{H}_{2} \mathrm{O}$-rich $\mathrm{MIs}$ of Augustine volcano display similar high S concentration (i.e., Webster et al., 2010; in The 2006 eruption of Augustine volcano, Alaska, US Prof paper 1769).

Response: It was our error to stress the high S content. We revised the text, "Dissolved S concentrations, up to $3750 \mathrm{ppm}$ in the mafic endmember melt inclusions, are higher than many in subduction-like hydrous basalt (Fig. 6a, mostly S between 900 and 2500 ppm; e.g. Wallace 2005), while similar high S content appears to occur in oxidized magmas (Roggensack 2001; Webster et al., 2010)." [Line 493-496]

P12, l17-19. I am confused also here. How are calculated these ratios? There is no sulfur concentration as high as 5050 ppm? What are they representative of?

Response: We admit it was confusing. Now we only use the maximum ratios $\mathrm{S} / \mathrm{K}_{2} \mathrm{O}(0.711), \mathrm{Cl} / \mathrm{K}_{2} \mathrm{O}$ $(0.170)$ and $\mathrm{F} / \mathrm{K}_{2} \mathrm{O}(0.047)$ as representative of the primitive composition, and we did not demonstrate a strong ground to choose a concentration of $\mathrm{K}_{2} \mathrm{O}$. The endmember composition is now defined by melt inclusion values. The text now reads: "Because the composition of the mafic endmember points towards that of the primitive magma, the maximum values are, taken as the primitive volatile ratios: $\mathrm{S} / \mathrm{K}_{2} \mathrm{O}=$ 0.711, $\mathrm{Cl} / \mathrm{K}_{2} \mathrm{O}=0.170$, and $\mathrm{F} / \mathrm{K}_{2} \mathrm{O}=0.047 . ”[$ Line 489-492]

P12, 123-24. "In fact, as shown in the previous section, we assessed the maficendmember $\mathrm{H}_{2} \mathrm{O}$ concentration as $4.43-4.68$ wt.\%. Thus, the initial primitive $\mathrm{H}_{2} \mathrm{O}$ concentration is at least 4.5 wt. \%". This sentence is redundant. Could it be just one section where the volatile $\left(\mathrm{H}_{2} \mathrm{O}, \mathrm{S}, \mathrm{Cl}\right)$ contents of the end-member are clearly described: what is the best candidate (KKO, KSS)? Why is it representative of THE parental melt of the ASO series? 
Response: Absolutely agree. We decided to rewrite the section about "Characterization of mixing endmembers", and "Volatile concentrations of primitive basaltic melt". We have paid particular attention to suppress redundancy.

P14, l10-14. What is the pressure of sulfur exsolution in such magma? The question of the sulfur supply from deep basalt magmas is detailed in Wallace and Edmonds (2011).

Response: In the passage here, we did not specify the exact depth as the discussion is developed later Fig. 8. As the conclusion of the paper, we think $S$ is degassed between $9-10 \mathrm{~km}$ and we added a summary figure to synthesize our finding to the reader.

\section{P15, 11-7. It is well known that $\mathrm{CO}_{2}$ is almost totally exsolved as a gas phase at pressure less than $500 \mathrm{MPa}$ (see Wallace and co-authors).}

Response: Indeed, that is the point of our discussion as well. Now, in our new revision, we simplified the discussion regarding $\mathrm{CO}_{2} . \mathrm{CO}_{2}$ is nearly all degassed at shallow depth, and all the inclusions have low $\mathrm{CO}_{2}$. We have no information regarding the $\mathrm{CO}_{2}$ at the source. Taking high values of $\mathrm{CO}_{2}$, it is possible to infer the depths of equilibrium, however the inclusions were degassed already. Our conclusion is that observed gas composition is consistent with the equilibrium pressure of $2.2-2.3 \mathrm{~kb}$ which is derived from 400-750 ppm initial $\mathrm{CO}_{2}$. Our finding is therefore coherent with the point mentioned here. Yes, the major degassing and segregation occurs at depth shallower than $5 \mathrm{~kb}$.

P16, l19. What are the gas species exsolved at 300MPa ( \pm equivalent to $9 \mathrm{~km}$ )? I suppose that it $9 \mathrm{~km}$ below the vents? Geophysicists generally indicate depth below sea level.

Response: yes the $9 \mathrm{~km}$ here is from the vent. The difference between vent and sea level is $1000 \mathrm{~m}$ the height of the volcano, so $9 \mathrm{~km}$ from the vent, means $8 \mathrm{~km}$ below sea level. As SolEx model ignores gas speciation completely, the gas species at the depth must be $\mathrm{H}_{2} \mathrm{O}-\mathrm{CO}_{2}$-(dissolved $\mathrm{S}, \mathrm{Cl}$, and $\mathrm{F}$ ).

\section{Other remarks}

Table S1. Analysis OP2-M1. Is there an error in the $\mathrm{Na}_{2} \mathrm{O}$ concentration (0.63wt\%) that is very low?

The data with the $\mathrm{Na}_{2} \mathrm{O}$ outlier was suppressed from the Table.

Table S3 some of the analyses have a relatively low total (among others: OJSU olivine a2c\& a4c: 95.8; c1c: 96.2; c5c: 91.2) or >102wt\%.

Response: we have deleted these low total data after check the stoichiometry. Data of olivine and plagioclase presented in S3 are those measured by an EDS detector in SEM. Since stoichiometry of minerals are good, even for these with low total, we remained these EDS data as $100 \mathrm{wt} . \%$ normalized value unless total is too low ( $\pm 4 \mathrm{wt} . \%)$, and suppressed all low total data. For WDS data, while stoichiometry of minerals is excellent, we decided to suppress data with low or high total (>102 wt.\% or $<98$ wt.\%).

Fig. 4. Temperature

ESM 2: $C^{i}{ }_{\text {obs }}-C^{i}{ }_{B}$ written two times

Response: The spelling error is corrected, so is the error of the equation. 
Electronic supplementary material 1
Electronic supplementary material
ESM1.xisx

Electronic supplementary material 1
$\begin{aligned} & \text { Electronic supplementary material } \\ & \text { ESM1.xisx }\end{aligned}$

Electronic supplementary material 1
\[ \begin{array}{c}\text { Electronic supplementary material } \\ \text { ESM1.xlsx }\end{array} \]
Click here access/download Electronic supplementary material 1
\[ \begin{array}{c}\text { Click here to access/download } \\ \text { Electronic supplementary material } \\ \text { ESM1.xlsx }\end{array} \]

\section{ESM1.xlsx

.

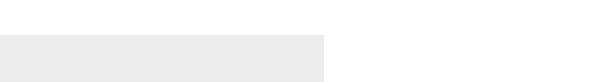

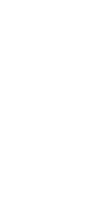

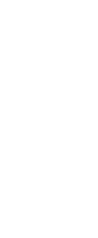

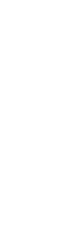

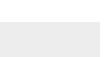


Electronic supplementary material 2

\section{Click here to access/download \\ Electronic supplementary material ESM2.pdf}

